\title{
INTENSITY SELECTION AND REGULATION USING THE OMNI SCALE OF PERCEIVED EXERTION DURING INTERMITTENT EXERCISE
}

\author{
by \\ Mark Anthony Schafer \\ B.S. Sport Sciences, Ohio University, 1996 \\ M.S., Ohio University, 1997

\begin{abstract}
Submitted to the Graduate Faculty of
of the requirements for the degree of
\end{abstract} \\ School of Education in partial fulfillment \\ Doctor of Philosophy
}

University of Pittsburgh 


\section{UNIVERSITY OF PITTSBURGH SCHOOL OF EDUCATION}

This dissertation was presented

By

Mark A. Schafer

It was defended on

May 23, 2007

and approved by

Fredric L. Goss, Associate Professor, School of Education

Robert J. Robertson, Professor, School of Education

Elizabeth Nagle-Stilly, Assistant Professor, School of Education

Kevin Kim, Assistant Professor, School of Education 
Copyright (C) by [Mark A. Schafer]

[2007] 


\section{INTENSITY SELECTION AND REGULATION USING THE OMNI SCALE OF PERCEIVED EXERTION DURING INTERMITTENT EXERCISE}

Mark Schafer, Ph.D.

University of Pittsburgh, 2007

The primary purpose of this investigation was to determine if college age males and females (18 to 25 year old) can self-regulate exercise intensity during a 20 minute intermittent bout of aerobic exercise on the treadmill using the OMNI RPE scale. All subjects completed an estimation trial (EST) graded exercise test using the Bruce protocol to measure heart rate (HR), oxygen consumption $\left(\mathrm{VO}_{2}\right)$, and rating of perceived exertion (RPE) every minute until exhaustion. Using data from the EST, target RPEs corresponding to $50 \%$ and $70 \%$ of $\mathrm{VO}_{2} \mathrm{R}$ were determined via regression analysis. A production trial (PROD) was then performed in which subjects titrated speed and grade on the treadmill to elicit the target RPEs corresponding to $50 \%$ and $70 \%$ of $\mathrm{VO}_{2} \mathrm{R}$ in counterbalance order. At an RPE corresponding to $50 \%$ of $\mathrm{VO}_{2} \mathrm{R}$, $\mathrm{HR}$ and $\mathrm{VO}_{2}$ were significantly higher in the PROD compared to the EST for counterbalance order I $(70 \%-50 \%)(p<.001)$. However, there was no significant difference in $\mathrm{HR}$ and $\mathrm{VO}_{2}$ between the EST and PROD for counterbalance order II $(50 \%-70 \%)(p>.05)$. When subjects exercised at an RPE corresponding to $70 \%$ of $\mathrm{VO}_{2} \mathrm{R}$, the $\mathrm{HR}$ was significantly higher in the PROD compared to the EST for counterbalance order I (70\% - 50\%), $(p<.05)$. However, there was no significant difference in HR between the EST and PROD trials for counterbalance order II (50\% - 70\%), $(p>.05)$. At an RPE corresponding to $70 \%$ of $\mathrm{VO}_{2} \mathrm{R}$, there was no significant difference in the $\mathrm{VO}_{2}$ between the EST and PROD trials $(p>.05)$. Subjects were also able to perceptually differentiate between the two target RPEs corresponding to $50 \%$ and $70 \%$ of $\mathrm{VO}_{2} \mathrm{R}$ 
as indicated by the significant difference in $\mathrm{HR}(p<.05)$ and $\mathrm{VO}_{2}(p<.05)$ between the two prescribed PROD RPE intensities. The present investigation indicates that subjects were able to use RPE to self-regulate exercise intensity during 20 min of exercise at varying intensity when starting the exercise bout at the RPE corresponding to $50 \%$ of $\mathrm{VO}_{2} \mathrm{R}$. 
TABLE OF CONTENTS

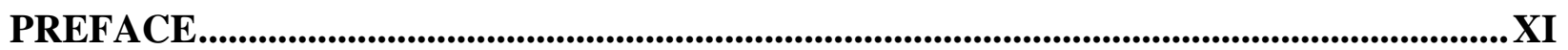

1.0 INTRODUCTION AND RATIONALE ............................................................... 1

1.1 INTRODUCTION .......................................................................................... 1

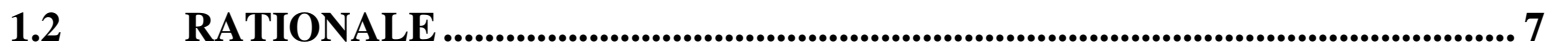

1.3 STATEMENT OF THE PROBLEM ............................................................ 8

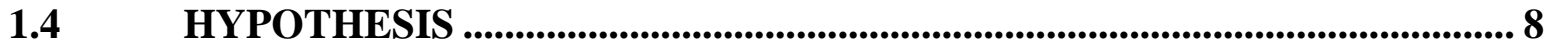

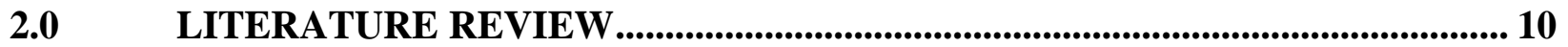

2.1 PERCEIVED EXERTION .......................................................................... 10

2.1.1 Rating of Perceived Exertion (RPE) ........................................................... 10

2.1.2 Global Model .................................................................................................... 11

2.1.3 Borg's Range model.............................................................................................. 12

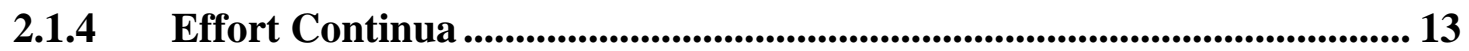

2.1.5 Physiological Mediators........................................................................................ 14

2.2 OMNI SCALE OF PERCEIVED EXERTION ................................................ 14

2.2.1 Validation of the OMNI Walk/Run scale...................................................... 15

$2.3 \quad$ ESTIMATION-PRODUCTION EXERCISE PRESCRIPTION ..................... 17

2.4 SELF-REGULATION OF EXERCISE USING RPE ........................................ 18

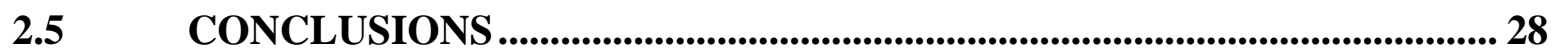

3.0 METHODS .......................................................................................................... 29

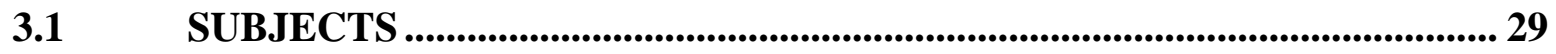

EXPERIMENTAL DESIGN .......................................................................... 30

3.2.1 Pre-test instructions ..................................................................................... 30

3.2.2 Body weight and height ................................................................................ 31

3.2.3 Body composition .................................................................................................... 31 
3.2.4 Estimation Trial ............................................................................ 31

3.2.4.1 Maximal Graded Exercise Test .......................................................... 31

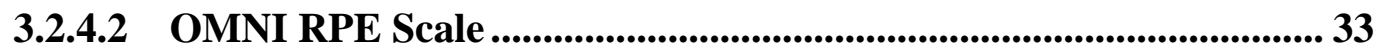

3.2.4.3 Target RPE ................................................................................... 34

3.2.5 Production Trial................................................................................... 35

EXPERIMENTAL VARIABLES ....................................................... 37

3.3.1 Dependent variables............................................................................. 37

Independent variable ................................................................................ 38

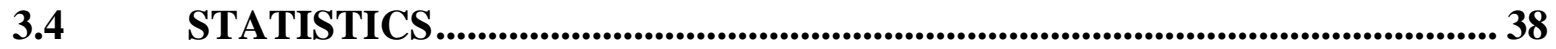

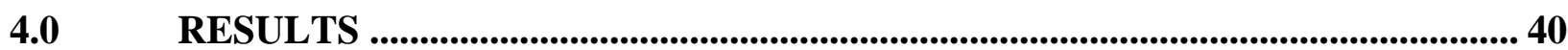

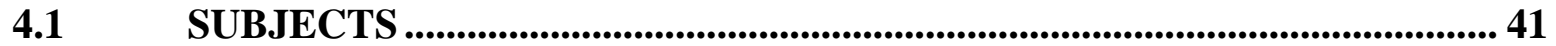

4.2 PRESCRIPTION CONGRUENCE AND SEQUENCE............................. 41

4.2.1 Heart Rate at $50 \%$ of $\mathrm{VO}_{2} \mathrm{R}$.................................................................... 41

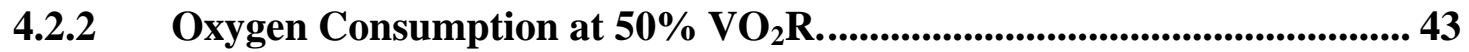

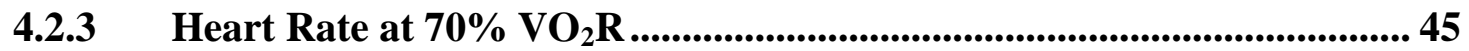

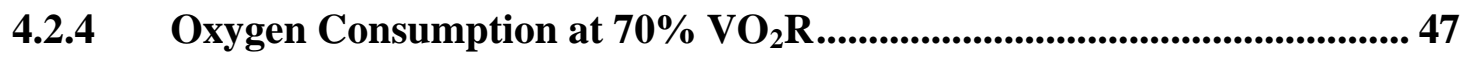

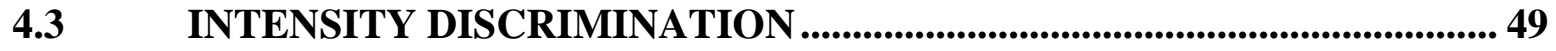

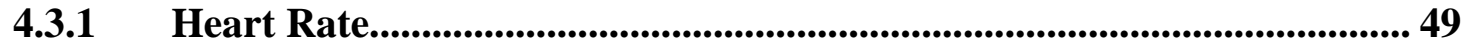

4.3.2 Oxygen consumption .......................................................................50

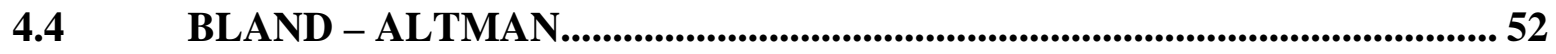

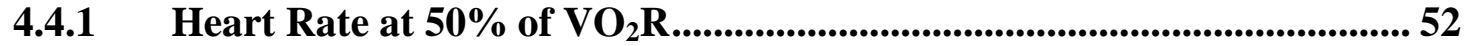

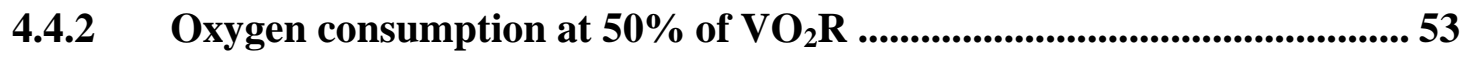

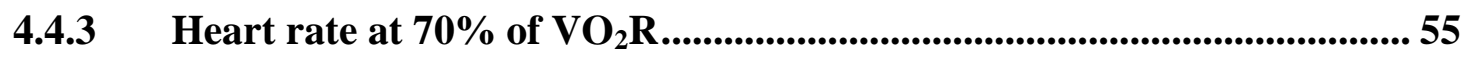

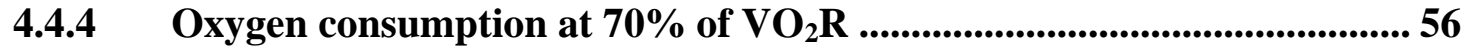

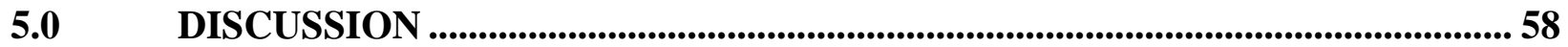

P.1 PRESCRIPTION CONGRUENCE AND SEQUENCE.............................60

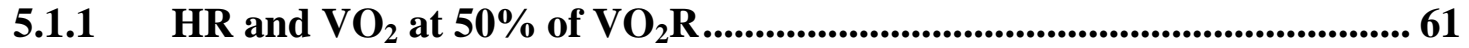

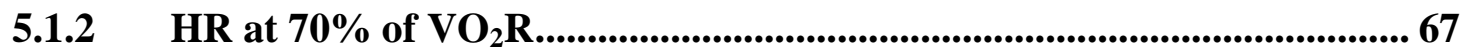

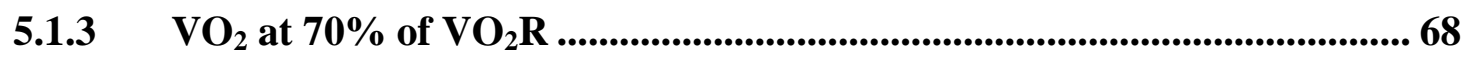

INTENSITY DESCRIMINATION ..................................................................... 71

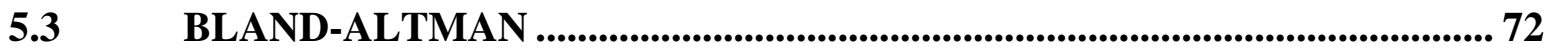




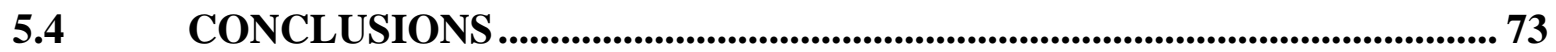

5.5 RECOMMENDATIONS FOR FUTURE RESEARCH ................................ 74

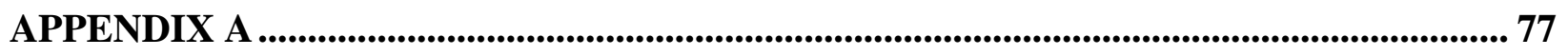

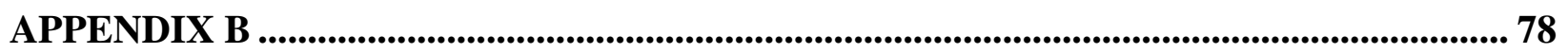

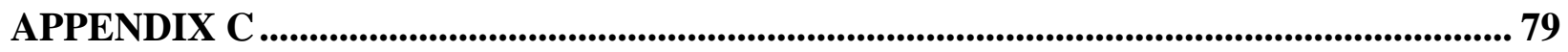

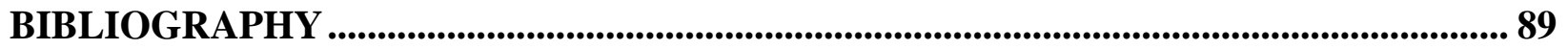




\section{LIST OF TABLES}

Table 1. Descriptive Characteristics of Subjects............................................................ 41 


\section{LIST OF FIGURES}

Figure 1. Global explanatory model of perceived exertion ................................................. 12

Figure 2. Estimation-Production Prescription Procedure ..................................................... 35

Figure 3. OMNI-Walk/Run scale of Perceived Exertion for Adults ...................................... 35

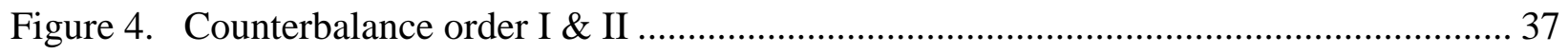

Figure 5. Prescription congruence and sequence............................................................ 43

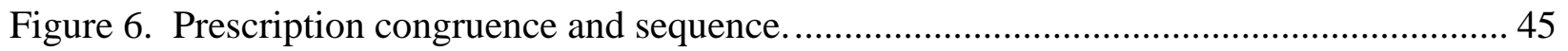

Figure 7. Prescription congruence and sequence.......................................................... 47

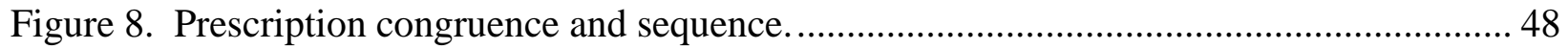

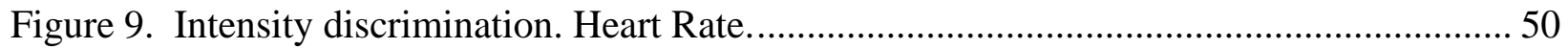

Figure 10. Intensity discrimination. Oxygen consumption............................................... 51

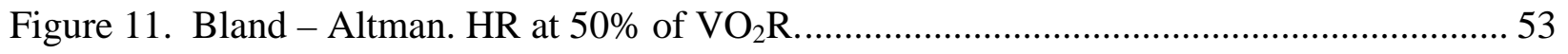

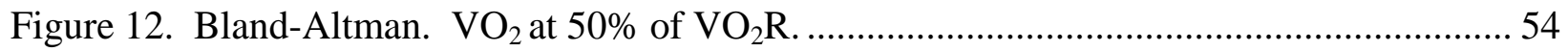

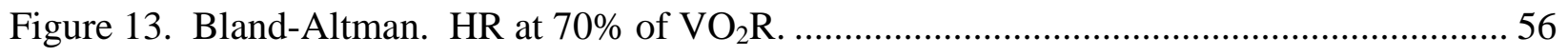

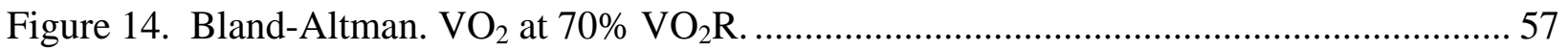




\section{PREFACE}

The author would like to extend the most sincere appreciation to the following individuals:

- Fredric L. Goss, Ph.D., for his mentoring and support throughout the doctoral program and my dissertation.

- $\quad$ Robert J Robertson, Ph.D., Elizabeth Nagle-Stilly, Ph.D., and Kevin Kim, Ph.D. for their assistance with my dissertation.

\section{DEDICATION}

I would like to make a special expression of gratitude to my wife, Minda Schafer. Thank you does not begin to articulate the sentiment being expressed. Minda is the reason why I have been able to accomplish my goal of obtaining my Ph.D. Her love and support throughout graduate school has been monumental in completing my degree. This degree is just as much hers, as it is mine. I would also like to express my love for my daughter Sumer. You have made life so very special and I look forward to all the things we will experience together. Finally, to Hannah, your

arrival is much anticipated. There is a lot more love to give in this family and you will be a wonderful addition to the family.

I am and will be forever grateful to my parents Vic and Pat Schafer. Your love and support throughout my life has inspired me pursue all of my goals. Your strong work ethic has set the standard that I aspire to achieve. I aspire to pass the strong family values to future generations of the Schafer family.

In loving memory of “Coach” David Thomas. I will be forever grateful that you encouraged me to attend college. It turned out to be a pretty wonderful experience! 


\subsection{INTRODUCTION AND RATIONALE}

\subsection{INTRODUCTION}

Ratings of perceived exertion (RPE) is commonly used as part of an individualized exercise prescription to define the cardiorespiratory training zone and to regulate exercise intensity (Noble et al., 1996). Previous investigations have indicated that RPE scales are valid tools for regulating exercise intensity during continuous aerobic exercise (Bayles et al., 1990; Ceci et al., 1991; Chow et al., 1984; Dunbar et al., 1992; Dunbar et al., 1994; Eston et al., 1987; Eston et al., 1988; Glass et al., 1992; Groslambert et al., 2005; Kang et al., 1998; Kang et al., 2003; Marriott et al., 1996; Robertson et al., 2002; Smutok et al., 1980). Exercise intensity is a fundamental component of the exercise prescription. The prescription of exercise intensity assumes that a predetermined level of total body oxygen uptake is achieved during the stimulus portion of each training session, producing a physiological overload that improves aerobic fitness (Robertson, 2001). Utilizing RPE to regulate exercise intensity during aerobic activities lessens the need to perform more cumbersome measures such as heart rate palpation or having to purchase costly heart rate monitors. Concerns also arise when prescribing exercise using heart rate to regulate intensity. When using the common procedure of age-predicted maximal heart rate to determine a target heart rate zone for prescriptive purposes there may be errors of up to 11 beats per minute above or below the intended stimulus zone (Dishman, 1994). Therefore, when

prescribing exercise intensity using the age-predicted maximum heart rate there may be a wide 
range in the stimulus zone. Ambient air temperature, humidity, psychological stress, caffeine, medications, and clinical status may also contribute to variability in the heart rate response to exercise. However, RPE may be independent of these factors.

The Perceived Exertion knowledge base has undergone substantial development and refinement over the last four decades. The initial development of the concept of perceived exertion was undertaken by Borg in the 1960's. Since that time various scales have been developed and validated using the theoretical groundwork established by Borg. Extensive research has been completed on specific models that are responsible for the gestalt properties of the exertional milieu. Using the same scaling principles and the range model developed by Borg, perceptual exertion scales continue to be developed and validated for the use with various population cohorts performing a wide array of aerobic and resistance exercises.

An appropriate training intensity is necessary to ensure that exercise is safe and effective. Guidelines for exercise intensity developed by the American College of Sports Medicine (ACSM, 2006a, 2006b) state that an intensity range corresponding to 40 to $85 \%$ of maximal oxygen uptake reserve $\left(\mathrm{VO}_{2} \mathrm{R}\right)$ is safe and provides an adequate cardiovascular training stimulus. Exercising at 40 to $50 \%$ of $\mathrm{VO}_{2} \mathrm{R}$ is the minimal training intensity stimulus for improvement in maximal oxygen uptake. Exercising below this minimal threshold intensity may not provide the stimulus necessary to achieve significant cardiorespiratory/health/fitness benefits. Conversely, performing aerobic activity at intensities greater than $85 \%$ of $\mathrm{VO}_{2} \mathrm{R}$ may increase the risk of injury, medical complications, and may adversely affect exercise adherence.

Historically target training zones were used to establish a constant intensity during a submaximal bout of aerobic exercise. However, intermittent or interval training formats are routinely used in clinical, recreational, and athletic settings. The terms "intermittent exercise" 
and "interval training" exercise appear to be used interchangeably in the literature. However, there is lack of consensus within the scientific community on how the terms are defined. The nebulous nature of the terminology can cause confusion when prescribing exercise or conducting research. Therefore, it is critically important to operationally define these training techniques.

A number of investigations have used the term "intermittent exercise" to signify multiple short bouts of exercise separated by periods of rest. Often this exercise format has been used to compare the effects of short exercise intervals interspersed throughout the day with continuous aerobic exercise bouts, e.g. 10 minute bouts three times a day compared to 30 minutes of continuous exercise (Fulton et al., 2001; Jakicic et al., 1999; Peterson et al., 2004). Their investigations suggest that intermittent bouts throughout the day result in similar health benefits compared to a continuous exercise bout of similar total duration. In addition, intermittent exercise sessions may result in a higher rate of compliance when compared to traditional continuous exercise bout of aerobic exercise.

According to Noble et al. (1996), intermittent exercise intensity can be regulated by producing target RPE's that correspond to metabolic rates $\left(\% \mathrm{VO}_{2 \max }\right)$ set alternately at low and high ends of the physiological training zone. In this context, Intermittent exercise can be defined as a continuous exercise bout that includes alternating intensities with no rest periods. By varying the exercise intensity during a continuous exercise bout a greater aerobic metabolic energy expenditure may be achieved compared to continuous constant low intensity training. When a training session includes intermittent exercise, it is helpful to use sliding target RPE's (Robertson, 2004). Using this strategy, a subject can exercise intermittently for 10 minutes at a target RPE of 4 and then at a target RPE of 7 for 5 minutes. The subject can slide up and down 
the RPE scale between the low and high intensity range until the desired exercise duration is achieved.

Historically, “interval training” has been used as a form of high intensity training for the purposes of increasing $\mathrm{VO}_{2 \max }$, speed, and/or explosiveness for sport specific performance (Laursen \& Jenkins, 2002; Laursen, Shing et al., 2002). Interval training sessions mix short maximal or supra-maximal exercise intervals followed by periods of active recovery at a lower exercise intensity. Interval training is responsible for increasing the athlete's ability to perform during short bouts of high intensity exercise.

According to the ACSM (2006b), interval training is a form of cardiorespiratory training that combines segments of high intensity work with segments of light to moderate intensity work. The specific duration of the work and rest intervals can vary depending upon program goals. More recently, interval training has been used by recreational exercisers to vary the training intensity during step aerobics classes, walking, cycling, cardio kickboxing and cycle spinning classes.

Clearly there is a lack of consistency within the scientific literature in the use of terms “intermittent exercise" and "interval training”. For the purpose of the present investigation the term “intermittent exercise” will be defined as “a continuous exercise bout of varying intensity”. The subjects in the present investigation will perform a continuous bout of aerobic exercise and alternate the exercise intensity.

The OMNI Scale of Perceived Exertion (RPE) is the most recent advancement in the discipline of perceived exertion research. The term OMNI is short for omnibus, which in this context means that the perceived exertion scale is applicable for a wide range of clients and physical activity settings. The OMNI scale employs pictures of an individual exercising at 
different intensity levels. The pictures are combined with short verbal cues and arranged along a numerical scale ranging from $0-10$ that depicts gradually increasing exercise intensity such as that encountered when going up a hill (Robertson, 2004). The initial validation of the OMNI RPE scale was performed on children using a cycle ergometer protocol (Robertson et al., 2000). Subsequent validation studies have been completed on adult male and females and for a range of exercise modalities (Gairola et al., 2006; Groslambert et al., 2005; Kang et al., 1998; Kang et al., 2003; Pfeiffer et al., 2002; Robertson, Goss, Andreacci, Dube, Rutkowski, Frazee et al., 2005; Robertson, Goss, Andreacci, Dube, Rutkowski, Snee et al., 2005; Robertson et al., 2002; Robertson et al., 2001; Robertson et al., 2000; Robertson et al., 2004; Robertson et al., 2003; Utter et al., 2006; Utter et al., 2004; Utter et al., 2002)

The OMNI rating of perceived exertion scale has demonstrated both concurrent and construct validity for weight bearing exercise for men and women during walking and running exercise (Utter et al., 2004). A concomitant increase in OMNI RPE and respiratory-metabolic measures provided the basis for concurrent validation. Construct validity was demonstrated by a strong positive correlation between the Borg 6-20 RPE scale and the OMNI RPE scale.

An important practical application of the OMNI RPE scale is its use in regulating intensity during a bout of aerobic exercise. An investigation by Robertson et al., (2002), demonstrated that children were capable of regulating exercise intensity during an intermittent cycle ergometer protocol (i.e. start and stop) with each interval at 6 minutes in duration. Ceci et al., (1991) indicated that adult subjects were able to regulate intensity using the Borg 6-20 RPE scale during ten minutes of treadmill and field running. Kang et al., (1998) determined that subjects could use the OMNI RPE scales to regulate exercise intensity during an 8 minute bout of arm and leg ergometry. Dunbar et al., (1992) determined that subjects were able to use the 
Borg RPE scale to regulate exercise intensity for 5 minute exercise bouts on both the treadmill and cycle ergometer. These studies clearly demonstrate that children and adults can use perceptual scaling metrics to self regulate exercise intensity during various aerobic activities.

Typically, an exercise prescription developed to enhance cardiovascular fitness would have a minimum duration of 20 minutes. Dunbar et al. (1994) and Chow et al. (1984) investigated the use of RPE to regulate the intensity of a continuous exercise bout of 15 to 25 minutes. The results of the Chow et al. (1984) study indicated that RPE scaling metrics can be used to maintain a constant exercise intensity for durations of 15 to 20 minutes. In addition, the OMNI RPE scale has recently been established as a valid instrument for regulating exercise intensity during longer exercise bouts on both the cycle ergometer and the treadmill (Kang et al., 2003; Utter et al., 2006).

Perceptual regulation of exercise intensity is considered physiologically and clinically valid if $\mathrm{HR}, \mathrm{VO}_{2}$, rate-pressure product, or ECG criteria do not differ when comparisons are made at similar levels of exertion between a GXT (estimation trial) and the individual training session (production trial) (Noble et al., 1996). Previous investigations that used the estimation production procedures include: (Ceci et al., 1991; Dunbar et al., 1992; Eston et al., 1987; Glass et al., 1992; Kang et al., 1998; Robertson et al., 2002; Smutok et al., 1980). These studies were able to use the estimation-production procedure to prescribe a target RPE from the results of the estimation trial GXT. Subjects then used the target RPE in the production trial to titrate the exercise intensity to elicit a physiological response, i.e., $\mathrm{HR}, \mathrm{VO}_{2}, \mathrm{~V}_{\mathrm{E}}$. The details of these studies will be discussed in detail in Chapter 2 .

Traditionally, an aerobic exercise prescription is generated by first performing a symptom limited maximal GXT and then prescribing the intensity based on a percentage of the $\mathrm{HR}_{\max }, \mathrm{HR}$ 
reserve, $\mathrm{VO}_{2} \mathrm{R}$, or $\mathrm{VO}_{2 \text { max }}$. However, perceptually-based exercise prescriptions can also be developed using an estimation-production procedure (Noble et al., 1996) (Robertson, 2004). This technique involves the development of a target RPE range that is based on the individual RPE, $\mathrm{VO}_{2}$, or $\mathrm{HR}$ relation determined during the estimation trial. Next, subjects can titrate the exercise intensity to "produce" the target RPE. Throughout this production trial the subject can adjust the workload by increasing or decreasing the speed and/or grade to obtain and maintain the prescribed RPE intensity. When the target RPE range is produced during an aerobic exercise session it will result in the stimulus necessary to provide health-fitness benefits. This estimationproduction procedure (Figure 2) will be described in greater detail in Chapter 3.

\subsection{RATIONALE}

Various scaling metrics have been shown to be valid in establishing and maintaining exercise intensity during steady state aerobic exercise ranging from 8 - 25 minutes in duration (Dunbar et al., 1992; Dunbar et al., 1994; Kang et al., 2003). The next logical step is to examine if RPE can be used to regulate exercise intensity during an intermittent training bout. Intermittent exercise is often employed in athletic, clinical, and health-fitness settings as it allows for a greater amount of physiological work to be done in a given period of time when compared to continuous constant intensity training. However, it is unknown if individuals can use the OMNI RPE scale to self regulate exercise intensities that correspond to metabolic rates $\left(\% \mathrm{VO}_{2} \mathrm{R}\right)$ set alternately at the low and high end of the physiological training zone during intermittent exercise. 


\subsection{STATEMENT OF THE PROBLEM}

The goal of the present study is to determine if subjects can self-regulate exercise intensity during a 20 minute intermittent bout of aerobic exercise on the treadmill using the OMNI RPE scale.

\subsection{HYPOTHESIS}

It is hypothesized that once target RPE's are established based upon the results of a maximal graded treadmill test (Estimation trial), subjects will be able to produce perceptual intensities corresponding to $50 \%$ and $70 \%$ of $\mathrm{VO}_{2} \mathrm{R}$ using the OMNI RPE scale during intermittent treadmill exercise (Production trial).

Sub-hypotheses

1. The HR from the estimation and production trials will not differ throughout the 20 minute exercise session at an RPE corresponding to $50 \%$ of $\mathrm{VO}_{2} \mathrm{R}$. (Prescription congruence)

2. The HR from the estimation and production trials will not differ throughout the 20 minute exercise session at an RPE corresponding to $70 \%$ of $\mathrm{VO}_{2} \mathrm{R}$. (Prescription congruence)

3. The $\mathrm{VO}_{2}$ from the estimation and production trials will not differ throughout the 20 minute exercise session at an RPE corresponding to $50 \%$ of $\mathrm{VO}_{2} \mathrm{R}$. (Prescription congruence) 
4. The $\mathrm{VO}_{2}$ from the estimation and production trials will not differ throughout the 20 minute exercise session at an RPE corresponding to $70 \%$ of $\mathrm{VO}_{2} \mathrm{R}$. (Prescription congruence)

5. The HR will be greater for the RPE corresponding to $70 \%$ of $\mathrm{VO}_{2} \mathrm{R}$ compared to the $\mathrm{RPE}$ corresponding to $50 \%$ of $\mathrm{VO}_{2} \mathrm{R}$ during the production trial. (Intensity discrimination)

6. $\mathrm{VO}_{2}$ will be greater for the RPE corresponding to $70 \%$ of $\mathrm{VO}_{2} \mathrm{R}$ compared to the RPE corresponding to $50 \%$ of $\mathrm{VO}_{2} \mathrm{R}$ during the production trial. (Intensity discrimination)

7. The production order (counterbalance order I \& counterbalance order II) will not alter the subject's ability to self regulate intensity using the OMNI RPE scale at 50\% of $\mathrm{VO}_{2} \mathrm{R}$. (Sequence)

8. The production order (counterbalance order I \& counterbalance order II) will not alter the subject's ability to self regulate intensity using the OMNI RPE scale at $70 \%$ of $\mathrm{VO}_{2} \mathrm{R}$. (Sequence) 


\subsection{LITERATURE REVIEW}

\subsection{PERCEIVED EXERTION}

\subsubsection{Rating of Perceived Exertion (RPE)}

The first scale to measure perceived exertion was developed and validated in the 1960's by psychologist Gunnar Borg (Borg, 1961, 1962; Borg et al., 1960). The early work by Borg provided the impetus for further research in the domain of perceived exertion and provided the conceptual framework by which other scales were created and validated. One of the most widely used RPE scales by health care professionals, researchers, and personal trainers is the Fifteencategory (6-20) Borg Perceived Exertion Scale (Borg, 1982). Research focusing on ratings of perceived exertion has been extensive during the past four decades. Of particular interest has been the development of new scaling methodologies, defining physiological / psychological mediators of exertion, and application of scaling metrics in various athletic and health-fitness settings. 


\subsubsection{Global Model}

There are several interrelated elements that produce a person's perception of exertion during dynamic exercise. A global explanatory model of perceived exertion discussed by Noble et al. (1996) attempts to explain the Gestalt properties of the exertional milieu. The model in (Figure 1) explains the perceptual responsiveness sequentially by interpreting the model from left to right. Physiological responses to an exercise stimulus serve as the initial mediators that shape the intensity of the perceptual signal. The effect of these signal mediators is to alter tensionproducing properties of the skeletal muscle. An increase in peripheral and/or respiratory muscle tension during exercise is brought about by a greater discharge of the central feed-forward commands arising from the motor cortex. Corollary pathways carrying a copy of these central commands terminate in the sensory cortex. These corollary discharges are subsequently interpreted as perceptual signals of exertion. The final mediating step in the exertional process occurs when the signal arising from the sensory cortex is matched with the contents of the perceptual cognitive reference filter. As the signal passes through the reference filter it is fine tuned, its intensity modulated according to the matrix of past and present events that reflect the individual’s psychological characteristics and perceptual style (Robertson et al., 1997). 


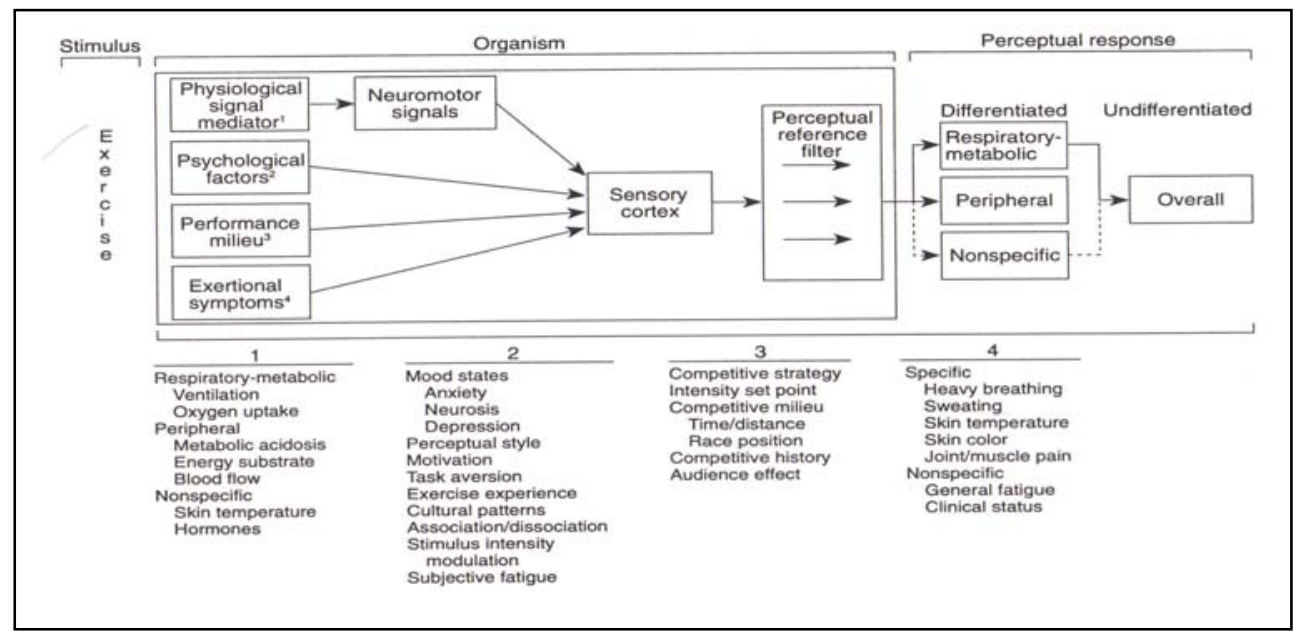

Figure 1. Global explanatory model of perceived exertion

(Noble and Robertson, 1996. Reprinted with permission)

\subsubsection{Borg's Range model}

Borg's range model explains the validity of the RPE scale to measure interindividual differences in perception of physical exertion. To be valid the RPE scale must be capable of measuring perceptual responses across the entire physiological range during exercise. The principal assumptions that comprise the conceptual framework of the range model are as follows: (a) for any given stimulus range (rest-to-peak exercise intensity), there exists a corresponding and equal perceived-exertion range. (b) for all clinically normal individuals, both the perceptual range and the intensity of the perceptual signals at the low and high ends of the stimulus range are equal (Robertson et al., 1997). The practical application of such assumptions allows for comparisons of rating of perceived exertion responses of individuals with different levels of aerobic fitness.

The development of the range model for perceived exertion provided the theoretical foundation in which Borg's ratings of perceived exertion scales were validated. The range model served as the framework for the development and validation of the OMNI RPE scale. 
The range model allows for the high and low RPE anchors to be established for each individual. The perceptual anchoring procedures allow each person to cognitively establish a subjective correspondence between the exercise intensity and high and low exertional perceptions. When RPE anchors are established using the appropriate scaling instructions and anchoring procedures, the range model subjectively equates the lowest and highest intensity between individuals who differ in physiological, psychological, or health-fitness characteristics.

\subsubsection{Effort Continua}

The perception of physical exertion involves the feelings of effort, strain, discomfort, and fatigue that a person experiences during exercise (Noble et al., 1996). As one begins to exercise, there are interrelated physiological, psychological, and symptomatic mediators that are integrated to create the sensation of effort, strain, discomfort, or fatigue throughout the effort continua. Borg's effort continua states that the subjective response to an exercise stimulus involves three main effort continua that can be characterized as: physiological, perceptual, and performance (Borg, 1982). The Borg effort continuum indicates that as exercise performance increases along an intensity dependent continuum there are corresponding and interdependent increases in response intensity along perceptual (RPE) and physiological $\left(\mathrm{VO}_{2}, \mathrm{HR}, \mathrm{V}_{\mathrm{E}}\right)$ continua, demonstrating a positive relation. The functional link between the three effort continua indicates that perceptual responses provide much of the same information about exercise performance as do selected physiological variables (Robertson et al., 1997). 


\subsubsection{Physiological Mediators}

The physiological mediators that influence perceived exertion are classified as peripheral, respiratory-metabolic, and nonspecific (Robertson, 2004). Blood pH, lactic acid, blood glucose, muscle blood flow, muscle fiber type, free fatty acids, and muscle glycogen mediate the perception of exertion in the trunk and the limbs of the body. Pulmonary ventilation $\left(\mathrm{V}_{\mathrm{E}}\right)$, Oxygen uptake $\left(\mathrm{VO}_{2}\right)$, carbon dioxide production, heart rate (HR), and blood pressure (BP) influence the respiratory-metabolic drive during dynamic exercise. The nonspecific mediators are considered to be more general and consist of changes in catecholamines, body temperature, pain, cortisol, serotonin, and cerebral blood flow.

Not much is known of the direct impact of the psychosocial mediators on the rating of perceived exertion during exercise. Many researchers agree that certain psychological and sociological factors systematically influence self-assessment of effort (Morgan, 1994; Noble et al., 1996). The interindividual differences in the psychosocial mediators of RPE are complex and variable. As such it is difficult to determine the impact of these variables on perceived exertion. For example, a possible mediator such as anxiety could increase the perceptual rating in one subject and decrease the rating in another.

\subsection{OMNI SCALE OF PERCEIVED EXERTION}

The development of the OMNI rating of perceived exertion scale is the most recent advancement in the discipline of perceived exertion. The OMNI Scale of perceived exertion has undergone validation paradigms for resistance training for children (Robertson, Goss, Andreacci,

Dube, Rutkowski, Frazee et al., 2005), stepping exercise for children (Robertson, Goss, 
Andreacci, Dube, Rutkowski, Snee et al., 2005), cycling for children (Robertson et al., 2002), cycling for young adults (Robertson et al., 2004), resistance training in young adults (Robertson et al., 2003), and walking and running exercise for adults (Utter et al., 2004), prolonged cycling in young healthy adults (Utter et al., 2006), and intermittent running for children (Groslambert et al., 2005). The OMNI RPE scale has expanded the use of RPE in public health settings, exercise prescriptions, clinical exercise testing, and research.

According to Robertson (2004) the OMNI scale has several distinct advantages over other perceived exertion scales that make it easier for health-fitness and clinical exercise practitioners to use. Foremost is that the OMNI scale employs a single set of verbal cues for all of the interchangeable sets of picture cues. The interchangeable sets of picture cues allows the scale to be used for exercise assessment and program prescription for clients of various ages, fitness levels, clinical status, and physical activity preferences. Another plus of the OMNI scale is its comparatively narrow numerical rating range of 0 to10. Because the range of 0 to 10 is commonly used to evaluate many aspects of daily living, most people easily understand the scale. Finally, users report that the upper picture cue of the OMNI scale helps to sharpen their memory of maximal exertion, which often eliminates the need to engage in expensive and uncomfortable maximal exercise testing to establish the high perceptual anchor.

\subsubsection{Validation of the OMNI Walk/Run scale}

An investigation by Utter et al. (2004) examined the validity of the OMNI Walk/Run perceived exertion scale for adults. The investigation utilized clinically healthy male and female subjects 18 to 36 years old. Subjects performed a perceptual estimation paradigm during a single 
graded exercise test (GXT). Concurrent and construct validity paradigms were implemented to determine the response validity of the OMNI RPE scale.

Concurrent validity was investigated by examining the relationship of RPE with submaximal oxygen uptake $\left(\mathrm{VO}_{2}\right)$, relative maximal oxygen uptake $\left(\% \mathrm{VO}_{2 \max }\right)$, pulmonary ventilation $\left(\mathrm{V}_{\mathrm{E}}\right)$, respiratory rate (RR), respiratory exchange ratio (RER) and heart rate (HR). Concurrent validity is demonstrated when there are increases in the concurrent and criterion variables with an increase in exercise intensity. Regression analysis determined that the criterion variables $\left(\mathrm{VO}_{2}\right.$, $\mathrm{HR}$, etc.) and concurrent variable (RPE) distributed in a positive linear fashion. Validity was established by the high correlation coefficients ranging from $r=0.67$ to 0.88 for both males and females for the respiratory-metabolic measures. According to Utter et al. (2004) the RPE response linearity as an applied validation criterion is consistent with the basic tenants of Borg's Effort Continua Model. The positive linear relation observed in the investigation between the OMNI-Walk/Run scale RPE responses and selected physiological variables is consistent with the application outcomes underlying the Borg Effort Continua Model. Construct validity was established by using the previously validated Borg 6-20 RPE scale (Borg, 1982) as the criterion metric and the OMNI RPE scale as the conditional metric. Validity is demonstrated when there is a positive correlation between the criterion and conditional metrics. The investigation demonstrated that the OMNI RPE scale was positively correlated $(r=0.96)$ to the Borg 6-20 scale for walking and running exercise for both males and females. The comparatively high level of construct validity observed by Utter et al. (2004) indicates that the OMNI - Walk/Run Scale measures the same exertional properties as does the Borg (6-20) Scale. 


\subsection{ESTIMATION-PRODUCTION EXERCISE PRESCRIPTION}

A typical exercise prescription is based on data obtained (i.e. $\mathrm{HR}, \mathrm{VO}_{2}$ ) during a maximal graded exercise test or a submaximal test. An individual prescription can be based on heart rate, $\mathrm{VO}_{2} \mathrm{R}$, or a metabolic equivalents (MET). The Target Heart Rate (THR) can be developed from the maximal heart rate $\left(\mathrm{HR}_{\max }\right)$ obtained during the maximal graded exercise test or it can be estimated from equations such as (220 - age). Once the $\mathrm{HR}_{\max }$ is determined, a calculation can be made to determine a training intensity zone. Another method of prescribing a THR is called the heart rate reserve (HRR). The HRR method is closely associated with the $\mathrm{VO}_{2} \mathrm{R}$ and thus provides the appropriate intensity in relation to the $\mathrm{VO}_{2} \mathrm{R}$ (Swain et al., 1997). The American College of Sports Medicine (ACSM 2006a) recommends a THR between 55/65\% to 90\% of $\mathrm{HR}_{\max }$ and $40 / 50 \%$ to $85 \%$ of the HRR. A graded exercise test measuring oxygen uptake will determine the $\mathrm{VO}_{2 \max }$ or $\mathrm{VO}_{2 \text { peak }}$ depending on the modality used. According to the ACSM (2006a), exercise intensity should be prescribed from $40 / 50 \%-85 \%$ of $\mathrm{VO}_{2} \mathrm{R}$.

Using RPE to regulate exercise intensity is not as common as using a target HR or

$\mathrm{VO}_{2}$. However many studies have shown that using RPE to regulate exercise intensity is safe and effective. The perceptually based exercise prescription is derived by plotting the RPE that has been estimated during the graded exercise test against the corresponding $\mathrm{VO}_{2}$ responses (Noble et al., 1996). The exercise intensity prescription is then based on a predetermined percentage of $\mathrm{VO}_{2} \mathrm{R}$. For example, the RPE's corresponding to $50 \%$ and $70 \%$ of $\mathrm{VO}_{2} \mathrm{R}$ can be identified (Figure 2). Next, the subject selects the exercise intensity (e.g. workload) that results in the target RPE. Once the prescribed RPE is produced during exercise an individual will attain the prescribed physiological load that will provide a safe and effective training stimulus. 


\subsection{SELF-REGULATION OF EXERCISE USING RPE}

Using heart rate to regulate exercise intensity is commonly used technique in healthfitness facilities. However, the use of RPE to regulate exercise intensity has been investigated using various exercise modalities, durations, intensities and populations. Several investigations have established the validity of regulating exercise intensity using rating of perceived exertion scales. The ability to self regulate exercise intensity using RPE lessens the need for the palpation of heart rate to determine exercise intensity.

Sumtok et al. (1980) conducted one of the initial investigations that examined the validity of intensity self regulation using RPE. Healthy young male subjects performed an initial exercise trial at predetermined speeds on the treadmill while measuring perceptual, metabolic and cardiopulmonary data. For the second exercise trial subjects were instructed to produce the RPEs that were estimated during the first exercise trial. The results indicated that there were mean errors in HR responses of $1.8 \%$ to $5.5 \%$ during running exercise in the $78 \%$ to $92 \%$ maximum HR range (RPE 12.5 to 14.6) when subjects regulated exercise intensity by RPE alone. Higher mean errors of $22.3 \%$ and $34.7 \%$ were reported for walking exercise in the $49 \%$ to 73\% $\mathrm{HR}_{\max }$ range (RPE 7.9 to 10.3) when regulating exercise using RPE. The authors indicated that running exercise on the treadmill mediated by RPE is reliable at HR responses above 150 beats per minute $\left(80 \% \mathrm{HR}_{\max }\right)$.

Eston et al. (1987) determined the capability of young male and female subjects to regulate exercise intensity using RPE during treadmill exercise. Initially, a GXT was administered to determine perceptual and aerobic-metabolic responses. During a subsequent effort production test subjects were requested to run at constant exercise intensity at RPEs of 9, 13, and 17 on the Borg $6-20$ scale. The results indicated that subjects produced relative 
exercise intensities $\left(\% \mathrm{VO}_{2 \max }\right)$ at each of the prescribed RPEs during treadmill running that were similar to those observed during the estimation trial. The greatest accuracy for self-regulation was noted at the higher exercise intensities (RPE 13 and 17). This finding is consistent with the results from Smutok et al. (1980).

Easton et al. (1988) examined the reliability of RPE for the regulation of cycle ergometer exercise. Initially, healthy young men performed a GXT on a cycle ergometer to measure perceptual, aerobic-metabolic and cardiovascular responses. During three subsequent production sessions subjects were requested to cycle at intensities that resulted in RPE's of 9, 13, and17 in that order. The subjects demonstrated a greater capacity for self regulation using RPE at the higher intensities (RPE 12 or greater) and with more experience (third trial). Despite the initial greater accuracy at higher intensities, the subjects were able to use RPE to self regulate at the lower intensities during the later production trials. This study suggests that RPE is a reliable frame of reference for the production of a wide range of exercise intensities on the cycle ergometer.

An investigation by Chow et al. (1984) examined the ability of subjects to monitor and maintain an exercise prescription based on RPE. Adult male subjects were randomly assigned to one of three different exercise prescription groups. One group used a target heart rate (THR) to monitor exercise intensity. The exercise prescription for the second group was based on RPE. The final group served as the control and was instructed to exercise as they normally would with no formal feedback. Subjects completed four 15 minute exercise trials on the treadmill in which they exercised at the prescribed target HR or RPE. The results demonstrated that the subjects with no method of monitoring their exercise intensity were not able to maintain the appropriate exercise intensity. The THR method provided the best results out of the three groups. Subjects 
were able to meet their prescriptive heart rate range $55.3 \%$ of the time. However, the accuracy of the RPE method provided similar accuracy compared to the THR where subjects were able to meet their prescriptive range $48.5 \%$ of the time. The authors indicate that the RPE is a method that can be used separately or in conjunction with the THR method. The RPE method for monitoring and controlling exercise intensity provided a means to control the exercise intensity with no interruption and minimal training.

A study by Dunbar et al. (1992) utilized estimation and production trials to determine the validity of the Borg RPE scale for the intra- and intermodal regulation of exercise intensity. The estimation trial consisted of a progressively incremented graded exercise test (GXT) that was administered to male subjects on both a treadmill and a cycle ergometer. Utilizing the data from the GXT's an RPE corresponding to $50 \%$ of $\mathrm{VO}_{2 \max }$ and $70 \%$ of $\mathrm{VO}_{2 \max }$ was calculated for both modes. Subjects underwent four production trials using the prescriptive RPE's on both the treadmill and cycle ergometer. Intramodal production accuracy for the treadmill was tested by performing both the estimation and production trials on the treadmill. Intermodal production accuracy was tested by using the perceptual and physiologic data from the cycle ergometer estimation trial and the treadmill for the production. The same strategy was used for the intraand intermodal production accuracy using the cycle ergometer. The investigation indicated that RPE was accurate for regulating exercise intensity. This accuracy held up in both the intra- and intermodal production trials and at both of the prescribed exercise intensities. An interesting finding of this study is that there was only an average of $2 \%$ difference between the target $\mathrm{VO}_{2}$ and the production $\mathrm{VO}_{2}$ when using RPE to regulate intensity. The traditional method of using a target heart rate yields a greater percent error (8\%) when used to produce a given $\mathrm{VO}_{2}$ (McArdle et al., 1986). 
In a similar study Dunbar et al. (1994) addressed the question of whether the RPE method for prescribing exercise is physiologically valid (in terms of maintaining a given $\%$ of $\mathrm{VO}_{2 \max }$ ) for a duration of aerobic exercise that is typically recommended to improve cardiovascular fitness. Using the same estimation - production trial employed by Dunbar et al. (1992) the RPE corresponding to $60 \%$ of $\mathrm{VO}_{2 \max }$ was determined. The estimation trial was performed on a cycle ergometer and the production trials were performed on both the treadmill and cycle ergometer. The production trials consisted of a continuous 25 minute exercise session. The results demonstrated that subjects were capable of regulating the intensity of exercise on the treadmill and cycle ergometer using the prescribed RPE. Subjects were able to titrate the exercise intensity using RPE during exercise and the $\mathrm{VO}_{2}$ and $\mathrm{HR}$ did not differ between the estimation and production trials. This provided evidence of the validity of perceptual self regulation of exercise intensity. In addition, the authors indicate that the accuracy of RPE to regulate intensity did not change over the 25 minute of exercise. The results of this investigation are applicable to the clinical and health-fitness setting because both the duration and intensity used in the study are more representative of those typically recommended (ACSM, 2006a; NIH, 1996).

Kang et al. (2003) used an estimation production paradigm to evaluate the regulation of exercise intensity utilizing RPE zones to regulate exercise intensity during 20 minute aerobic exercise bouts on a treadmill and cycle ergometer. The estimation trials were performed on both the treadmill (TM) and cycle ergometer (C). The production trials were then performed using the same estimation and production exercise modality (Intramodal, TM/TM, C/C) or the estimation production trials alternated the exercise modalities (Intermodal, TM/C, C/TM). A best-fit linear regression in which $\mathrm{HR}$ and $\mathrm{RPE}$ were plotted as a function of $\mathrm{VO}_{2}$ were calculated to provide the target RPE which the subjects would produce during the exercise 
session. The prescriptive RPE's for the exercise session corresponded to 50 and $70 \%$ of the $\mathrm{VO}_{2 \max }$. The study found that there were no differences in $\mathrm{VO}_{2}$ between the intramodal (TM/TM and $\mathrm{C} / \mathrm{C}$ ) estimation and production trials throughout the 20 minute exercise bout at both 50 and $70 \%$ of $\mathrm{VO}_{2 \max }$. The results indicate that a prescriptive RPE from a GXT can be used to accurately regulate and maintain an exercise intensity (i.e., intra modal congruence). However, the results for the study were not as favorable for the intermodal comparisons (TM/C \& C/TM). $\mathrm{VO}_{2}$ was higher for the $\mathrm{C} / \mathrm{TM}$ and lower for the $\mathrm{TM} / \mathrm{C}$ for both exercise intensities and the differences were constant throughout the 20 minute exercise session. These findings do not agree with the results from the intramodal comparisons as well as previous investigations (Dunbar et al.,, 1994; Dunbar et al., 1992). The authors explain the differences in the $\mathrm{VO}_{2}$ for the intermodal comparisons by explaining the results in relative $(\mathrm{ml} / \mathrm{kg} / \mathrm{min})$ as opposed to absolute $(\mathrm{l} / \mathrm{min})$ metabolic units. Once the $\mathrm{VO}_{2}$ for the intermodal comparisons were expressed in relative metabolic units the values were similar. The investigators concluded that the OMNI RPE scale is effective in establishing the target intensity at the onset of exercise and maintaining the intensity throughout a 20 minute exercise session.

Investigators using the same estimation-production protocol as (Kang et al., 2003) examined the ability of male and female subjects to use RPE to regulate arm and leg ergometry during five minutes of exercise (Kang et al., 1998). The study performed only intramodal comparisons. Subjects were prescribed RPEs that correspond to $50 \%$ and $70 \%$ of the mode specific production trial $\mathrm{VO}_{2 \text { peak }}$. The subjects then completed a 5 minute training session using RPE to select and maintain the exercise intensity. The results indicated that there was no difference in heart rate, $\mathrm{VO}_{2}$, and power output between the estimation and production trials at $50 \%$ and $70 \%$ of $\mathrm{VO}_{2 \text { peak }}$ for the cycle ergometer exercise. However, for the leg ergometer at 
$70 \%$ of $\mathrm{VO}_{2 \text { peak, }}$, the $\mathrm{VO}_{2}$ and power output were significantly lower during the production trial than the estimation trial. The authors recommend using RPE in conjunction with periodic heart rate monitoring when leg cycling at moderate to high intensities.

Marriott et al. (1996) investigated the ability of subjects to perceptually regulate intensity while exercising on a rowing ergometer. Competitive male rowers first performed an estimation trial on a rowing ergometer. For the subsequent productions trials, subjects were asked to titrate exercise intensity to produce RPEs for 3 minutes in the irregular order of: 15, 11, 17, 13, 19. The HR and power outputs were compared between the estimation and production trials. The results indicated that the subjects were capable of accurately regulating the exercise intensity using RPE at the higher intensities (RPE $>15)$. The greatest inaccuracy in regulating exercise was demonstrated during the production trial at an intensity of RPE 13. The HR was significantly higher $(17 \mathrm{bpm})$ in the production trial. These findings generally agree with previous investigations (Eston et al., 1987; Smutok et al., 1980) where the highest levels of accuracy for self-regulation were demonstrated during the higher levels of exercise intensity.

A study by Bayles et al. (1990) determined the effect of a perceptual reinforcement program on the accuracy of an exercise prescription based on target levels of perceived exertion. The male subjects were divided into practice with feedback, practice without feedback, and a control group. The perceptual reinforcement program consisted of audio tapes that described the type of sensory information that must be monitored in order to achieve a target training RPE and were played during the learning periods between the exercise sessions. All the subjects completed four exercise trials. The results indicate that the presentation of a standard reinforcement in combination with the RPE scale improved the accuracy of the self-regulation 
during exercise. The greatest accuracy was found at moderate to high intensities (60-80\% $\mathrm{VO}_{2 \max }$ ) which is in agreement with previous findings (Eston et al., 1987; Smutok et al., 1980).

Glass et al. (1992) investigated the accuracy of using RPE values from a GXT to prescribe steady state treadmill exercise. Subjects performed a maximal GXT and RPE responses were recorded during each minute of exercise. The "target RPE" was identified by examining the GXT data to determine the RPE at $75 \%$ of HRR. The target RPE was then produced during treadmill exercise by making speed and grade adjustments during the 10 minute trial. The results indicate that the subjects were able to titrate the exercise intensity on the treadmill to produce the target RPE intensity as indicated by no significant difference in $\mathrm{VO}_{2}$ and $\mathrm{V}_{\mathrm{E}}$ between the GXT and the exercise production trial. However, the HR was 12 beats per minute lower than the target until the target steady state was reached at minute six. Despite the lower HR response the authors indicate that the HR's were within four beats per minute of the target heart rate by the sixth minute of exercise. The investigators attribute the lower initial HR to an insufficient warm-up prior to starting the exercise trial. The authors indicate that RPE obtained from a GXT can accurately serve as a method for prescribing exercise intensity during treadmill running.

Ceci et al. (1991) investigated the use of the RPE scale at 3 specific intensity levels (RPE 11, 13, and 15). The aim of the study was to determine the subjects' ability to produce an RPE response during indoor and outdoor running. Heart rate, Blood lactate concentration (Hla) $\left(\mathrm{mmol} \cdot \mathrm{l}^{-1}\right)$ and running velocity $\left(\mathrm{m}^{\cdot} \mathrm{s}^{-1}\right)$ were compared between the indoor and outdoor trials at each exercise intensity. Subjects were asked to produce a RPE on the treadmill and outdoor track for continuous intervals ranging from $3-11$ minutes. A 1-2 minute rest periods separated the prescribed exercise intensities. The treadmill and outdoor track sessions were conducted on 
the same day and separated by a 20 minute rest period. The exercise bouts continued until all RPE's were completed. The results indicate that subjects were able to produce the prescribed RPE's during exercise. However, the HR, Hla, and velocity were higher during the outdoor run on the track. The authors suggest that RPE is an accurate method for regulating indoor exercise, but caution the use of RPE in outdoor settings.

Robertson et al. (2002) studied the ability of children to self-regulate exercise intensity on the cycle ergometer using the OMNI Scale of Perceived Exertion. The investigation examined the subject's ability to self-regulate exercise intensity (prescription congruence) and to perceptually discriminate (intensity discrimination) between exercise intensities. Using an estimation - production procedure, subjects initially performed a peak exercise tolerance test on the cycle ergometer. For the subsequent production trial subjects were asked to produce exertional perceptions equal to 2 (a little tired) and 6 (getting more tired). The three minute exercise trials at each RPE were produced in an intermittent fashion with a 90 second rest between each of the trials. The results demonstrated the subject's ability to self-regulate exercise intensity at each of the target RPEs as determined by the similar $\mathrm{VO}_{2}$ and $\mathrm{HR}$ between the estimation and production trials. Subject's were also able to discriminate between each of the prescribed RPEs as determined by the significantly higher $\mathrm{VO}_{2}$ and $\mathrm{HR}$ for the RPE of 6 compared to the RPE of 2. This investigation supports the use of RPE to self-regulate exercise intensity in young children 8 - 12 years old.

An investigation by Groslambert, et al. (2005) evaluated the ability of children to selfregulate running intermittent intensity using the OMNI scale of perceived exertion. During an estimation trial the subjects performed a 20 m shuttle run and HR was recorded. The production trials were performed on an indoor track by performing 3 separate intermittent bouts of running 
at RPEs of 2, 6, and 10. Subjects were asked to produce each of the RPEs in three intermittent bouts of running exercise. Results of the study indicated that the HR did not differ between the estimation and production trials which established prescription congruence. The HR responses were significantly different between each of the prescribed RPEs indicating the subject's ability to perceptually discriminate between each of the intensities. The investigation demonstrated the ability of young male and female subjects to self-regulate exercise intensity while running on a track.

There are numerous investigations that support the use of RPE to regulate exercise intensity during dynamic exercise. However, some investigations have not come to the same conclusions. One such investigation by Whaley et al. (1990) attempted to determine the value of HR, RPE, or HR + RPE intensity feedback on the ability to self-regulate exercise intensity in a field setting. Subjects' performed four 800 meter exercise trials while regulating exercise intensity using HR, RPE, RPE + HR, or free exercise with no feedback. The results indicated that the group that used HR and HR + RPE were able to accurately self - regulate exercise intensity during the four training sessions. The authors indicated that the combined feedback of HR + RPE was no more effective in maintaining exercise intensity than HR alone. The use of RPE alone was not effective in regulating exercise intensity during any of the four trials. The RPE group exceeded the target heart rate for each of the exercise trials. In fact, the authors point out that the RPE group was no more accurate than the control group in maintaining exercise at the target intensity.

Potteiger et al. (1995) investigated the ability of subjects to self-regulate outdoor running intensity using HR and RPE. Subjects performed a GXT and the THR and RPE were determined. The subsequent $5000 \mathrm{~m}$ field runs were performed on an outdoor track and subjects 
were prescribed a THR or target RPE and asked to maintain the prescribed intensity. The findings indicated that the HR obtained from the GXT was superior to the target RPE for reproducing similar blood lactate levels and metabolic intensity during the outdoor steady state running. The authors indicated that RPE underestimated the metabolic intensity for each of the field runs. The authors concluded that RPE may not be as accurate as HR for regulating exercise intensity during outdoor running.

Thompson et al. (1998) compared the blood lactate values and HR responses of male subjects performing both indoor treadmill running and outdoor running on a track. Subjects were prescribed an exercise intensity (RPE) that would elicit a given blood lactate concentration. Using RPE to titrate the exercise intensity, subjects performed a thirty minute run on the track. The results indicated that the HR and blood lactate were significantly higher during the outdoor run compared to those observed during the indoor treadmill run when using RPE to regulate exercise intensity. These results are in agreement with Ceci et al. (1991) that found the same higher HR responses for the outdoor run compared to the indoor run.

Joo et al. (2004) investigated the physiologic demand $\left(\% \mathrm{VO}_{2} \mathrm{R}\right)$ of phase 2 cardiac rehabilitation patients during an exercise session. The authors wanted to determine the safety and efficacy of the common methods of intensity regulation such as rest +20 or an RPE range of 11-13. The results indicated that subjects were in the target metabolic range (40-60\% $\left.\mathrm{VO}_{2} \mathrm{R}\right)$ when using rest +20 to gauge exercise intensity. However, using the RPE produced a higher metabolic rate during the exercise bout with several subjects exceeding $60 \%$ of $\mathrm{VO}_{2} \mathrm{R}$ and two subjects exceeding $85 \% \mathrm{VO}_{2} \mathrm{R}$. The authors emphasize that each of the methods for regulating exercise intensity had a significant intersubject variability with the observed $\% \mathrm{VO}_{2} \mathrm{R}$. Caution 
is suggested when using either method for intensity regulation in phase 2 cardiac rehabilitation patients.

Hartshorn et al. (2004) investigated the reproducibility of perceptually regulated exercise responses during short term cycle ergometry. Subjects completed four cycle ergometer trials producing RPE's in the following order 13, 15, 9, 17. The results question the test-retest reproducibility of the use of RPE for the regulation of exercise intensity. Subjects were not able to use RPE to reproduce exercise power outputs over four repeated bouts of cycle ergometry. The authors also point out that the subjects demonstrated no improvement over the repeated trials. This is in agreement with Lamb et al. (1999) who reported a low test-retest reproducibility for subjects using the treadmill to produce target RPEs.

\subsection{CONCLUSIONS}

There is considerable evidence in the scientific literature to support the use of RPE to regulate exercise at different intensities using various modalities. Much of the evidence supports the use of RPE for self-regulation for short term aerobic activities that are continuous in nature. However, many of the activities that the athletic, health-fitness, clinical and the general population participates in are intermittent (continuous exercise at varying intensity) in nature. No previous investigation has examined if individuals can use the OMNI RPE Scale to self regulate exercise intensities that correspond to metabolic rates $\left(\% \mathrm{VO}_{2} \mathrm{R}\right)$ set alternately at the low and high end of the physiological training zone. This gap in the perceived exertion literature was the conceptual basis for the present investigation. 


\subsection{METHODS}

\section{$3.1 \quad$ SUBJECTS}

Thirty one, male $(\mathrm{N}=16)$ and female $(\mathrm{N}=15)$, volunteers 18 -34 years of age participated in this study. Subjects were free of musculoskeletal limitations and of diagnosed cardiovascular or metabolic disease. Each subject completed the Physical Activity Readiness Questionnaire (PARQ), Medical History, and sign an informed consent prior to participation. The PAR-Q, Medical History form, and the informed consent can be found in appendix A, appendix B, and appendix C, respectively. All experimental procedures was approved by the University of Pittsburgh's Institutional Review Board for human subject experimentation. Subjects were recreationally active. For the purposes of this investigation recreationally active is defined as: "aerobic or weight training 1 -3 times per week for 30 to 60 minute sessions and not participating in collegiate athletics”. Subjects were excluded from the study based on the following criteria:

1. Answering yes to one or more of the questions on the PAR-Q without obtaining clearance from their physician.

2. Currently pregnant.

3. Subject's with implantable devices such as Pacemakers or Automatic Implantable Cardioverter Defibrillators (AICD). 
4. Orthopedic (Acute or chronic musculoskeletal injury), cardiovascular (coronary artery disease), respiratory (Chronic Obstructive Pulmonary Disease or Asthma), and/or metabolic conditions (Diabetes).

\section{Current smoker}

Subjects were recruited from the University of Pittsburgh’s Oakland campus. Subjects were recruited using flyers posted throughout campus and via flyers distributed to basic instruction classes (PEDC: soccer, volleyball, swimming, personal fitness, Aerobics, Yoga and weight training). Interested subjects were asked to respond via phone or e-mail and will be scheduled for an appointment at the Human Energy Research Lab (HERL) to fill out the informed consent, medical history, and PAR-Q. Subjects agreeing to participate in the study and meeting all of the study criteria underwent the anthropometric measurements and the maximal treadmill test (estimation trial) the same day.

\subsection{EXPERIMENTAL DESIGN}

\subsubsection{Pre-test instructions}

Subjects were instructed to wear loose fitting clothing (i.e. shorts and t-shirt) and to report to HERL euhydrated and in a 2 hour post-prandial state. Subjects were instructed not to consume caffeine, alcohol, or smoke cigarettes during the day of the exercise trials. In addition, subjects were asked to abstain from their regular exercise routine the day of the experimental trials. The maximal treadmill test (estimation trial) and the intermittent exercise session (production trial) were conducted at the same time of day. The experimental trials were 
conducted in the HERL where ambient temperature will range from $70^{\circ} \mathrm{F}$ to $74^{0} \mathrm{~F}\left(21^{0}\right.$ to $\left.23^{0} \mathrm{C}\right)$ and percent humidity will be less than $60 \%$.

\subsubsection{Body weight and height}

Body weight $(\mathrm{kg})$ and height $(\mathrm{cm})$ were determined using a Detect-Medic Scale and attached standiometer (Detecto Scales Inc., New York). Subjects were asked to remove their shoes and were wearing a $\mathrm{t}$ - shirt and shorts.

\subsubsection{Body composition}

Percent body fat was determined using a Tanita body fat analyzer (Tanita Corporation of America, Inc. Skokie, IL.). Subjects were instructed to remove their shoes and socks and to stand on the Tanita sensors with their bare feet until a body fat reading is determined. The subject's height, age, and gender were entered into the Tanitia analyzer. The "standard" mode for calculating body fat was used for all subjects.

\subsubsection{Estimation Trial}

\subsubsection{Maximal Graded Exercise Test}

The estimation trial consisted of a maximal graded treadmill test (GXT) using the Bruce protocol. The Bruce protocol is the standard protocol employed for the population in the present study. The GXT was performed on a Trackmaster motor driven treadmill (JAS Fitness System, Newton, KS). Open circuit respiratory-metabolic system (Parvo Medics, Salt Lake City, Utah) was used to measure: $\mathrm{VO}_{2}, \mathrm{ml} / \mathrm{kg} / \mathrm{min}$ (STPD), $\mathrm{V}_{\mathrm{E}} \mathrm{L} / \mathrm{min}$ (STPD), and RER in fifteen second 
intervals. A standard respiratory valve (Rudolph, Model 2700, Kansas City MO) with an adult mouthpiece was used for all respiratory metabolic measurements. The respiratory-metabolic system was calibrated before each estimation and production trial. Heart rate (HR) was measured every minute throughout the estimation and production trials using a wireless Polar Monitoring System (Woodbury, NJ). A Polar transmitter belt was fitted to the subject's chest, just below the pectoralis major. A polar wristwatch was attached to the treadmill and will provide the HR readings.

The Bruce protocol consists of 3-minute stages as follows: Stage $1-45.6 \mathrm{~m} \cdot \mathrm{min}^{-1}$ at a $10.0 \%$ grade; Stage $2-67 \mathrm{~m} \cdot \mathrm{min}^{-1}$ at a $12 \%$ grade; Stage $3-91 \mathrm{~m} \cdot \mathrm{min}^{-1}$ at a $14 \%$ grade, Stage 4 - $112.5 \mathrm{~m} \cdot \mathrm{min}^{-1}$ at a $16 \%$ grade; Stage $5-147.4 \mathrm{~m} \cdot \mathrm{min}^{-1}$ at a $18 \%$ grade. To ensure a true $\mathrm{VO}_{2 \max }$ has been obtained, two of the following criteria must be met: (a) a change in $\mathrm{VO}_{2}$ of $<2.1 \mathrm{ml} / \mathrm{kg} / \mathrm{min}$ with increasing exercise intensity; (b) a Respiratory Exchange Ratio (RER) of greater than or equal to 1.10 (c) heart rate plus or minus 5 beats per minute of the age predicted maximum at the end of the exercise test, (d) volitional termination due to exhaustion.

Prior to the GXT, the subjects received standard instructions on RPE scaling procedures. These procedures include: definition of RPE, scale instructions, setting high and low anchor points (Utter et al., 2004) and (Robertson, 2004).

Subjects were oriented to the OMNI Scale through the following anchoring procedures. The investigator read the following definition of RPE: "The perception of physical exertion is defined as the subjective intensity of effort, strain, discomfort, and/or fatigue that you feel during exercise".

The investigator then read the following script to each subject prior to the estimation and production trials. 
"We would like you to walk and then run on a treadmill. Please use the numbers on this scale to tell us how your body feels when walking or running. Look at the person at the bottom of the hill who is just starting to walk. If you feel like this person when you are walking, the exertion will be Extremely Easy. In this case, your rating should be a number zero. Now look at the person who is exhausted at the top of the hill. If you feel like this person when walking/running, the exertion will be Extremely Hard. In this case, your rating should be a number 10 . If you feel somewhere between Extremely Easy (0) and Extremely Hard (10) then give a number between 0 and 10 . We will ask you to point to a number that tells how your whole body feels including your legs and

chest/breathing. Remember, there are no right or wrong numbers. Use both the pictures and words to help you select a number. Use any of the numbers to tell us how you feel when walking or running”.

\subsubsection{OMNI RPE Scale}

An undifferentiated RPE were estimated for the overall body using the walk/run format of the adult OMNI Perceived Exertion Scale (Utter et al., 2004) (Figure 3) every minute throughout the GXT. The investigator asked each subject their RPE starting at :50 of each minute. The OMNI RPE scale was in the subject's view at all times throughout the GXT. Since subjects will not be able to speak clearly due to the mouthpiece, the subjects pointed to the OMNI RPE scale to indicate their level of exertion. To insure accuracy the investigator confirmed the RPE once the subject has indicated their intensity level. 


\subsubsection{Target RPE}

The target RPE's used in the production trial were calculated using regression analysis. The best fit linear regression in which RPE is plotted as a function of $\mathrm{VO}_{2}$ were calculated for each subject. The RPE's corresponding to $50 \%$ and $70 \%$ of $\mathrm{VO}_{2} \mathrm{R}$ were used for prescribing exercise for each subject in the production trials. An example of the prescription procedure can be seen in Figure 2.

RPE Estimation-Production Procedure (Robertson, 2004)

1). Measure RPE and $\mathrm{VO}_{2}$ during each stage of the estimation GXT

2). Plot the RPE for each exercise stage against its corresponding $\mathrm{VO}_{2}$

3). Generate via regression analysis a reference line representing the best fit through the data points

4). Determine $\mathrm{VO}_{2 \max }$ from load incremented estimation trial

5). Calculate $50 \%$ and $70 \%$ of $\mathrm{VO}_{2} \mathrm{R}$

$\left[\mathrm{VO}_{2 \max }-\operatorname{Rest} \mathrm{VO}_{2}(3.5 \mathrm{ml} / \mathrm{kg} / \mathrm{min})\right]$ x .5 $+3.5 \mathrm{ml} / \mathrm{kg} / \mathrm{min}$

$\left[\mathrm{VO}_{2 \mathrm{max}}-\mathrm{Rest} \mathrm{VO}_{2}(3.5 \mathrm{ml} / \mathrm{kg} / \mathrm{min})\right]$ x .7 $+3.5 \mathrm{ml} / \mathrm{kg} / \mathrm{min}$

6). Draw vertical lines from the points on the $\mathrm{x}$-axis corresponding to $50 \%$ and $70 \%$ of $\mathrm{VO}_{2} \mathrm{R}$ intersecting the regression line.

7). Draw horizontal lines from the points of intersection of the regression line to the y-axis

8). The intersection points on the y-axis mark the low and high target RPEs to be used in the production trial for each subject 


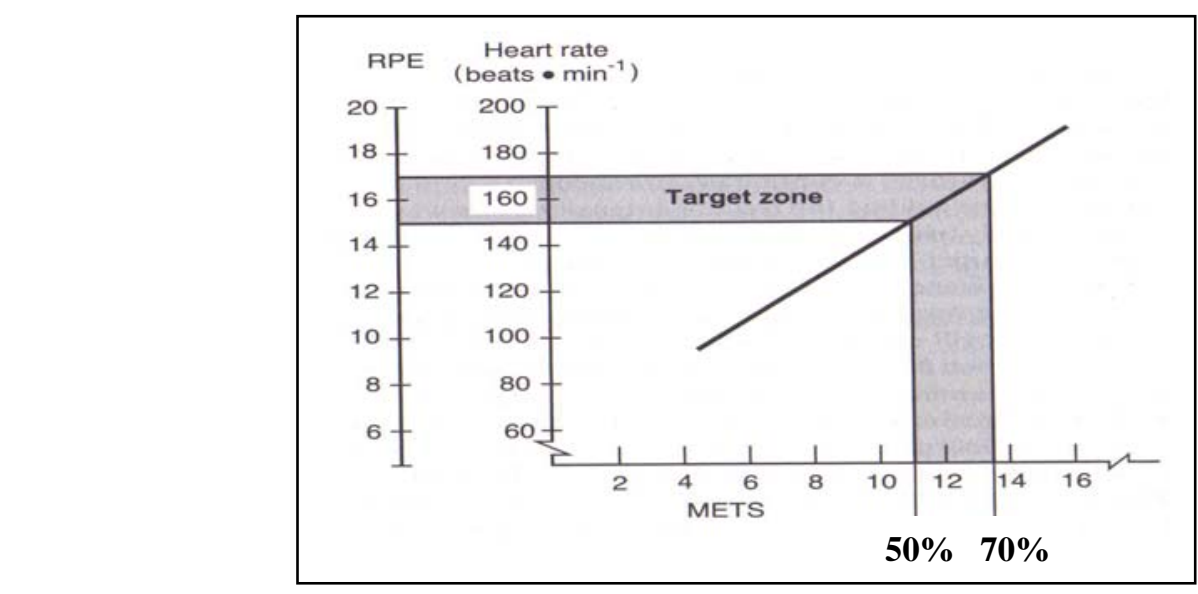

Figure 2. Estimation-Production Prescription Procedure

(R. Robertson, 2004. Reprinted with permission)

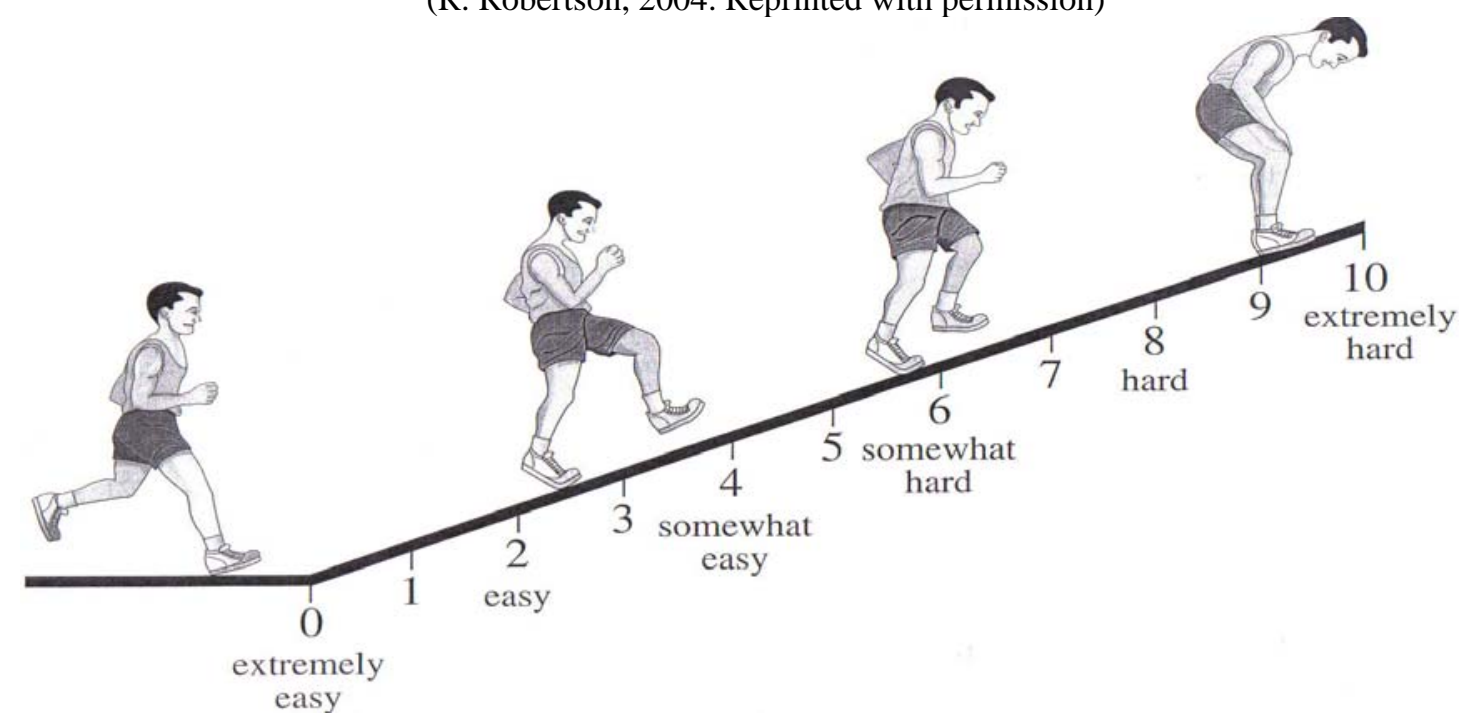

Figure 3. OMNI-Walk/Run scale of Perceived Exertion for Adults

(R. Robertson, 2004. Reprinted with permission)

\subsubsection{Production Trial}

Each subject returned to the HERL between 48 and 72 hours following the Estimation trial to perform the intermittent bouts (production trial) of treadmill exercise. The 20 minute exercise session consisted of four, five minute intervals with target RPE's alternating between 50 $\%$ and $70 \%$ of $\mathrm{VO}_{2} \mathrm{R}$. Subjects were randomly assigned to counterbalance I or counterbalance II (Figure 4). Prior to the production trial, subjects again received the standard instructions on 
RPE scaling procedures (see pages 32-33). Next, each subject was given the target RPE's that corresponds to $50 \%$ and $70 \%$ of $\mathrm{VO}_{2} \mathrm{R}$ from the estimation trial.

During the production trial the subjects were responsible for producing an RPE that corresponds to both $50 \%$ and $70 \%$ of $\mathrm{VO}_{2} \mathrm{R}$ while exercising on the treadmill. Preceding each interval (i.e. $50 \% \mathrm{VO}_{2} \mathrm{R}$ and $70 \% \mathrm{VO}_{2} \mathrm{R}$ ): the investigator pointed to and verbally announced the prescribed RPE they are responsible for producing during the exercise interval. During each exercise interval the investigator read instructions from a script at minutes 1:00, 2:00, 3:00 and 3:30 during the titration phase. The investigator read the following instructions to the subjects at the designated time intervals: "Your target RPE is make sure the effort/strain/discomfort and/or fatigue you are experiencing represents your target RPE of - If necessary, make adjustments in speed or grade that will bring you to your target RPE.”

There was a $3 \mathrm{~min}$ low intensity warm-up at $1.5 \mathrm{mph}$ at $0 \%$ grade prior the production trial. For each exercise interval (i.e., $50 \%$ and $70 \% \mathrm{VO}_{2} \mathrm{R}$ ) the subject had 4 minutes to titrate the speed and grade to establish the target RPE intensity. The OMNI RPE scale will be in sight of the subjects at all times throughout the exercise session. The subjects had full access to the treadmill control panel only to make adjustments in speed and grade. The control panel will be concealed and as such, the subjects will be blinded to the actual speed and grade of the treadmill. At the end of the 4 minute titration period subjects were informed not to make any additional speed or grade adjustments and the $\mathrm{VO}_{2}$ and $\mathrm{HR}$ will be measured for one minute. $\mathrm{VO}_{2}$ was measured in 15 second intervals and HR will be measured from: 50 to 1:00 of the one minute measurement phase. The average of the 15 second $\mathrm{VO}_{2}$ measurements during the one minute measurement phase was used in the data analysis. At the end of the one minute measurement phase the subjects were asked to rate their RPE to ensure they attained the target RPE prescribed. 
At the start of the next prescribed exercise intensity, the subject was given a written and verbal reminder of the next target RPE. The subject then had four minutes to adjust the speed and grade for the next prescribed RPE. The $\mathrm{VO}_{2}$ and $\mathrm{HR}$ were measured during the last minute of exercise. This procedure was repeated for the next two exercise intervals according to the corresponding counterbalanced order. Counterbalance protocols are presented in figure 4.

\begin{tabular}{|c|c|c|c|}
\hline$\underline{\text { Order \# I }}$ & $\% \mathrm{VO} 2 \mathrm{R}$ & Order \# II & $\%$ VO2 R \\
\hline Warm-up (3min) & & Warm-up (3min) & \\
\hline $\begin{array}{l}\text { Titration (4min) } \\
\mathrm{HR}, \mathrm{VO}_{2} \text { measurement (1min) }\end{array}$ & $70 \%$ & $\begin{array}{l}\text { Titration (4min) } \\
\mathrm{HR}, \mathrm{VO}_{2} \text { measurement (1min) }\end{array}$ & $50 \%$ \\
\hline $\begin{array}{l}\text { Titration (4min) } \\
\mathrm{HR}, \mathrm{VO}_{2} \text { measurement (1min) }\end{array}$ & $50 \%$ & $\begin{array}{l}\text { Titration (4min) } \\
\mathrm{HR}, \mathrm{VO}_{2} \text { measurement (1min) }\end{array}$ & $70 \%$ \\
\hline $\begin{array}{l}\text { Titration (4min) } \\
\mathrm{HR}, \mathrm{VO}_{2} \text { measurement (1min) }\end{array}$ & $70 \%$ & $\begin{array}{l}\text { Titration (4min) } \\
\mathrm{HR}, \mathrm{VO}_{2} \text { measurement (1min) }\end{array}$ & $50 \%$ \\
\hline $\begin{array}{l}\text { Titration (4min) } \\
\mathrm{HR}, \mathrm{VO}_{2} \text { measurement (1min) }\end{array}$ & $50 \%$ & $\begin{array}{l}\text { Titration (4min) } \\
\mathrm{HR}, \mathrm{VO}_{2} \text { measurement (1min) }\end{array}$ & $70 \%$ \\
\hline 20 minutes total & & 20 minutes total & \\
\hline
\end{tabular}

Figure 4. Counterbalance order I \& II

\subsection{EXPERIMENTAL VARIABLES}

\subsubsection{Dependent variables}

The following dependent variables were measured during the last 60 seconds of each five minute interval throughout the 20 minute exercise session. $\mathrm{VO}_{2}$ and $\mathrm{HR}$ were compared between 
the estimation and production trials. Since the purpose of the study is to determine if RPE can be used to regulate intensity during intermittent exercise the $\mathrm{VO}_{2}$ and $\mathrm{HR}$ from both trials should not differ at the same prescribed RPE.

1. $\mathrm{VO}_{2}(\mathrm{ml} / \mathrm{kg} / \mathrm{min})$

2. HR (beats/min)

\subsubsection{Independent variable}

OMNI RPE: The RPE that corresponds to each subject's $50 \%$ and $70 \%$ of $\mathrm{VO}_{2} \mathrm{R}$ were determined from the estimation trial GXT. These RPE's were used to regulate exercise intensity throughout the intermittent exercise bout and as such, served as the independent variables.

\section{$3.4 \quad$ STATISTICS}

Descriptive data for anthropometric and physiological variables were be calculated as mean \pm standard deviation (SD). All analyses were performed using the Statistical Package for the Social Sciences (SPSS, version 13.0, Chicago, Ill., USA). Statistical significance were set at an alpha $\leq 0.05$ level for all analysis.

Sample size is based upon the statistical power required to demonstrate an interaction effect within the repeated measures comparisons of $\mathrm{VO}_{2}$ and $\mathrm{HR}$. This power requirement effect is the most stringent among any of the statistical models employed and as such required the

greatest number of subjects for each contrast cell (Tran, 1997). Using a power of 0.80, alpha of 0.05 and an effect size of 0.50 , it was determined that a minimum of 16 males and 16 females were required to test both the main and interaction effects within the factorial analysis. The 
within subject factor in the power calculation assumed an intra-class correlation of 0.70 across repeated measures.

Prescription congruence and sequence was examined using a 2 x 2 (trial x sequence) mixed analysis of variance (ANOVA) with repeated measures on the first factor. A significant interaction effect was followed by a post-hoc analysis using paired-samples $t$ test. The statistical analysis was run separately for both $\mathrm{HR}$ and $\mathrm{VO}_{2}$ at each of the exercise intensities (i.e. $50 \%$ $\mathrm{VO}_{2} \mathrm{R}$ and $\left.70 \% \mathrm{VO}_{2} \mathrm{R}\right)$.

Intensity discrimination for $\mathrm{VO}_{2}$ and $\mathrm{HR}$ derived from the production trials at $50 \% \mathrm{VO}_{2} \mathrm{R}$ and $70 \% \mathrm{VO}_{2} \mathrm{R}$ was examined with a $2 \times 2$ (production trial $\mathrm{x}$ sequence) ANOVA with repeated measures on the first factor. The analysis was run for both $\mathrm{VO}_{2}$ and $\mathrm{HR}$. An a priori main effect for production $\mathrm{VO}_{2}$ and $\mathrm{HR}$ was analyzed.

Bland and Altman's limits of agreements plots Bland et al. (1986) was used to assess the level of agreement in the $\mathrm{HR}$ and $\mathrm{VO}_{2}$ between the estimation and production trials. 


\subsection{RESULTS}

The purpose of the present study was to examine if subjects can self-regulate exercise intensity during a 20 minute intermittent bout of aerobic exercise on the treadmill using the OMNI RPE scale. During the estimation trial the subjects underwent a maximal graded exercise test to determine oxygen uptake, heart rate, and RPE every minute until maximal oxygen uptake was determined. Using the data from the estimation trial, the target RPE's corresponding to 50\% and $70 \%$ of $\mathrm{VO}_{2} \mathrm{R}$ were determined using an estimation-production procedure (Figure 2). During the production trial, the subjects titrated the speed and grade on the treadmill to attain the target RPE's corresponding to $50 \%$ and $70 \%$ of $\mathrm{VO}_{2} \mathrm{R}$. To represent the metabolic cost of each exercise intensity, the dependent variables $\left(\mathrm{HR}\right.$ and $\left.\mathrm{VO}_{2}\right)$ for both five minute intervals were averaged. The $\mathrm{HR}$ and the $\mathrm{VO}_{2}$ from the estimation trial and the production trial were then compared. 


\subsection{SUBJECTS}

Subjects for this investigation included male $(n=16)$ and female $(n=15)$ college-age individuals. Subject descriptive data are presented in Table 1.

Table 1. Descriptive Characteristics of Subjects

\begin{tabular}{lcc} 
& Male & Female \\
\hline Age $(\mathrm{yr})$ & $20.6 \pm 2.1$ & $20.8 \pm 1.2$ \\
Height $(\mathrm{cm})$ & $178.1 \pm 6.6$ & $170.2 \pm 6.2$ \\
Weight $(\mathrm{kg})$ & $75.6 \pm 10.0$ & $57.9 \pm 6.7$ \\
Body Fat $(\%)$ & $14.6 \pm 5.4$ & $23.1 \pm 6.1$ \\
$\mathrm{VO}_{2 \max }(\mathrm{ml} / \mathrm{kg} / \mathrm{min})$ & $54.4 \pm 6.4$ & $42.3 \pm 4.4$ \\
\hline
\end{tabular}

Values are means $\pm \mathrm{SD} . \mathrm{VO}_{2} \max =$ Maximal Oxygen Consumption.

\subsection{PRESCRIPTION CONGRUENCE AND SEQUENCE}

\subsubsection{Heart Rate at $50 \%$ of $\mathrm{VO}_{2} \mathrm{R}$}

The RPE corresponding to $50 \%$ of $\mathrm{VO}_{2} \mathrm{R}$ determined during the estimation trial was used by the subjects to regulate their exercise intensity during the production trial. The mean HR from the intermittent production intervals corresponding to $50 \%$ of $\mathrm{VO}_{2} \mathrm{R}$ was compared to the HR from the estimation trial at the same RPE. Sub-hypothesis states that the HR from the estimation and production trials will not differ throughout the 20 minute exercise session at an $\mathrm{RPE}$ corresponding to $50 \%$ of $\mathrm{VO}_{2} \mathrm{R}$ (Prescription congruence). In addition, the production order (counterbalance order I vs. counterbalance order II) will not influence the subject's ability to self regulate exercise intensity using the OMNI RPE scale at 50\% of $\mathrm{VO}_{2} \mathrm{R}$ (Sequence). 
A 2 x 2 (trial x sequence) mixed analysis of variance (ANOVA) with repeated measures on the first factor was used to compare HR from the estimation and production trials. A significant main effect was found for trial $\mathrm{F}(1,29=11.779, p<.05)$. In addition, a significant interaction (trial $\mathrm{x}$ sequence) was found $\mathrm{F}(1,29=20.298, p<.001)$. The between-subject main effect for counterbalance order was significant $\mathrm{F}(1,29=9.928, \mathrm{p}<.05)$. Simple main effect procedure was used to decompose the interaction effect. Results are summarized in Figure 5. The trial $\mathrm{x}$ sequence interaction indicated that the HR was significantly higher in the production trial $(165.7 \pm 19.9$ beats $/ \mathrm{min})$ compared to the estimation trial $(139.3 \pm 15.3$ beats $/ \mathrm{min})$ for counterbalance order number I $(70 \%-50 \%),(t(15)=-5.229, p<.001)$. There was no significant difference in HR between the estimation (138.2 \pm 9.2 beats/min) and production trials (134.6 \pm 20.7 beats/min) for counterbalance order II (50\% - 70\%), $(t(14)=.837, p>.05)$. 


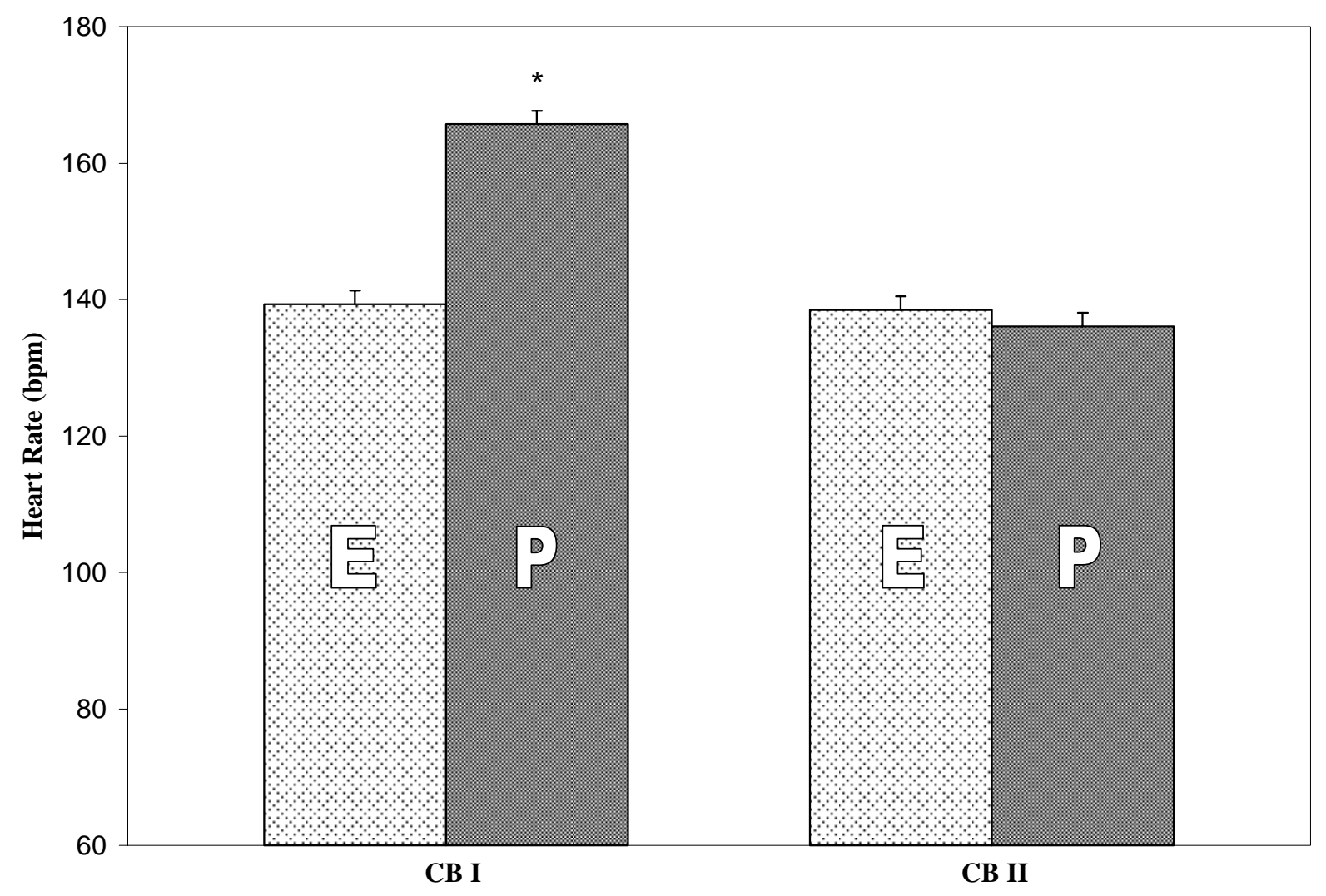

Figure 5. Prescription congruence and sequence.

Heart Rate at $50 \%$ of $\mathrm{VO}_{2} \mathrm{R}$. Heart Rate responses for the Estimation (E) and Production (P) trials at the RPE corresponding to $50 \%$ of $\mathrm{VO}_{2} \mathrm{R}$ for each counterbalance order. Counterbalance order I (70\% - 50\%) (CB I). Counterbalance order II (50\% - 70\%) (CB II). Data are mean \pm SE. $\left.\quad{ }^{*}\right)$ signifies significantly greater HR response during production trial for CB I $(p<0.05)$.

\subsubsection{Oxygen Consumption at $50 \% \mathrm{VO}_{2} \mathrm{R}$.}

The RPE corresponding to $50 \%$ of $\mathrm{VO}_{2} \mathrm{R}$ determined during the estimation trial was used by the subjects to regulate their exercise intensity during the production trial. The mean $\mathrm{VO}_{2}$ from the intermittent production intervals corresponding to $50 \%$ of $\mathrm{VO}_{2} \mathrm{R}$ was compared to the $\mathrm{VO}_{2}$ from the estimation trial. Sub-hypothesis states that the $\mathrm{VO}_{2}$ from the estimation and production trials will not differ throughout the 20 minute exercise session at an RPE corresponding to $50 \%$ of $\mathrm{VO}_{2} \mathrm{R}$ (Prescription congruence). In addition, the production order 
(counterbalance order I vs. counterbalance order II) will not influence the subject's ability to self regulate intensity using the OMNI RPE scale at $50 \%$ of $\mathrm{VO}_{2} \mathrm{R}$ (Sequence).

A 2 x 2 (trial x sequence) mixed analysis of variance (ANOVA) with repeated measures on the first factor was used to compare $\mathrm{VO}_{2}$ from the estimation and production trials. A significant main effect was found for trial $\mathrm{F}(1,29=4.269, p<.05)$. In addition, a significant interaction (trial $\mathrm{x}$ sequence) was found $\mathrm{F}(1,29=12.8, p<.05)$. The between-subject main effect for counterbalance order was not significant $F(1,29=3.687, \mathrm{p}>.05)$. Simple main effect procedure was used to decompose the interaction effects. Results are summarized in Figure 6. The trial $\mathrm{x}$ sequence interaction indicated that the $\mathrm{VO}_{2}$ was significantly higher in the production trial $(32.5 \pm 9.8 \mathrm{ml} / \mathrm{kg} / \mathrm{min})$ compared to the estimation trial $(25.9 \pm 4.0 \mathrm{ml} / \mathrm{kg} / \mathrm{min})$ for counterbalance order number I $(70 \%-50 \%),(t(15)=-3.370, p<.05)$. There was no significant difference in $\mathrm{VO}_{2}$ between the estimation $(26.0 \pm 4.1 \mathrm{ml} / \mathrm{kg} / \mathrm{min})$ and production trials $(24.2 \pm$ $7.3 \mathrm{ml} / \mathrm{kg} / \mathrm{min})$ for counterbalance order II (50\% - 70\%), $(t(14)=1.46, p>.05)$. 


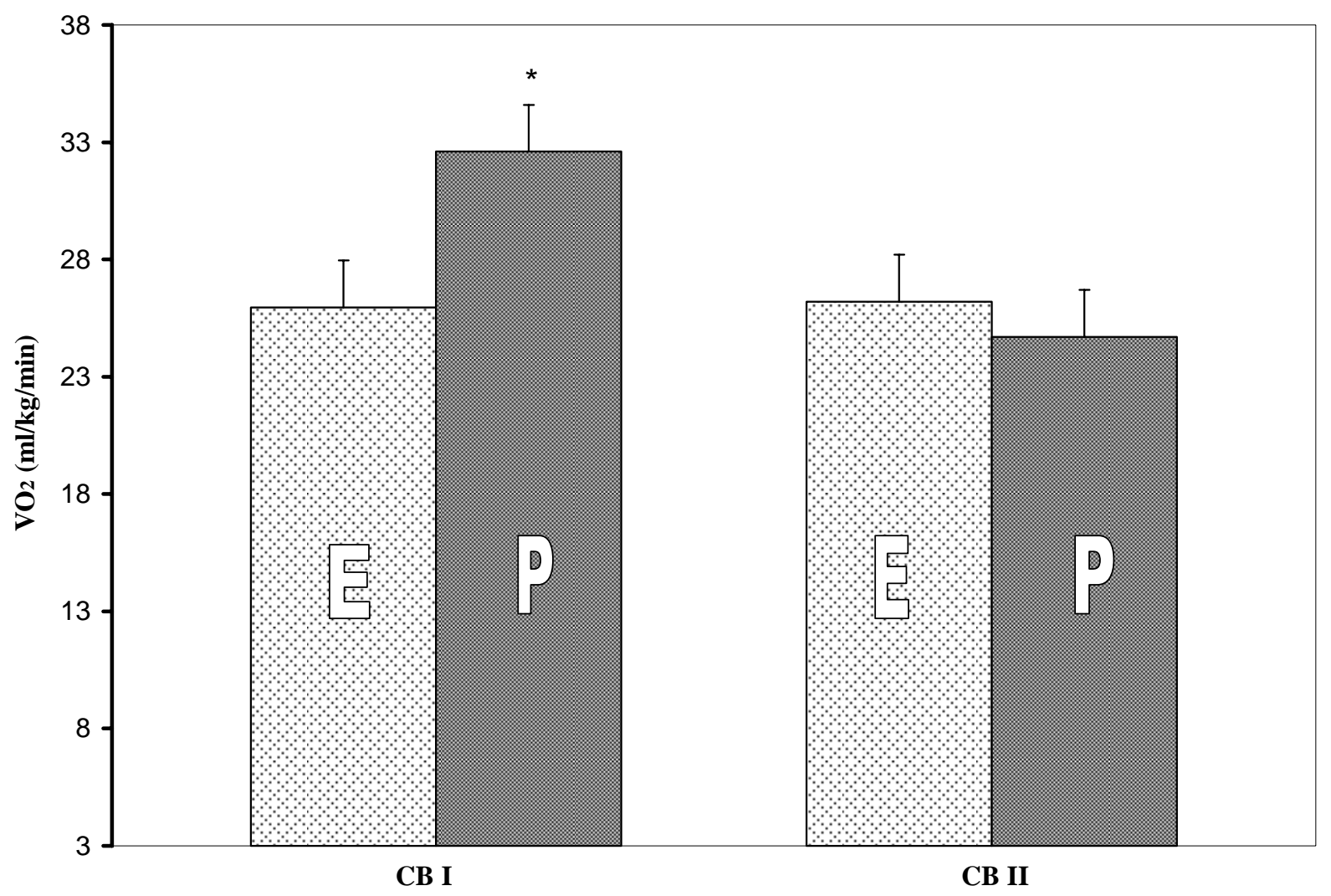

Figure 6. Prescription congruence and sequence.

Oxygen consumption at $50 \%$ of $\mathrm{VO}_{2} \mathrm{R}$. Oxygen consumption $\left(\mathrm{VO}_{2}\right)$ responses for the Estimation $(\mathrm{E})$ and Production (P) trials at the RPE corresponding to $50 \%$ of $\mathrm{VO}_{2} \mathrm{R}$ for each counterbalance order. Counterbalance order I (70\% - 50\%) (CB I). Counterbalance order II (50\% - 70\%) (CB II). Data are mean \pm SE. (*) signifies significantly greater $\mathrm{VO}_{2}$ response during production trial for CB I $(p<0.05)$.

\subsubsection{Heart Rate at $70 \% \mathrm{VO}_{2} \mathrm{R}$}

The RPE corresponding to $70 \%$ of $\mathrm{VO}_{2} \mathrm{R}$ determined during the estimation trial was used by the subjects to regulate their exercise intensity during the production trial. The mean HR from the intermittent production intervals corresponding to $70 \%$ of $\mathrm{VO}_{2} \mathrm{R}$ was compared to the HR from the estimation trial. Sub-hypothesis states that the HR from the estimation and production trials will not differ throughout the 20 minute exercise session at an RPE corresponding to $70 \%$ of $\mathrm{VO}_{2} \mathrm{R}$ (Prescription congruence). In addition, the production order 
(counterbalance order I vs. counterbalance order II) will not influence the subject's ability to self regulate intensity using the OMNI RPE scale at $70 \%$ of $\mathrm{VO}_{2} \mathrm{R}$ (Sequence).

A 2 x 2 (trial x sequence) mixed analysis of variance (ANOVA) with repeated measures on the first factor was used to compare HR from the estimation and production trials. A significant main effect for trial $\mathrm{F}(1,29=7.737, p<.05)$ was found. In addition, a significant interaction (trial $\mathrm{x}$ sequence) was found $\mathrm{F}(1,29=4.21, p<.05)$. The between-subject main effect for counterbalance order was not significant $F(1,29=2.991, \mathrm{p}>.05)$. Simple main effect procedure was used to decompose the interaction effects. Results are summarized in Figure 7. The trial $\mathrm{x}$ sequence interaction indicated that the HR was significantly higher in the production trial $(176.8 \pm 17.8$ beats/min) compared to the estimation trial $(163.1 \pm 13.3$ beats $/ \mathrm{min})$ for counterbalance order number I (70\% - 50\%), $(t(15)=-3.634, p<.05)$. There was no significant difference in HR between the estimation $(160.5 \pm 8.11$ beats/min) and production trials $(162.5 \pm$ 20.7 beats/min) for counterbalance order II ( $50 \%-70 \%),(t(14)=-.486, p>.05)$. 


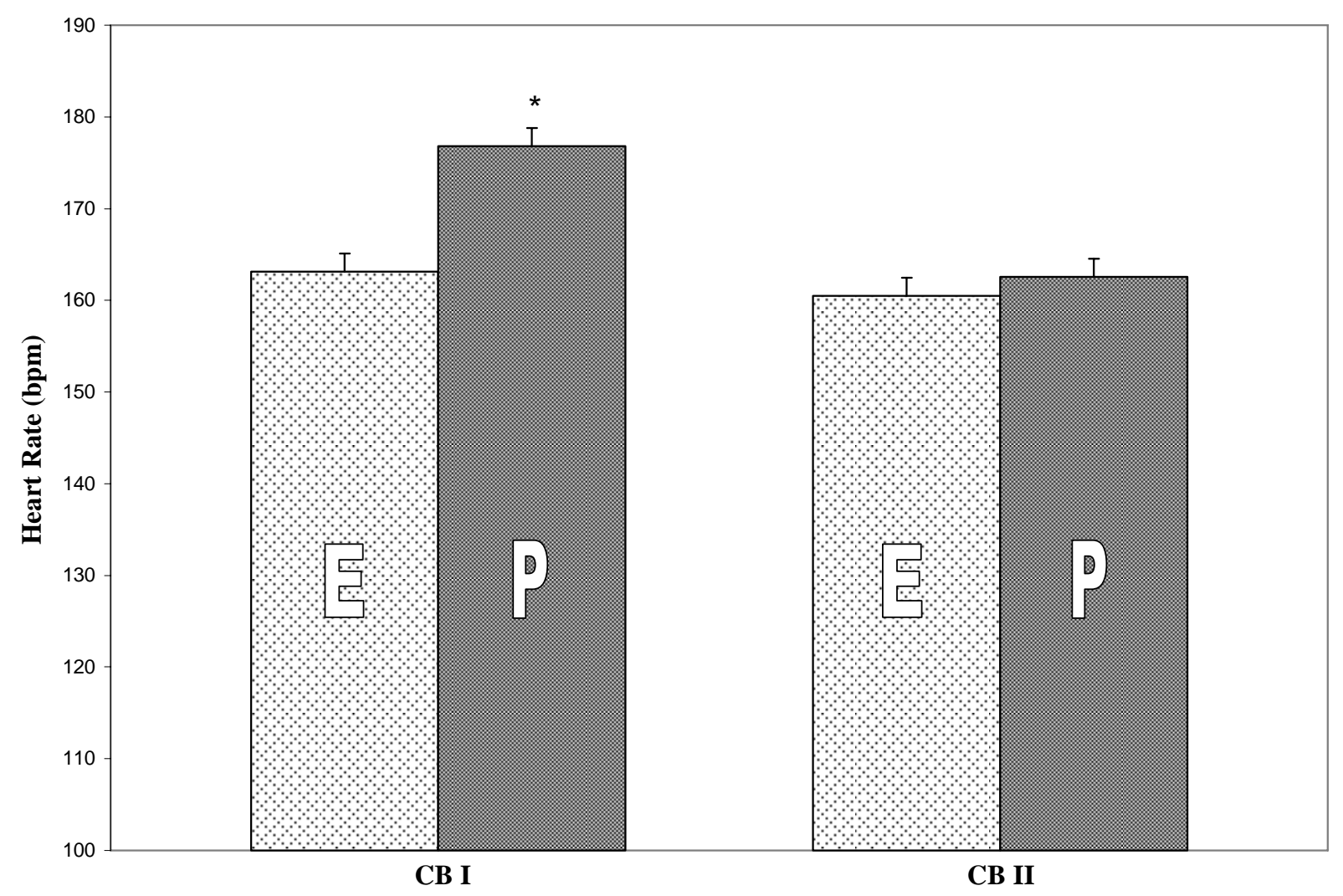

Figure 7. Prescription congruence and sequence.

Heart Rate at $70 \%$ of $\mathrm{VO}_{2} \mathrm{R}$. Heart Rate responses for the Estimation (E) and Production (P) trials at the RPE corresponding to $70 \%$ of $\mathrm{VO}_{2} \mathrm{R}$ for each counterbalance order. Counterbalance order I (70\% - 50\%) (CB I). Counterbalance order II $(50 \%-70 \%)$ (CB II). Data are mean \pm SE. $\quad\left(^{*}\right)$ signifies significantly greater HR response during production trial for CB I $(p<0.05)$.

\subsubsection{Oxygen Consumption at $70 \% \mathrm{VO}_{2} \mathrm{R}$}

The RPE corresponding to $70 \%$ of $\mathrm{VO}_{2} \mathrm{R}$ determined during the estimation trial was used by the subjects to regulate their exercise intensity during the production trial. The mean $\mathrm{VO}_{2}$ from the intermittent production intervals corresponding to $70 \%$ of $\mathrm{VO}_{2} \mathrm{R}$ was compared to the $\mathrm{VO}_{2}$ from the estimation trial. Sub-hypothesis states that the $\mathrm{VO}_{2}$ from the estimation and production trials will not differ throughout the 20 minute exercise session at an RPE corresponding to $70 \%$ of $\mathrm{VO}_{2} \mathrm{R}$ (Prescription congruence). In addition, the production order 
(counterbalance order I vs. counterbalance order II) will not influence the subject's ability to self regulate intensity using the OMNI RPE scale at $70 \%$ of $\mathrm{VO}_{2} \mathrm{R}$ (Sequence).

A 2 x 2 (trial x sequence) mixed analysis of variance (ANOVA) with repeated measures on the first factor was used to compare $\mathrm{VO}_{2}$ from the estimation and production trials. No significant main effect was found for trial $\mathrm{F}(1,29=1.141, p>.05)$. In addition, no significant interaction (trial $\mathrm{x}$ sequence) was found $\mathrm{F}(1,29=3.124, p>.05)$. The between-subject main effect for counterbalance order was not significant $\mathrm{F}(1,29=.818, \mathrm{p}>.05)$. Results are summarized in Figure 8.

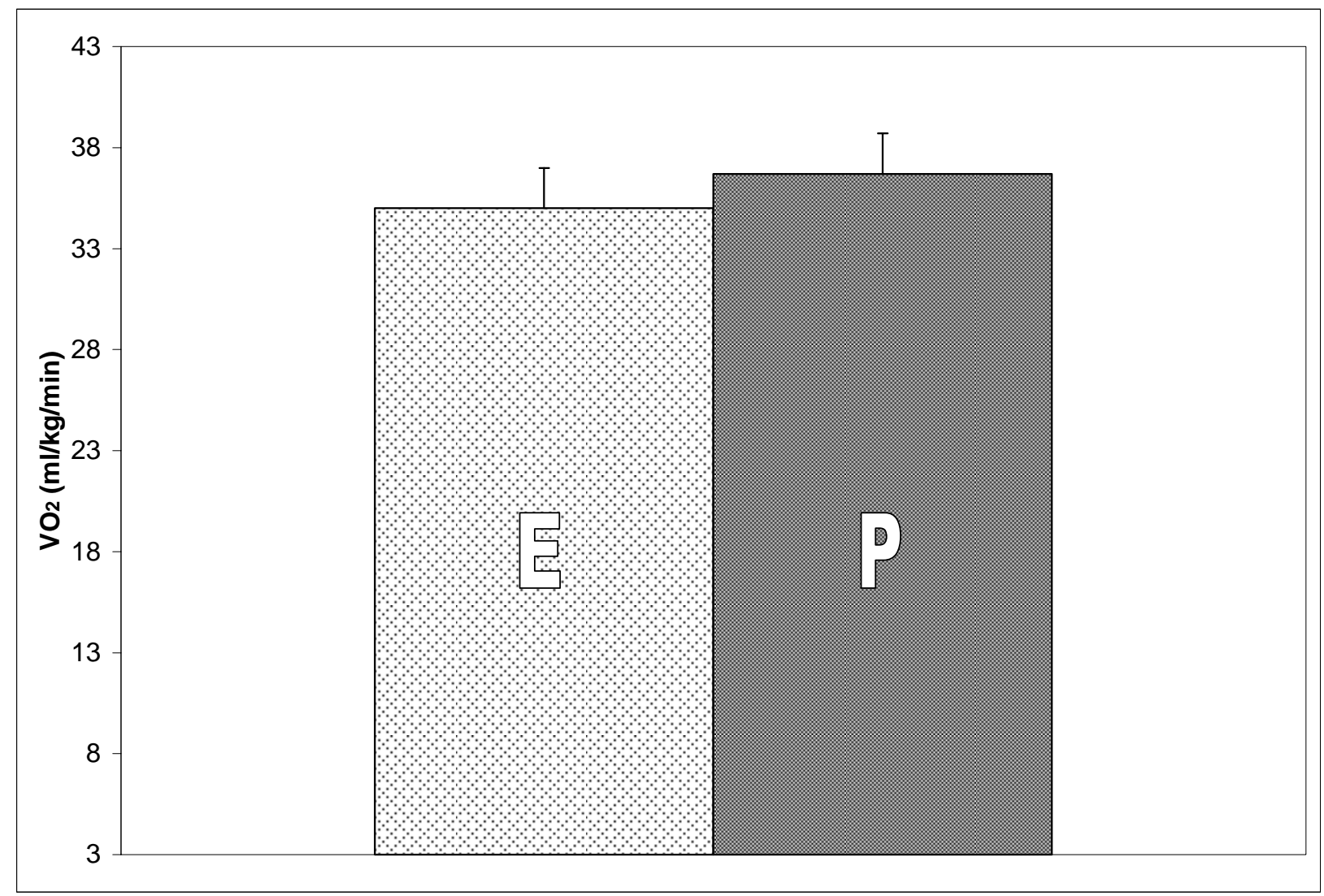

Figure 8. Prescription congruence and sequence.

Oxygen consumption at $70 \%$ of $\mathrm{VO}_{2} \mathrm{R}$. Heart Rate responses for the Estimation (E) and Production (P) trials. Data are mean $\pm \mathrm{SE}$. No significant difference in $\mathrm{VO}_{2}$ between the estimation and production trials $(p>0.05)$. 


\subsection{INTENSITY DISCRIMINATION}

\subsubsection{Heart Rate}

During the production trial the subjects regulated their exercise intensity at a RPE corresponding to $50 \%$ and $70 \%$ of $\mathrm{VO}_{2} \mathrm{R}$. Intensity discrimination is demonstrated when the $\mathrm{HR}$ at the RPE corresponding to $70 \%$ of $\mathrm{VO}_{2} \mathrm{R}$ is greater than the $\mathrm{HR}$ at the RPE corresponding to $50 \%$ of $\mathrm{VO}_{2} \mathrm{R}$ during the production trials.

A $2 \times 2$ (intensity $\times$ sequence) mixed analysis of variance (ANOVA) with repeated measures on the first factor was used to compare HR from the production trials. The a priori comparison of interest (i.e. intensity main effect for HR) was analyzed. A significant production trial intensity main effect was found $\mathrm{F}(1,29=66.49, p<.001)$ indicating the HR was significantly higher at the RPE corresponding to $70 \%$ of $\mathrm{VO}_{2} \mathrm{R}(169.9 \pm 20.3$ beats/min $)$ compared to the $\mathrm{HR}$ at an RPE corresponding to $50 \%$ of $\mathrm{VO}_{2} \mathrm{R}(150.7 \pm 25.4$ beats $/ \mathrm{min})$. In addition, a significant interaction (trial $x$ sequence) was found $F(1,29=12.286, p<.05)$. The between-subject main effect for counterbalance order was significant $F(1,29=11.464$, $\mathrm{p}<.05)$. Results are summarized in Figure 9. 


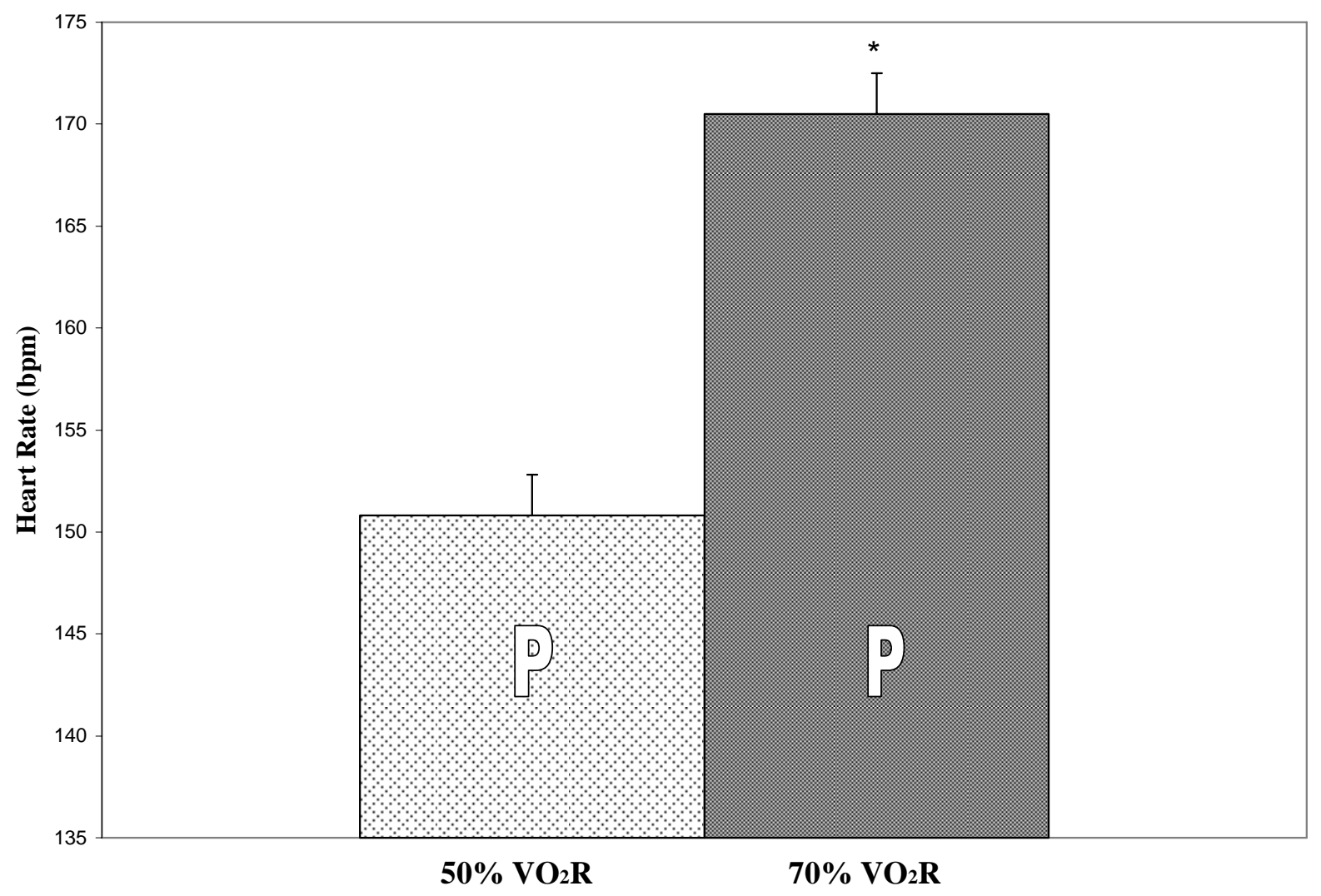

Figure 9. Intensity discrimination. Heart Rate.

Heart Rate (HR) responses for the Production (P) trials at the RPE corresponding to $50 \%$ and $70 \%$ of $\mathrm{VO}_{2} \mathrm{R}$. Data are mean \pm SE. $\quad(*)$ signifies significantly greater $\mathrm{HR}$ response for the RPE corresponding to $70 \%$ of $\mathrm{VO}_{2} \mathrm{R}$ compared to $50 \% \mathrm{VO}_{2} \mathrm{R}$ for the production trials $(p<0.05)$.

\subsubsection{Oxygen consumption}

During the production trial the subjects regulated their exercise intensity at a RPE corresponding to $50 \%$ and $70 \% \mathrm{VO}_{2} \mathrm{R}$. Intensity discrimination is demonstrated when the $\mathrm{VO}_{2}$ at the RPE corresponding to $70 \%$ of $\mathrm{VO}_{2} \mathrm{R}$ is greater than the $\mathrm{VO}_{2}$ at the $\mathrm{RPE}$ corresponding to $50 \%$ of $\mathrm{VO}_{2} \mathrm{R}$ during the production trials.

A $2 \times 2$ (intensity x sequence) mixed analysis of variance (ANOVA) with repeated measures on the first factor was used to compare $\mathrm{VO}_{2}$ from the production trials per counterbalance order. The a priori comparison of interest (i.e. intensity main effect for $\mathrm{VO}_{2}$ ) was 
analyzed. A significant production trial intensity main effect was found $\mathrm{F}(1,29=67.1, p<.001)$ indicating the $\mathrm{VO}_{2}$ was significantly higher at the RPE corresponding to $70 \%$ of $\mathrm{VO}_{2} \mathrm{R}(36.4 \pm$ $9.0 \mathrm{ml} / \mathrm{kg} / \mathrm{min})$ compared to the $\mathrm{VO}_{2}$ at an $\mathrm{RPE}$ corresponding to $50 \%$ of $\mathrm{VO}_{2} \mathrm{R}(28.5 \pm 9.5$ $\mathrm{ml} / \mathrm{kg} / \mathrm{min}$ ). In addition, a significant interaction (trial $\mathrm{x}$ sequence) was found $\mathrm{F}(1,29=4.206, p<$ $.05)$. The between-subject main effect for counterbalance order was significant $\mathrm{F}(1,29=4.460$, $\mathrm{p}<.05)$. Results are summarized in Figure 10.

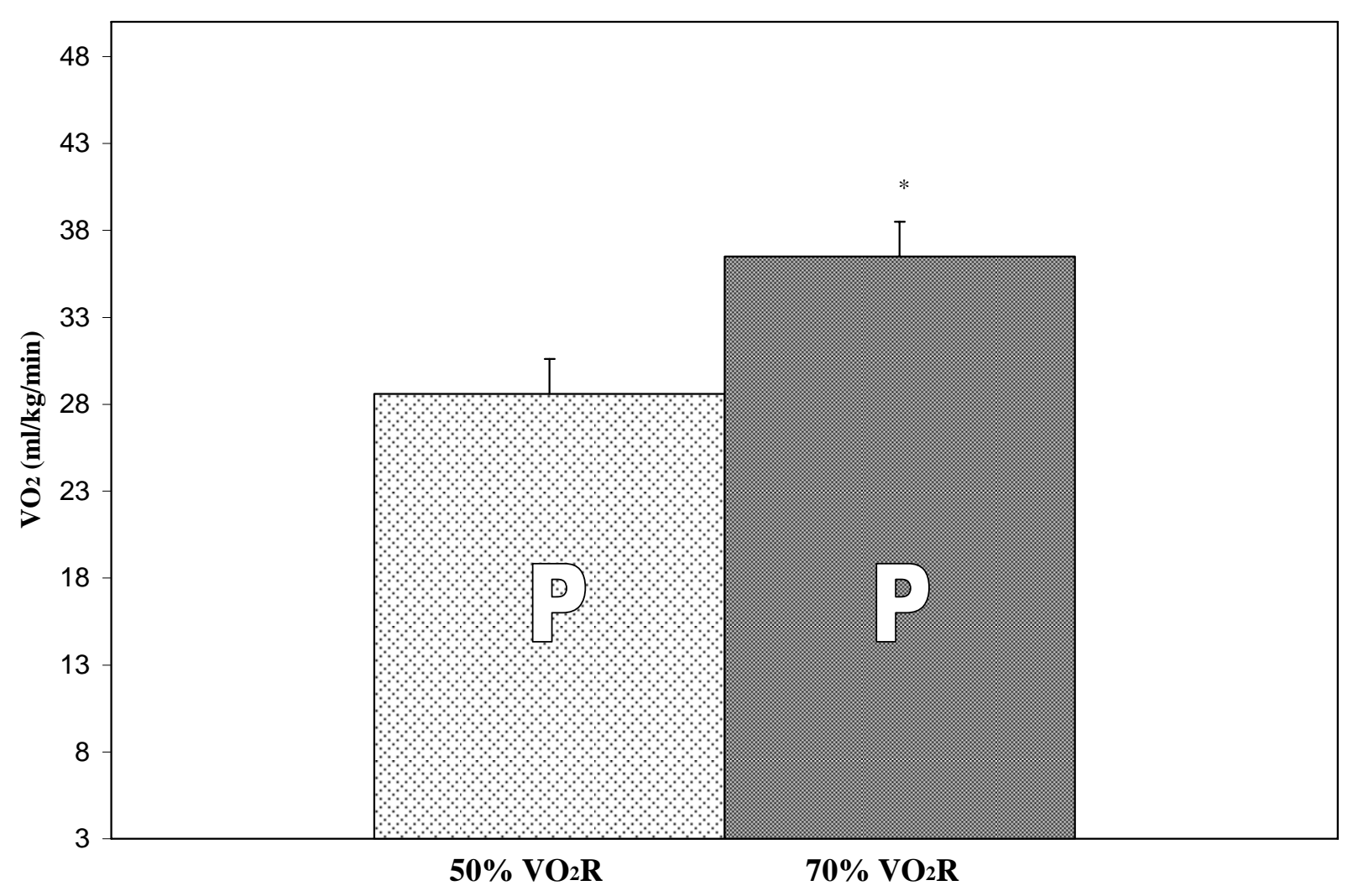

Figure 10. Intensity discrimination. Oxygen consumption.

Oxygen consumption $\left(\mathrm{VO}_{2}\right)$ responses for the Production $(\mathrm{P})$ trials at the RPE corresponding to $50 \%$ and $70 \%$ of $\mathrm{VO}_{2} \mathrm{R}$. Data are mean $\pm \mathrm{SE}$. ( $\left.{ }^{*}\right)$ signifies significantly greater $\mathrm{VO}_{2}$ for the $\mathrm{RPE}$ corresponding to $70 \%$ of $\mathrm{VO}_{2} \mathrm{R}$ compared to $50 \% \mathrm{VO}_{2} \mathrm{R}$ for the production trials $(p<0.05)$. 


\subsection{BLAND - ALTMAN}

\subsubsection{Heart Rate at $50 \%$ of $\mathrm{VO}_{2} \mathrm{R}$}

Bland - Altman plots (Bland et al., (1986) were used to assess the level of agreement in the HR between the estimation and production trials at the RPE corresponding to $50 \%$ of $\mathrm{VO}_{2} \mathrm{R}$ (Figure 11). Bland-Altman plots (Figures 11) displays the individual subject differences between the estimation and production RPE against the mean of the estimation and production RPE for HR at RPEs corresponding to $50 \%$ of $\mathrm{VO}_{2} \mathrm{R}$. Included in the figure is the mean difference and the 95\% confidence interval ( \pm 2 SD). Additionally, the range displayed on the yaxis represents the maximum possible difference between the estimation and production trials. The 95\% CI around the mean difference between the estimation and the production trials for HR at an RPE corresponding to $50 \%$ of $\mathrm{VO}_{2} \mathrm{R}$ was 40 to $-60 \mathrm{bpm}$. 


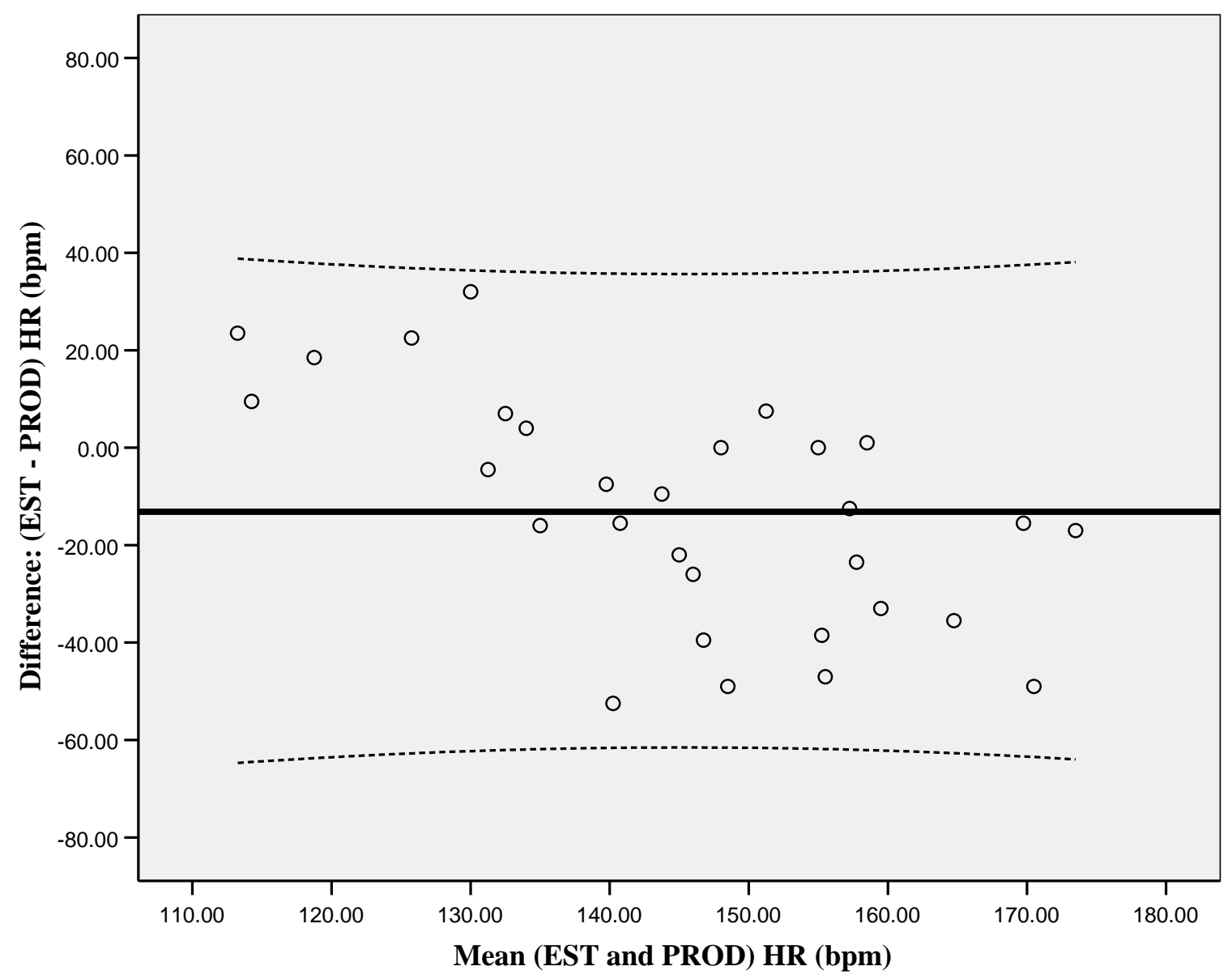

Figure 11. Bland - Altman. $\mathrm{HR}$ at $50 \%$ of $\mathrm{VO}_{2} \mathrm{R}$.

Bland-Altman plot for Estimation (EST) and Production (PROD) HR at the RPE corresponding to $50 \% \mathrm{VO}_{2} \mathrm{R}$. (-) signifies mean difference and (---) 95\% limits of agreement (mean \pm 2 SD).

\subsubsection{Oxygen consumption at $50 \%$ of $\mathrm{VO}_{2} \mathrm{R}$}

Bland - Altman plots (Bland et al., (1986) were used to assess the level of agreement in the $\mathrm{VO}_{2}$ between the estimation and production trials at the $\mathrm{RPE}$ corresponding to $50 \%$ of $\mathrm{VO}_{2} \mathrm{R}$ (Figure 12). Bland-Altman plot (Figures 12) displays the individual subject differences between the estimation and production RPE against the mean of the estimation and production RPE for the $\mathrm{VO}_{2}$ at $\mathrm{RPEs}$ corresponding to $50 \%$ of $\mathrm{VO}_{2} \mathrm{R}$. Included in the figure is the mean difference 
and the $95 \%$ confidence interval $( \pm 2 \mathrm{SD})$. Additionally, the range displayed on the y-axis represents the maximum possible difference between the estimation and production trials. The 95\% $\mathrm{CI}$ around the mean difference between the estimation and the production trials for $\mathrm{VO}_{2}$ at an $\mathrm{RPE}$ corresponding to $50 \%$ of $\mathrm{VO}_{2} \mathrm{R}$ was 13 to $-19 \mathrm{ml} / \mathrm{kg} / \mathrm{min}$.

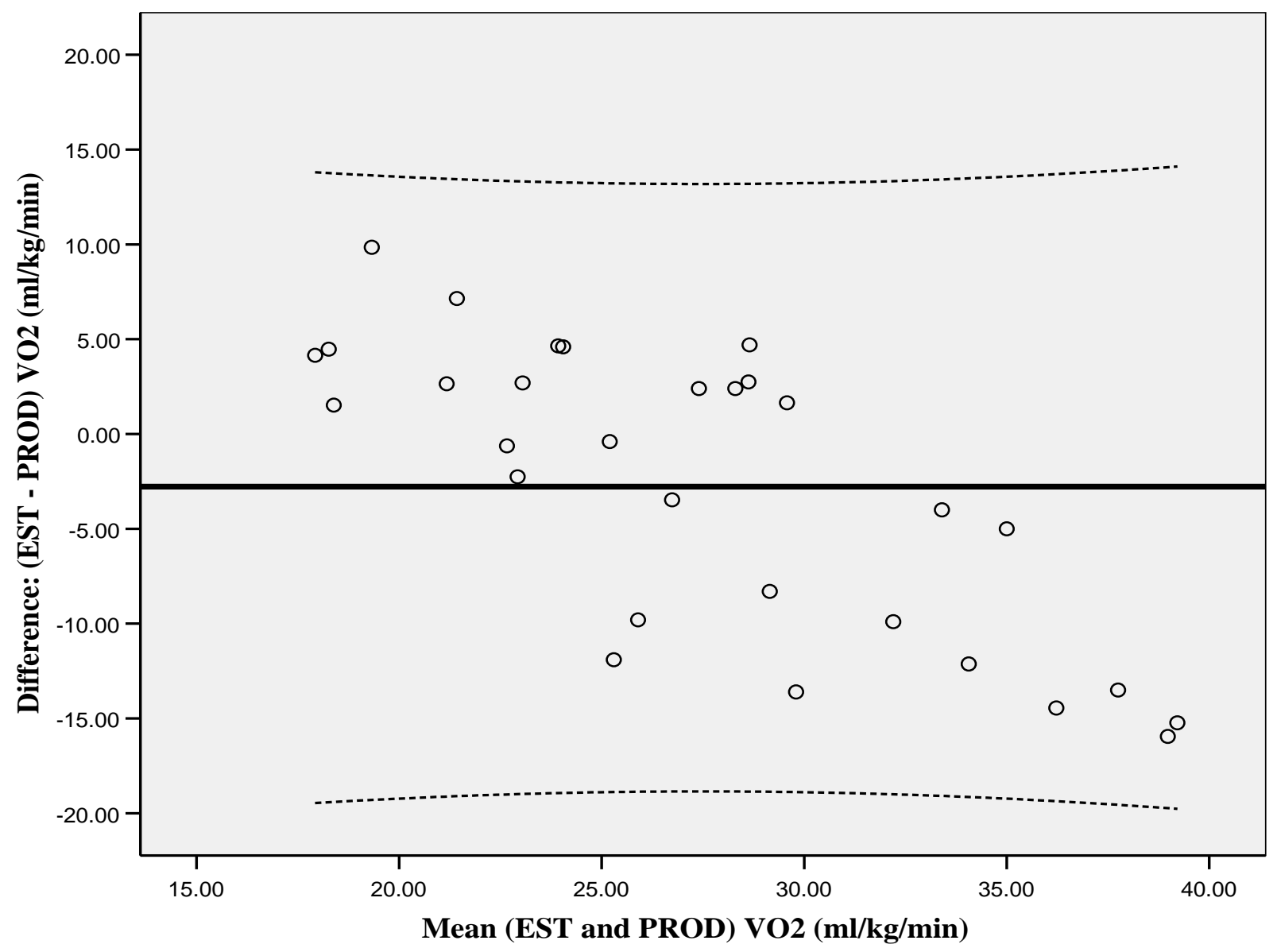

Figure 12. Bland-Altman. $\mathrm{VO}_{2}$ at $50 \%$ of $\mathrm{VO}_{2} \mathrm{R}$.

Bland-Altman plot for Estimation (EST) and Production (PROD) $\mathrm{VO}_{2}$ at the RPE corresponding to $50 \% \mathrm{VO}_{2} \mathrm{R}$. $(-)$ signifies mean difference and (---) 95\% limits of agreement (mean $\pm 2 \mathrm{SD}$ ). 


\subsubsection{Heart rate at $70 \%$ of $\mathrm{VO}_{2} \mathrm{R}$}

Bland - Altman plots (Bland et al., 1986) were used to assess the level of agreement in HR between the estimation and production trials at the RPE corresponding to $70 \% \mathrm{VO}_{2} \mathrm{R}$ (Figure 13). Bland-Altman plot (Figures 13) displays the individual subject differences between the estimation and production RPE against the mean of the estimation and production RPE for the $\mathrm{HR}$ at an $\mathrm{RPE}$ corresponding to $70 \%$ of $\mathrm{VO}_{2} \mathrm{R}$. Included in the figure is the mean difference and the 95\% confidence interval ( \pm 2 SD). Additionally, the range displayed on the y-axis represents the maximum possible difference between the estimation and production trials. The 95\% CI around the mean difference between the estimation and the production trials for HR at an RPE corresponding to $70 \%$ of $\mathrm{VO}_{2} \mathrm{R}$ were 25 to $-43 \mathrm{bpm}$. 


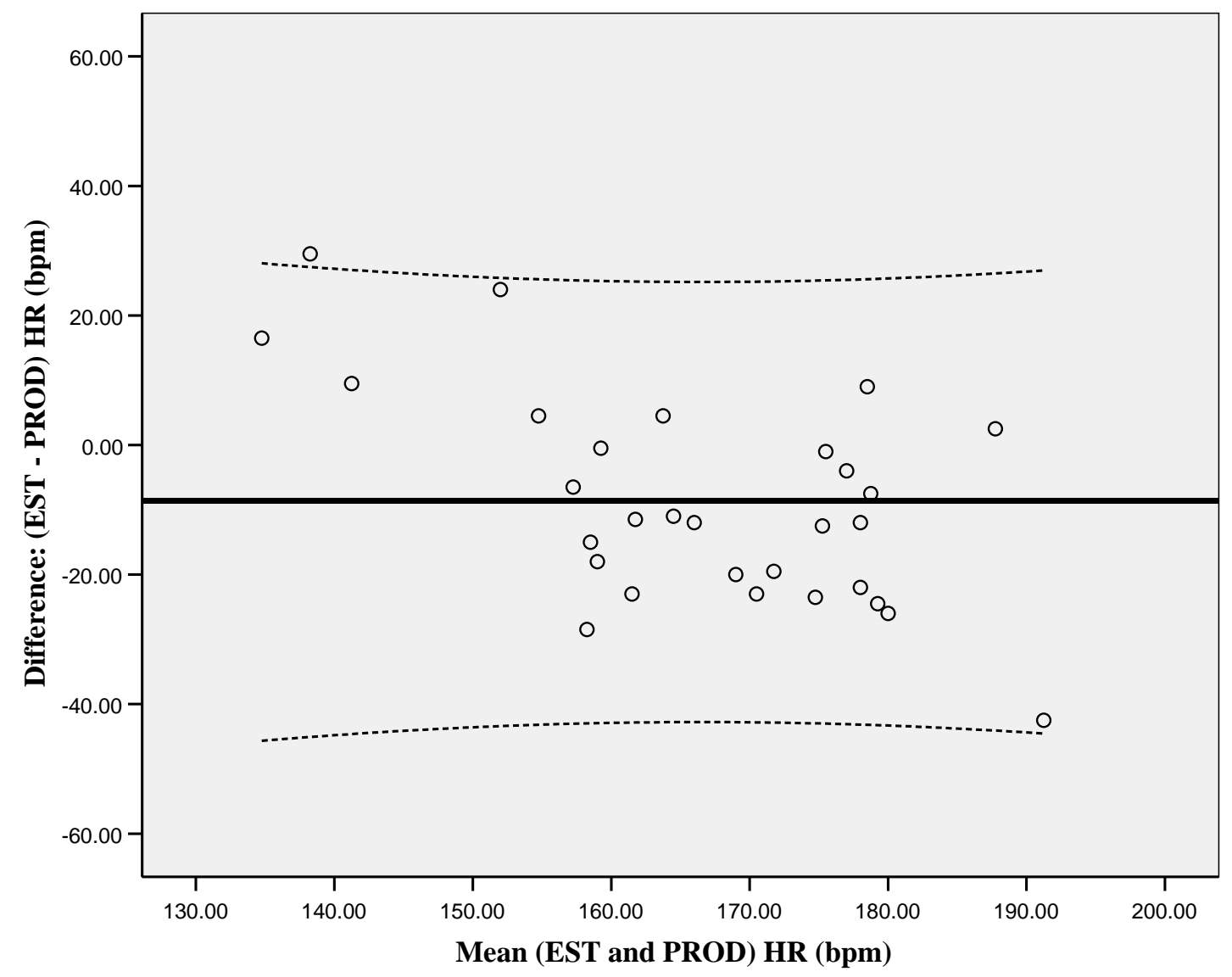

Figure 13. Bland-Altman. $\mathrm{HR}$ at $70 \%$ of $\mathrm{VO}_{2} \mathrm{R}$.

Bland-Altman plot for Estimation (EST) and Production (PROD) HR at the RPE corresponding to $70 \% \mathrm{VO}_{2} \mathrm{R}$. (-) signifies mean difference and (---) 95\% limits of agreement (mean \pm 2 SD).

\subsubsection{Oxygen consumption at $70 \%$ of $\mathrm{VO}_{2} \mathrm{R}$}

Bland - Altman plots (Bland et al., 1986)(1986) were used to assess the level of agreement in $\mathrm{VO}_{2}$ between the estimation and production trials at the RPE corresponding to $70 \%$ $\mathrm{VO}_{2} \mathrm{R}$ (Figure 14). Bland-Altman plot (Figures 14) displays the individual subject differences between the estimation and production RPE against the mean of the estimation and production $\mathrm{RPE}$ for the $\mathrm{VO}_{2}$ at an RPE corresponding to $70 \%$ of $\mathrm{VO}_{2} \mathrm{R}$. Included in the figure is the mean 
difference and the 95\% confidence interval ( \pm 2 SD). Additionally, the range displayed on the yaxis represents the maximum possible difference between the estimation and production trials. The 95\% CI around the mean difference between the estimation and the production trials for $\mathrm{VO}_{2}$ at an RPE corresponding to $70 \%$ of $\mathrm{VO} 2 \mathrm{R}$ were 13 to $-16 \mathrm{ml} / \mathrm{kg} / \mathrm{min}$.

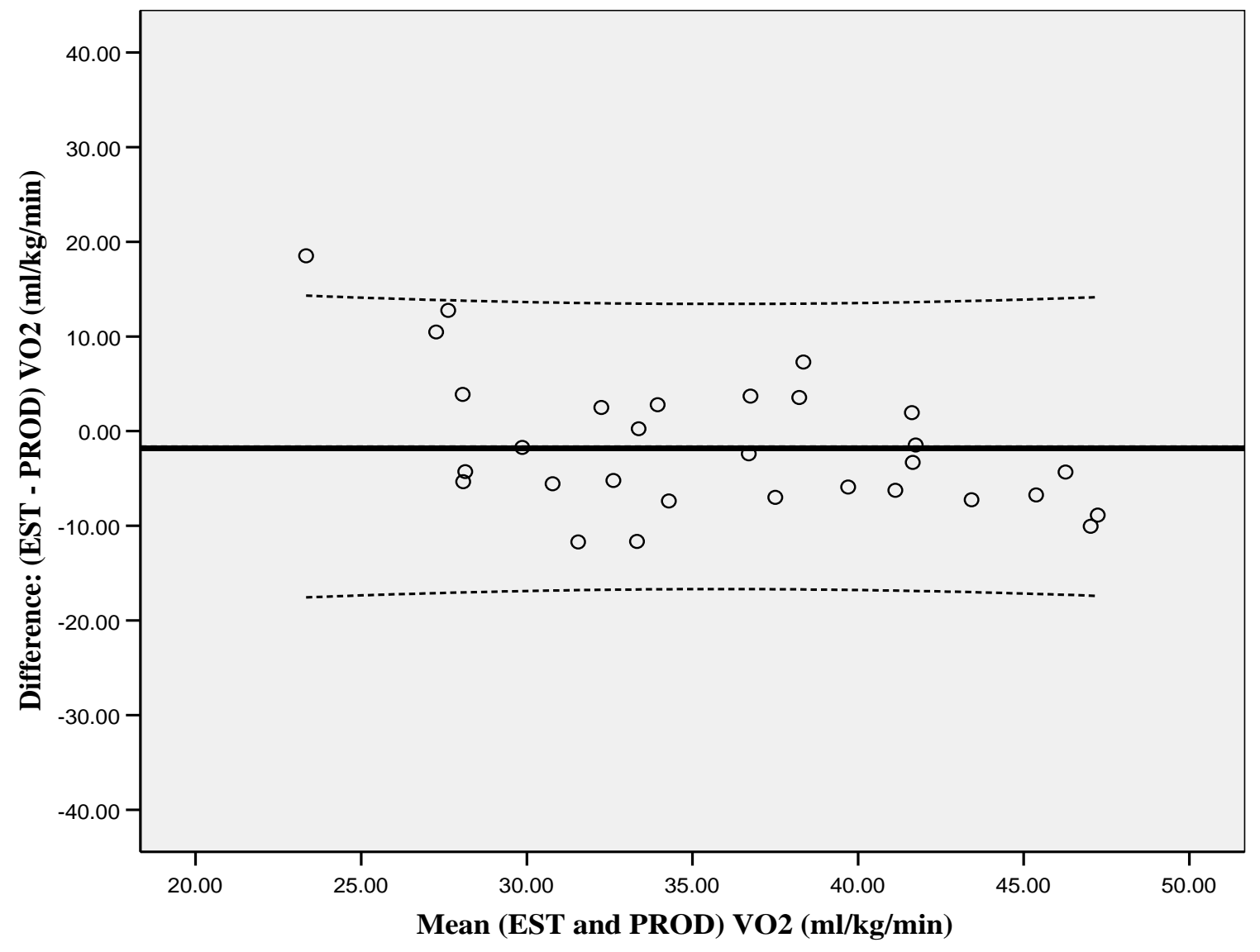

Figure 14. Bland-Altman. $\mathrm{VO}_{2}$ at $70 \% \mathrm{VO}_{2} \mathrm{R}$.

Bland-Altman plot for Estimation (EST) and Production (PROD) $\mathrm{VO}_{2}$ at the RPE corresponding to $70 \% \mathrm{VO}_{2} \mathrm{R}$. (-) signifies mean difference and (---) 95\% limits of agreement (mean \pm 2 SD). 


\subsection{DISCUSSION}

The primary purpose of this investigation was to determine if college age males and females (18 to 25 year old) can self-regulate exercise intensity during a 20 minute intermittent bout of aerobic exercise on the treadmill using the OMNI RPE scale. It was hypothesized that once target ratings of perceived exertion were established based upon the results of a maximal graded treadmill test (Estimation trial), subjects would be able to produce intensities corresponding to $50 \%$ and $70 \%$ of $\mathrm{VO}_{2} \mathrm{R}$ using the OMNI RPE scale during intermittent treadmill exercise (Production trial). No previous investigation has examined if individuals can use the OMNI RPE Scale to self regulate exercise intensities that correspond to metabolic rates $\left(\% \mathrm{VO}_{2} \mathrm{R}\right)$ set alternately at the low and high end of the physiological training zone. This gap in the perceived exertion literature was the conceptual basis for the present investigation.

The following research hypotheses were tested:

1. The HR from the estimation and production trials will not differ throughout the 20 minute exercise session at an RPE corresponding to $50 \%$ of $\mathrm{VO}_{2} \mathrm{R}$. (Prescription congruence). Additionally, the production order (counterbalance order I \& counterbalance order II) will not alter the subject's ability to self regulate intensity using the OMNI RPE scale at $50 \%$ of $\mathrm{VO}_{2} \mathrm{R}$. (Sequence).

2. The HR from the estimation and production trials will not differ throughout the 20 minute exercise session at an RPE corresponding to $70 \%$ of $\mathrm{VO}_{2} \mathrm{R}$. (Prescription congruence). Additionally, the production order (counterbalance order I \& 
counterbalance order II) will not alter the subject's ability to self regulate intensity using the OMNI RPE scale at $70 \%$ of $\mathrm{VO}_{2} \mathrm{R}$. (Sequence).

3. The $\mathrm{VO}_{2}$ from the estimation and production trials will not differ throughout the 20 minute exercise session at an RPE corresponding to $50 \%$ of $\mathrm{VO}_{2} \mathrm{R}$. (Prescription congruence). Additionally, the production order (counterbalance order I \& counterbalance order II) will not alter the subject's ability to self regulate intensity using the OMNI RPE scale at $50 \%$ of $\mathrm{VO}_{2} \mathrm{R}$. (Sequence).

4. The $\mathrm{VO}_{2}$ from the estimation and production trials will not differ throughout the 20 minute exercise session at an RPE corresponding to $70 \%$ of $\mathrm{VO}_{2} \mathrm{R}$. (Prescription congruence). Additionally, the production order (counterbalance order I \& counterbalance order II) will not alter the subject's ability to self regulate intensity using the OMNI RPE scale at $70 \%$ of $\mathrm{VO}_{2} \mathrm{R}$. (Sequence).

5. The HR will be greater for the RPE corresponding to $70 \%$ of $\mathrm{VO}_{2} \mathrm{R}$ compared to the $\mathrm{RPE}$ corresponding to $50 \%$ of $\mathrm{VO}_{2} \mathrm{R}$ during the production trial. (Intensity discrimination)

6. $\mathrm{VO}_{2}$ will be greater for the RPE corresponding to $70 \%$ of $\mathrm{VO}_{2} \mathrm{R}$ compared to the RPE corresponding to $50 \%$ of $\mathrm{VO}_{2} \mathrm{R}$ during the production trial. (Intensity discrimination)

The primary findings of this investigation were that subjects demonstrated the ability to self-regulate exercise intensity on the treadmill as indicated by the similar $\mathrm{HR}$ and $\mathrm{VO}_{2}$ between estimation and production trials when beginning an exercise session with the lower of the two prescribed exercise intensities. The present investigation is the first to examine that ability of subjects to self - regulate exercise intensity using the OMNI - Walk/Run scale during a 20 minute intermittent treadmill exercise session. Previous investigations have used various scaling metrics to establish the validity of regulating exercise intensity during steady state 
aerobic exercise ranging from 8 - 25 minutes in duration (Dunbar et al., 1992; Dunbar et al., 1994; Kang et al., 2003).

This investigation broadens the findings of (Kang et al., 2003) by having subjects perform continuous exercise at two different intensities. Using an estimation - production

protocol, Kang et al., 2003 determined that subjects could self-regulate their exercise intensity on the treadmill using the OMNI RPE scale for a continuous 20 minute exercise bout. Kang et al., 2003 indicated that validity was established at both $50 \%$ and $70 \%$ of $\mathrm{VO}_{2 \max }$ which was indicated by the similar $\mathrm{HR}$ and $\mathrm{VO}_{2}$ responses between the estimation and production trials throughout the 20 minute exercise session.

\subsection{PRESCRIPTION CONGRUENCE AND SEQUENCE}

Prescription congruence was examined using a perceptual estimation and production paradigm. Subjects were instructed to self-regulate exercise intensity by adjusting the speed and grade of the treadmill to attain a target RPE corresponding to $50 \%$ and $70 \%$ of $\mathrm{VO}_{2} \mathrm{R}$ during the production trial. Supporting the present research hypothesis, the dependent variables $\left(\mathrm{VO}_{2}\right.$ and HR) did not differ between the estimation and production trials when beginning the exercise session at the lower of the two prescribed exercise intensities.

The influence of sequence was determined by administering the 20 minute production bout at RPE intensities in ascending or descending order. In the present investigation subjects were randomly assigned to a counterbalanced production order. The results of the present investigation indicated a significant impact of sequence on the ability to self-regulate exercise intensity. This finding will be discussed in detail in subsequent sections. Only two previous 
investigations using an estimation - production paradigm studied the effect of sequence on the ability to use perceptual scaling metrics to self-regulate exercise intensity (Eston et al., 1994; Robertson et al., 2002). However, these two investigations were conducted on healthy male and female children ranging in age from 9 to 12 years using a cycle ergometer.

Prescription congruence and sequence will be addressed together in the following sections for each dependent variable ( $\mathrm{HR}$ and $\mathrm{VO}_{2}$ ) and for each of the exercise intensities (50\% and $70 \%$ of $\left.\mathrm{VO}_{2} \mathrm{R}\right)$.

\subsection{1 $\mathrm{HR}$ and $\mathrm{VO}_{2}$ at $50 \%$ of $\mathrm{VO}_{2} \mathrm{R}$}

Prescription congruence i.e., similar $\mathrm{HR}$ and $\mathrm{VO}_{2}$ responses between the estimation and production trial was demonstrated only for counterbalance order II. When subjects began the production exercise session using counterbalance order II (50\% - 70\%), there was no significant difference in $\mathrm{HR}$ or $\mathrm{VO}_{2}$ between the estimation and production trials. However, when subjects began the exercise session using counterbalance order I ( $70 \%-50 \%)$, there was a significant difference in $\mathrm{HR}(26.4 \mathrm{bpm})$ and $\mathrm{VO}_{2}(6.6 \mathrm{ml} / \mathrm{kg} / \mathrm{min})$ between the estimation and production trials.

Sequence played an integral role in the ability of subjects to self-regulate exercise intensity on the treadmill when using the OMNI RPE scale at a target intensity corresponding to $50 \%$ of $\mathrm{VO}_{2} \mathrm{R}$. Specifically, when subjects were instructed to titrate their exercise intensity to achieve the target $\mathrm{RPE}$ corresponding to $70 \%$ of $\mathrm{VO}_{2} \mathrm{R}$ during the first five minute interval of the

production trial, both the $\mathrm{HR}$ (Figure 5) and $\mathrm{VO}_{2}$ (Figure 6) where higher compared to the estimation trial. Conversely, when subjects started the production trial with the target RPE corresponding to $50 \%$ of $\mathrm{VO}_{2} \mathrm{R}$ they were able to accurately titrate exercise intensity. This was 
demonstrated by the similar $\mathrm{HR}$ (Figure 5) and $\mathrm{VO}_{2}$ (Figure 6) responses between the estimation and production trials indicating prescription congruence.

Subjects had a tendency to set the initial exercise intensity above the target (i.e. $70 \%$ of $\mathrm{VO}_{2} \mathrm{R}$ ) and then adjusted the intensity level down in an attempt to achieve the target during the titration phase. This seemed to impact the ability of some subjects to produce the target exercise intensity at both of the exercise intervals. The $\mathrm{HR}$ and $\mathrm{VO}_{2}$ responses of these subjects remained elevated throughout the entire exercise sessions. Anticipation bias is a possible explanation for the overestimation when starting the session at the RPE corresponding to $70 \%$ of $\mathrm{VO}_{2} \mathrm{R}$. It is possible that the pre-exercise cognitive set point lead subjects to titrate the initial exercise intensity above the target (i.e $70 \%$ of $\mathrm{VO}_{2} \mathrm{R}$ ) which resulted in an overestimation during the first 5 minute interval and disrupted the ability to perceptually regulate intensity when required to self-regulate at the lower intensity (i.e. $50 \% \mathrm{VO}_{2} \mathrm{R}$ ). Limited published data are available in regard to anticipation bias, however the few studies that are available indicate that anticipation bias does not impact the ability to self-regulate exercise intensity (Swank et al. 2005; Fonzi et al. 2007).

In contrast, subjects starting the exercise session with the lower prescribed intensities (i.e. $50 \% \mathrm{VO}_{2} \mathrm{R}$ ) made more gradual adjustments in the exercise intensity and were able to accurately produce the lower target intensity. When subjects were given the opportunity to begin the exercise session at the lower target RPE intensity, they were able to successfully titrate exercise intensity alternating RPE intensities throughout the exercise session. Perhaps starting at the lower intensity (i.e. $50 \% \mathrm{VO}_{2} \mathrm{R}$ ) provided subjects with a warm-up before increasing to the higher prescribed intensity (i.e. $70 \% \mathrm{VO}_{2} \mathrm{R}$ ). The results of the current investigation are in agreement with the findings of Weiser et al. (2007). Weiser and colleagues determined that 
subjects were able to more accurately self-regulate exercise intensity on a cycle ergometer when the bout began at the lower of the two prescribed intensities.

In the present investigation, subjects were blinded to the actual speed and grade of the treadmill during both estimation and production trials. During the estimation trial subjects had access to the control panel to make adjustments in speed and grade to achieve the target RPE intensity. Subjects utilized both the speed and grade to increase and decrease the exercise intensity. However, the treadmill grade was used much more than expected to regulate the exercise intensity. This could have been due to the subjects trying to match the speed and grade components of the estimation trial graded exercise test. All subjects in this investigation performed running or jogging when exercising at the RPE corresponding to $70 \%$ of $\mathrm{VO}_{2} \mathrm{R}$. However, only half of the subjects performed running or jogging during the RPE corresponding to $50 \%$ of $\mathrm{VO}_{2} \mathrm{R}$ with the remaining subjects fast walking with an increased percent grade.

An investigation by Robertson et al., (2002) determined that sequence (i.e. production order) did not have an impact on the ability of children to self-regulate exercise intensity on a cycle ergometer. Subjects were able to self- regulate exercise intensity using the Child OMNI RPE scale during intermittent exercise when starting the production trial at either the high (RPE 6) or low (RPE 2) target RPE. According to Robertson et. al., (2002) the ability of the children to self-regulate a mixed order of intermittent exercise intensities has important applications for free-form patterns of children's play where initial intensities can be either low or moderate, depending on the play scheme of the moment. However, for adults an exercise session typically should begin with the lower of the two prescribed exercise intensities. This would allow for a warm-up period to gradually increase the metabolic rate and the cardiovascular response prior to increasing the intensity. Beginning exercise at a lower intensity and then increasing the intensity 
during an acute bout of aerobic exercise is consistent with the current recommendations (ACSM 2006a). Prescription congruence during intermittent exercise was observed only when beginning the exercise session at the lower (i.e. $50 \% \mathrm{VO}_{2} \mathrm{R}$ ) of the two prescribed target RPEs.

Previous investigations using perceptual estimation-production paradigms validated the self-regulation of exercise intensity using relatively short durations (i.e. 3 - 10 minutes) (Dunbar et al., 1992; Eston et al., 1988; Glass et al., 1992; Kang et al., 1998; Marriott et al., 1996; Smutok et al., 1980). In addition, these prior investigations employed continuous exercise modalities (i.e. cycling, treadmill) and a different perceived exertion scale (i.e. Borg 6-20) therefore it is difficult to directly compare these investigations with the present study. The current investigation is the first to examine perceptual self-regulation during an extended duration (i.e. $\geq$ 20 minutes) at two different intensities using the OMNI RPE scale. However, the current investigation did utilize five minute intervals in which the subjects had four minutes to titrate the exercise intensity before the measurement period. The duration of the intermittent exercise intervals from the current investigation are similar to those employed in previous investigations.

The current investigation determined that subjects were able to self-regulate exercise intensity at an RPE corresponding to $50 \%$ of $\mathrm{VO}_{2} \mathrm{R}$ when starting the exercise session at the lower of the two target RPE's. Previous investigations indicated that using RPE to self-regulate exercise intensity was more accurate at higher intensities. Smutok et al., (1980) determined that healthy college-age male subjects had a high rate of error when using a Borg's 15 category scale to regulate exercise intensity during a six minute exercise session at a HR $<150 \mathrm{bpm}$ on the treadmill. The mean HR For the present investigation for the RPE corresponding to $50 \% \mathrm{VO}_{2} \mathrm{R}$ during the production trial was $(134.6 \pm 20.7$ beats/min) which is somewhat lower than the HR reported by Sumtok et al., (1980) which reported the greatest error in intensity self-regulation at 
heart rates less than 150 bpm. Eston et al., (1987) also reported that perceptual self-regulation was most accurate at higher intensities corresponding to RPEs of 13 and 17 on the Borg fifteen category scale for healthy male and female college-age subjects. Bayles et al., (1990) found the greatest accuracy for perceptual self-regulation during a 10 minute exercise session for adult male subjects at moderate to high intensities i.e. 60 - $80 \%$ of $\mathrm{VO}_{2 \max }$.

The current findings are supported by an investigation by Dunbar et al., (1992). Using a perceptual estimation-production paradigm, college-age male subjects demonstrated the ability to self-regulate exercise intensity using the Borg fifteen category scale on the treadmill. The methods used in the investigation by Dunbar et al., (1992) are very similar to the present investigation. Subjects regulated exercise intensity using a target RPE determined from a graded treadmill exercise test (i.e. estimation trial). During the production trials subjects titrated the exercise intensity during the first three minutes, then the exercise intensity was maintained for a five minute steady-state exercise bout. Validity was established at $50 \%$ of $\mathrm{VO}_{2 \max }$ as indicated by the similar $\mathrm{VO}_{2}$ responses between the estimation and production trials.

The findings from the current investigation bolsters the existing perceptual regulation literature by determining that subjects can self-regulate exercise intensity using the OMNI RPE scale at lower intensities i.e. $50 \%$ of $\mathrm{VO}_{2} \mathrm{R}$. In the present investigation, prescription congruence was demonstrated at each of the 5 minute intervals in which subjects accurately titrated their exercise intensity at an RPE corresponding to $50 \%$ of $\mathrm{VO}_{2} \mathrm{R}$ when starting the exercise session with the lower (i.e. $50 \%$ of $\mathrm{VO}_{2} \mathrm{R}$ ) of the two prescribed RPE intensities. However, prescription congruence was not observed at each of the 5 minute intervals at an RPE corresponding to 50\% of $\mathrm{VO}_{2} \mathrm{R}$ when starting the exercise session with the higher (i.e. $70 \%$ of $\mathrm{VO}_{2} \mathrm{R}$ ) of the two prescribed RPE intensities. 
The inability of subjects to self-regulate exercise intensity at an RPE corresponding to $50 \%$ of $\mathrm{VO}_{2} \mathrm{R}$ when starting the exercise session at the higher (i.e. $70 \% \mathrm{VO}_{2} \mathrm{R}$ ) of the two prescribed intensities could be due to a few factors. In the present investigation, none of the subjects had experience with using the OMNI RPE scale. All subjects were given standard OMNI RPE scale instructions (pg. 33) and high and low perceptual anchors were established. Perhaps the inexperience of the subjects contributed to the overproduction during the first higher intensity (i.e. $70 \% \mathrm{VO}_{2} \mathrm{R}$ ) interval where subjects increased the speed and grade above the target level. This overproduction impacted the subsequent intervals at the lower (i.e. $50 \%$ of $\mathrm{VO}_{2} \mathrm{R}$ ) prescribed RPE intensity. At the start of the $70 \%$ of $\mathrm{VO}_{2} \mathrm{R}$ exercise session, the subjects tended to increase the intensity (i.e. speed and grade) much more quickly in the first few minutes and spent the remainder of the titration period decreasing the intensity to try to produce the target RPE. Clearly, the overproduction during the first interval impacted the ability of subjects to titrate the intensity back down to the lower (i.e. $50 \%$ of $\mathrm{VO}_{2} \mathrm{R}$ ) target $\mathrm{RPE}$ for the next five minute interval.

Fatigue is another potential factor that could have impacted the ability of subjects to selfregulate exercise intensity during intermittent exercise. Fatigue can be defined as the inability to maintain a given exercise intensity during an acute bout of exercise. It is characterized by a lowering of the exercise workload or exercise intensity. Fatigue is a multi factorial process that potentially involves metabolic depletion (i.e. ATP, CP), metabolite accumulation (i.e. lactic acidosis) as well as central and neuromuscular fatigue. According to Brooks et al., (2005) fatigue occurs sooner in an untrained person exercising at $75 \%$ of $\mathrm{VO}_{2 \max }$ than in endurancetrained individuals exercising at the same work rate, or at a higher work rate that elicits $70 \%$ of the trained individual's $\mathrm{VO}_{2 \max }$. In the present investigation, the exact mechanism for the 
differences in estimation and production trial $\mathrm{HR}$ and $\mathrm{VO}_{2}$ is unclear. It is possible that as exercise intensity increases, factors other than cardiorespiratory and metabolic strain, such as increased metabolic acidosis and elevated body temperature, may become more important physiological mediators for exertional perceptions (Kang et.al., 1998). Perhaps fatigue disrupted the ability of subjects to self regulate exercise intensity due to abrupt increases in $\mathrm{VO}_{2}$ and $\mathrm{HR}$ during the initial interval at an RPE corresponding to $70 \%$ of $\mathrm{VO}_{2} \mathrm{R}$. As such, subjects may not have recovered during the subsequent interval corresponding to $50 \%$ of $\mathrm{VO}_{2} \mathrm{R}$. Given that the population cohort for this investigation was comparatively unfit, they may have experienced fatigue that could delay recovery.

\subsection{2 $\mathrm{HR}$ at $70 \%$ of $\mathrm{VO}_{2} \mathrm{R}$}

Prescription congruence was demonstrated by the similar HR response between the estimation and production trial for counterbalance order II. Sequence influenced the subjects' ability to accurately produce exercise intensity at an RPE corresponding to $70 \%$ of $\mathrm{VO}_{2} \mathrm{R}$. When subjects began the exercise session using counterbalance order II (50\% - 70\%), there was no significant difference in $\mathrm{HR}$ between the estimation and production trials at an RPE corresponding to $70 \%$ of $\mathrm{VO}_{2} \mathrm{R}$. However, when subjects began the exercise session using counterbalance order I (70\% - 50\%), there was a significant difference in HR (13.7 bpm) between the estimation and production trials.

Unlike the impact of sequence at the RPE corresponding to $50 \%$ of $\mathrm{VO}_{2} \mathrm{R}$ which impacted both the $\mathrm{HR}$ and $\mathrm{VO}_{2}$ responses, sequence at a target $\mathrm{RPE}$ intensity of $70 \%$ of $\mathrm{VO}_{2} \mathrm{R}$ only influenced the HR response. In the current investigation, the ability of the subjects to selfregulate exercise intensity was influenced by the initial target intensity. When subjects began the 
production session with the higher (i.e. $70 \% \mathrm{VO}_{2} \mathrm{R}$ ) of the two target RPE intensities the HR (figure 7) was higher in the production trial compared to the estimation trial. Conversely, when the subjects started the exercise session with the lower (i.e. $50 \%$ of $\mathrm{VO}_{2} \mathrm{R}$ ) of the two target RPE intensities, HR was similar (Figure 7) between the estimation and production trials.

In the present investigation, only the subjects who began the exercise session at the higher (i.e. $70 \%$ of $\mathrm{VO}_{2} \mathrm{R}$ ) of the two target RPE intensities had difficulty self-regulating exercise intensity at an RPE corresponding to $70 \%$ of $\mathrm{VO}_{2} \mathrm{R}$. Perhaps the subjects starting off with the lower intensity had more of an opportunity to warm-up and gradually increase the HR before the subsequent higher intensity interval. Despite the statistically significant difference in HR, the difference was only $13 \mathrm{bpm}$ between the estimation and production trials. This error of producing a target RPE in the present investigation is less than the potential error when using a target heart rate to prescribe exercise intensity (Dishman 1994). The impact of sequence notwithstanding, subjects were able to accurately titrate their exercise intensity using the OMNI RPE scale.

\subsection{3 $\mathrm{VO}_{2}$ at $70 \%$ of $\mathrm{VO}_{2} \mathrm{R}$}

Subjects demonstrated the greatest level of accuracy in self-regulation at the RPE corresponding to $70 \%$ of $\mathrm{VO}_{2} \mathrm{R}$ as determined by similar metabolic rates during the estimation and production trials. Subjects were able to self-regulate their exercise intensity with no influence from sequence. The metabolic rate is preferred over the heart rate response when studying a subject's ability to self-regulate exercise intensity using RPE (Kang et al. 2003). Kang et.al., (2003), indicated that the metabolic demand may be one of the most important factors upon which the assessment of physical exertion is made throughout dynamic steady - 
state exercise. According to Dishman (1993), perceived exertion is more closely linked in many circumstances with relative oxygen consumption than with relative heart rate. Kang et. al. (2003) explains that $\mathrm{HR}$ does not respond as quickly during exercise as the $\mathrm{VO}_{2}$ response. It may be that the initial rise in $\mathrm{VO}_{2}$ is due primarily to an adjustment in stroke volume and/or oxygen extraction by skeletal muscle. The greater variability associated with HR responses suggests that under the circumstances where subjects use their effort sense to produce a power output, HR is not the primary cue upon which the perception is assessed. According to Easton et al. (1998) HR is known to fluctuate on an intra- and inter- subject basis and as a result of environmental and emotional influences and thus may be a confounding variable in perceptual self-regulation studies.

The ability of subjects in the present investigation to self-regulate exercise at $70 \%$ of VO2R was not influenced by production sequence. This finding supports previous investigations that indicated a greater accuracy in self-regulation at higher target intensities. As stated in a prior section, this is the first investigation to examine perceptual self-regulation during an extended duration (i.e. $\geq 20$ minutes) at two different intensities using the OMNI RPE scale. The current investigation utilized five minute intervals in which the subjects had four minutes to titrate the exercise intensity before the measurement period. The intermittent exercise intervals from the current investigation are similar in durations to those employed in some of the previous investigations.

Smutok et al., (1980) determined that healthy male subjects demonstrated the greatest accuracy in self-regulation of exercise intensity while performing treadmill running at a higher intensity (i.e. 80\% HRmax) during a six minute bout. Using similar methodology to the present investigation, Eston et al. (1987) indicated that there were similar metabolic rates between the 
estimation and production trials for healthy young male and female subjects during treadmill exercise. In a subsequent investigation, Eston et al., (1998) utilized an estimation - production paradigm in which subjects exercised on a cycle ergometer. Healthy male subjects performed 3 four minute trials at RPEs of 9, 13, and 17 on the Borg scale. The greatest accuracy for intensity self-regulation was reported at the higher intensities (i.e. 13 and 17). Dunbar et al., 1992 employed an estimation-production paradigm in which healthy male and female subjects exercised on both the treadmill and cycle ergometer. Subjects completed 5 minute intramodal (Treadmill/Treadmill) and intermodal (Cycle/Treadmill) trials. At both $50 \%$ and $70 \%$ of $\mathrm{VO}_{2 \max }$ there was less than $2 \%$ difference in $\mathrm{VO}_{2}$ between the estimation trial and the production trial.

The findings from the current investigation extended the findings of Glass et al., (1992) that indicated healthy male subjects could self-regulate exercise intensity using RPE at $75 \%$ of Heart Rate Reserve (HRR) on the treadmill during a 10 minute production trial. Subjects performed an estimation graded exercise test using the Bruce protocol and during the subsequent session self-regulated exercise intensity using the Borg (6-20) RPE scale. Throughout the 10 minute exercise session, there was no difference between the estimation and production trial in $\mathrm{VO}_{2}$. However, the HR response did not follow the same pattern. The HR was below the target for the first 6 minutes of exercise. During the final 4 minutes of exercise HR did not differ between the estimation and production trials. The metabolic rate (i.e. $\mathrm{VO}_{2}$ ) was the best indicator of the subject's ability to self-regulate exercise intensity. The investigation by Glass et al., (1992) demonstrated that RPE obtained from a graded exercise test can accurately serve as a method of prescribing exercise intensity during treadmill running exercise. The present investigation demonstrated that subjects can self-regulate exercise intensity at a target RPE corresponding to $70 \%$ of $\mathrm{VO}_{2} \mathrm{R}$ during a 20 minute exercise bout of varying intensity. 


\section{$5.2 \quad$ INTENSITY DESCRIMINATION}

Intensity discrimination is demonstrated when the $\mathrm{HR}$ and $\mathrm{VO}_{2}$ responses differ between the production trials at $50 \%$ of $\mathrm{VO}_{2} \mathrm{R}$ and $70 \%$ of $\mathrm{VO}_{2} \mathrm{R}$. In the present investigation, target RPEs were determined from the estimation trial graded exercise test where $\mathrm{VO}_{2}$ and $\mathrm{RPE}$ were collected every minute. Once 50 and $70 \%$ of $\mathrm{VO}_{2} \mathrm{R}$ were calculated, the target RPEs to be used during the production trial were determined (Robertson, 2004). On average, only one RPE unit separated the two target RPE intensities ( $50 \%$ and $70 \%$ of $\mathrm{VO}_{2} \mathrm{R}$ ) that subjects used to titrate exercise intensity in the production trial. This is a more narrow target RPE range (i.e., 4 and 6) than reported by (Robertson et al., 2002) which used target RPE’s of range 2 and 6 (4 RPE unit difference). Both the present investigation and the (Robertson et al., 2002) study demonstrated intensity discrimination during the production trial.

The findings of the present investigation indicated that young healthy college age subjects were able to use the OMNI RPE scale to discriminate between two target OMNI RPE intensities corresponding to $50 \%$ and $70 \%$ of $\mathrm{VO}_{2} \mathrm{R}$ during the intermittent production trial. Despite the comparatively narrow perceptual target RPE range used presently, subjects were able to self-regulate their exercise intensity on the treadmill and differentiate between the RPE corresponding to $50 \%$ of $\mathrm{VO}_{2} \mathrm{R}$ and $70 \%$ of $\mathrm{VO}_{2} \mathrm{R}$. This finding will broaden the use of the

OMNI RPE scale of perceived exertion. RPE based exercise prescriptions typically consist of a target range of 1 to 2 OMNI RPE units separating the target RPE's (i.e. $60 \%$ to $75 \%$ of $\mathrm{VO}_{2} \mathrm{R}$ ). The ability of subjects to self-regulate exercise intensity with only one RPE unit separating target 
RPE intensities demonstrates that subjects were able perceptually discriminate between prescribed intensities.

\subsection{BLAND-ALTMAN}

Bland-Altman plots (Figures 11 - 14) display the individual subject differences between the estimation and production RPE against the mean of the estimation and production RPE for $\mathrm{HR}$ and $\mathrm{VO}_{2}$ at RPEs corresponding to $50 \%$ and $70 \%$ of $\mathrm{VO}_{2} \mathrm{R}$. Included in these figures is the mean difference and the 95\% confidence interval ( \pm 2 SD). Additionally, the range displayed on the $y$-axis represents the maximum possible difference between the estimation and production trials. The 95\% CI around the mean difference between the estimation and the production trials for $\mathrm{HR}$ at an RPE corresponding to $50 \%$ of $\mathrm{VO}_{2} \mathrm{R}$ was 40 to $-60 \mathrm{bpm}$. The $95 \% \mathrm{CI}$ around the mean difference between the estimation and the production trials for $\mathrm{VO}_{2}$ at an $\mathrm{RPE}$ corresponding to $50 \%$ of $\mathrm{VO}_{2} \mathrm{R}$ was 13 to $-19 \mathrm{ml} / \mathrm{kg} / \mathrm{min}$. The $95 \% \mathrm{CI}$ around the mean difference between the estimation and the production trials for HR at an RPE corresponding to $70 \%$ of $\mathrm{VO}_{2} \mathrm{R}$ were 25 to $-43 \mathrm{bpm}$. The $95 \% \mathrm{CI}$ around the mean difference between the estimation and the production trials for $\mathrm{VO}_{2}$ at an $\mathrm{RPE}$ corresponding to 70\% of VO2R were 13 to $-16 \mathrm{ml} / \mathrm{kg} / \mathrm{min}$.

At both of the prescribed exercise intensities (i.e. $50 \%$ and $70 \%$ of $\mathrm{VO}_{2} \mathrm{R}$ ) subjects were instructed to titrate the workload to produce a target RPE. Some subjects exceeded (i.e. overshoot) the target intensity by adjusting the workload such that $\mathrm{HR}$ and $\mathrm{VO}_{2}$ were greater than the target intensity. Conversely, some subjects selected a speed and grade combination that resulted in a $\mathrm{HR}$ and $\mathrm{VO}_{2}$ that were below the target intensity (i.e. undershoot). When 
examining the data there was a trend in the individual responses at $50 \%$ of $\mathrm{VO}_{2} \mathrm{R}$. There seems to be a greater numbers of values below the mean difference at the higher mean metabolic rates $\left(\mathrm{VO}_{2}\right)$ (Figure 12). It is possible that the subjects with the higher aerobic capacities (i.e. $\mathrm{VO}_{2 \max }$ ) were more likely to overshoot the target intensity.

When evaluating the efficiency of using RPE to self-regulate exercise intensity an ideographic approach may be warranted. Subjects that tend to overshoot the intended exercise intensity are at a greater potential risk for injury or for higher rates of recidivism from a regular exercise program. Conversely, subjects that undershoot the intended exercise intensity may receive less than optimal benefits from an exercise session. If individuals exercise below the target intensity on a regular basis they may not receive the cardio - protective health benefits that are obtained from regular exercise at commonly prescribed intensities (i.e. 40 to $80 \%$ of $\mathrm{VO}_{2} \mathrm{R}$ ).

\subsection{CONCLUSIONS}

The current investigation demonstrated that recreationally active college-age subjects could self-regulate exercise intensity on the treadmill at a RPE corresponding to $50 \%$ of $\mathrm{VO}_{2} \mathrm{R}$ when beginning the exercise bout at the lower (i.e. $50 \%$ of $\mathrm{VO}_{2} \mathrm{R}$ ) of the two prescribed RPE intensities. Having individuals start an exercise session at the higher of the two intensities is not a common practice nor is it consistent with established prescription guidelines. Based on the impact of sequence in the present investigation, it is evident that when using rating of perceived exertion to self-regulate exercise intensity an acute exercise bout should begin with a lower intensity and progress to higher intensities. 
The target RPE intensity corresponding to $70 \%$ of $\mathrm{VO}_{2} \mathrm{R}$ was not influenced by sequence. As indicated by the $\mathrm{VO}_{2}$ response in the present investigation subjects were able to self-regulate exercise intensity regardless of the counterbalance order. It appears that subjects demonstrated the greatest level of accuracy for intensity self-regulation at the higher target RPE intensity (i.e. $70 \%$ of $\left.\mathrm{VO}_{2} \mathrm{R}\right)$.

Previous investigations have determined that using RPE to self-regulate exercise intensity between at 50 and $70 \%$ of $\mathrm{VO}_{2 \max }$ results in error in the $\mathrm{VO}_{2}$ that are not greater than the errors observed when using a target HR range (Ceci et al., (1991), Dunbar, et al. (1992), Easton et al., (1988), Glass et al., (1992). Despite the literature to support the use of RPE to self-regulate exercise intensity the use of a target HR still remains the most widely used method for regulating exercise intensity. The present findings provide additional support for the use of RPE in the selfregulating of exercise intensity. This may lead to the greater utilization of RPE in health-fitness facilities to safely and effectively self-regulate intermittent exercise intensity.

\subsection{RECOMMENDATIONS FOR FUTURE RESEARCH}

Based upon the results of the current investigation, future research regarding selfregulation of exercise intensity during an extended exercise bout (i.e. 20 minutes) at varying intensity (50\% and $70 \%$ of $\mathrm{VO}_{2} \mathrm{R}$ ) using the OMNI RPE scale could consider the following:

1. The present investigation utilized college-age male and female subjects that are classified as recreationally active. It would be of interest to examine the ability of a younger as well as an older population cohort with varying degrees of aerobic fitness to perceptually self-regulate exercise intensity. 
2. The present experimental paradigm was not designed to determine the impact of gender on perceptual regulation of exercise intensity. It would be of interest to determine if gender has an impact on the ability to perceptually self-regulate exercise intensity.

3. The present investigation varied the intensity using two target RPEs intensities corresponding to $50 \%$ of $\mathrm{VO}_{2} \mathrm{R}$ and $70 \%$ of $\mathrm{VO}_{2} \mathrm{R}$. Future investigations should consider varying the intensity at higher (i.e. $>70 \%$ of $\mathrm{VO}_{2} \mathrm{R}$ ) and lower (i.e. < $50 \%$ of $\mathrm{VO}_{2} \mathrm{R}$ ) target intensities during an acute about of aerobic exercise.

4. The present investigation was performed in a laboratory setting. It would be of interest to examine the ability of subjects to perceptually self-regulate exercise intensity in an outdoor or recreational settings (i.e. track, bike path etc.).

5. Future investigations should examine the ability of clinical populations (Coronary artery disease, obesity, diabetes) to perceptually self-regulate exercise intensity at varying intensities.

6. Treadmill was the modality utilized for both the estimation and production trials in the current investigation. It would be of interest to examine the impact of performing the estimation and production trials using intermodal comparisons i.e. estimation trial (cycle) and production trial (treadmill). In addition to intermodal comparisons, it would be of interest to investigate the ability of subjects to perceptually regulate exercise using various weight bearing and nonweight bearing modes of exercise (i.e. cycle ergometer, rowing, arm crank, stepper, and elliptical). 
7. In the present investigation, a graded exercise test using the Bruce protocol was employed during the estimation trial to establish the perceptual and metabolic responses and determine maximal oxygen uptake. It would be of interest to examine the impact of using other graded exercise test protocols (i.e. Astrand) on subsequent production trials on the treadmill.

8. The present investigation employed an estimation trial and one production trial. Teleoanticipation should be investigated to determine if repeated production trials would improve the ability to perceptually self-regulate exercise intensity. 
APPENDIX A

\section{University of Pittsburgh \\ Center for Exercise and Health-Fitness Research \\ Physical Activity Readiness Questionnaire (PAR-Q)}

Now I am going to ask you a few questions to determine if you are eligible to complete the stationary cycle exercise ...

1. Has your doctor ever said that you have a heart condition and that you should only do physical activity recommended by a doctor?

$$
\text { No _ _ Yes __ If yes, specify: }
$$

2. Do you feel pain in your chest when you do physical activity?

$$
\text { No _ _ Yes __ If yes, specify: }
$$

3. In the past month, have you had chest pain when you were not doing physical activity?

$$
\text { No __ Yes ___ If yes, specify: }
$$

4. Do you lose your balance because of dizziness or do you ever lose consciousness?

$$
\text { No __ Yes __ If yes, specify: }
$$

5. Do you have a bone or joint problem that could be made worse by a change in your physical activity?

$$
\text { No __ Yes __ If yes, specify: }
$$

6. Is your doctor currently prescribing drugs (for example, water pills) for a blood pressure or heart condition?

$$
\text { No _ _ Yes __ If yes, specify: }
$$

7. Do you know of any other reason why you should not do physical activity?

No __ Yes __ If yes, specify: 
APPENDIX B

ID \#

\section{University of Pittsburgh \\ Center for Exercise and Health-Fitness Research MEDICAL HISTORY}

1. History of heart problems, chest pain, or stroke?

2. Increased blood pressure?

3. Any chronic illness or condition?

4. Difficulty with physical exercise?

5. Advice from a physician not to exercise?

6. Recent surgery? (Last 12 months)

7. Pregnancy? (Now or within the last 3 months)

8. History of breathing or lung problems?

9. Muscle, joint, back disorder, or any previous injury still affecting you

10. Diabetes or thyroid conditions?

11. Cigarette smoking habit?

12. Increased blood cholesterol?

13. History of heart problems in your immediate family?

14. Hernia or any condition that may be aggravated by lifting weights?

15 . Do you have any condition limiting your movement?

16. Are you aware of being allergic to any drugs or insect bites?

17. Do you have asthma?

18. Do you have epilepsy, convulsions, or seizures of any kind?

19. Do you follow any specific diet?

Please explain in detail any "YES” answers:

Family History

Has any member of you family had any of those listed above? 


\section{APPENDIX C}

\section{INFORMED CONSENT}

TITLE: INTENSITY SELECTION AND REGULATION USING THE OMNI SCALE OF PERCEIVED EXERTION DURING INTERMITTENT EXERCISE

PRINCIPAL INVESTIGATOR: $\quad$ Mark Schafer, MS, CSCS

ACSM Exercise Specialist ${ }^{\circledR}$

3025 Baierl Student Recreation Center

Peterson Event Center

Phone: (412) 383-8687

Fax: (412) 383-8725

Email: mas152@pitt.edu

Department of Health and Physical Activity

School of Education

\section{CO-INVESTIGATORS:}

Fredric L. Goss, Ph.D.

Associate Professor and Co-Director, Center for Exercise and Health-Fitness Research

113 Trees Hall

Phone: (412) 648-8259 Fax: (412) 648-7092

Email: goss@pitt.edu

Department of Health and Physical Activity

School of Education

Robert J. Robertson, Ph.D.

Professor and Co-Director, Center for Exercise and HealthFitness Research

107 Trees Hall

Phone: (412) 648-8251

Email: rrobert@pitt.edu

Department of Health and Physical Activity

School of Education 
University of Pittsburgh

Institutional Review Board

Approval Date: September 27, 2006

Renewal Date: September 27, 2007

IRB Number: 0609092

\author{
Elizabeth F. Nagle - Stilly, Ph.D. \\ Assistant Professor \\ 149 Trees Hall \\ Phone: (412) 648-826 \\ Email: nagle@pitt.edu \\ Department of Health and Physical Activity \\ School of Education
}

Kevin H. Kim, Ph.D.

Assistant Professor

5918 Wesley Posvar Hall

Phone: (412) 624-7272

Email: khkim@pitt.edu

Department of Psychology in Education

School of Education

\title{
SOURCE OF SUPPORT:
}

School of Education Alumni Doctoral Fellowship

\section{Why is this research being done?}

Using feelings of effort, also known as Ratings of perceived exertion (RPE), are commonly used as part of an individualized exercise prescription to define the intensity training zone and to regulate exercise intensity. Intermittent exercise is often employed in athletic, clinical, and health-fitness settings as it allows for a greater amount of physiological work to be done in a given period of time when compared to continuous constant intensity training. The purpose of the current investigation is to determine if subjects can self-regulate exercise intensity during a 20 minute intermittent bout of aerobic exercise on the treadmill using a $1-10$ scale (OMNI RPE scale) with pictures and verbal descriptors that determines the level of perceived exercise exertion. The perception of physical exertion is defined as the subjective intensity of effort, strain, discomfort, and/or fatigue that you feel during exercise. A total of 20 men and 20 women, 18 to 34 years of age will be enrolled in the study. 


\author{
Participant's Initials \\ University of Pittsburgh \\ Institutional Review Board \\ Approval Date: September 27, 2006 \\ Renewal Date: September 27, 2007 \\ IRB Number: 0609092
}

\title{
Who is being asked to take part in this research study?
}

You are being invited to take part in this research study because you are healthy, have normal body weight, and participate 2 to 3 times per week in recreational aerobic exercises. If you have an orthopedic (muscle or bone), cardiovascular (Heart), and/or metabolic disease (i.e. coronary artery disease (Heart Disease), prior myocardial infarction (Heart Attack), peripheral vascular disease (Blockages in legs), chronic obstructive pulmonary disease (Lung disease), and diabetes mellitus (High/low Blood sugar) and/or if you are knowingly pregnant or you are a current smoker, you will not be eligible to participate in this research study.

\section{What procedures will be performed for research purposes?}

If you decide to take part in this research study, you will complete two separate 30 - 45 minute exercise sessions, each separated by a 2 -3 day period. Exercise testing will consist of walking and then running on a treadmill to obtain your maximal aerobic fitness $\left(\mathrm{VO}_{2 \max }\right)$. The subsequent exercise session will consist of a 20 minute intermittent exercise bout. A flow-chart is shown in Figure 1 on page 4.

To minimize risks associated with maximal aerobic exercise testing, you will be asked to complete a Physical Activity Readiness Questionnaire (PAR-Q) and a medical history form which asks questions about your current health status. If you have an orthopedic (muscle or bone), cardiovascular (Heart), and/or metabolic disease (i.e. coronary artery disease (Heart Disease), prior myocardial infarction (Heart Attack), peripheral vascular disease (Blockages in legs), chronic obstructive pulmonary disease (Lung disease), and diabetes mellitus (High/low Blood sugar) you will be excluded from participation in this research study. If you are female, you will be asked if you are currently pregnant. If you are pregnant, you will be excluded from participation in this research study.

If an abnormal response occurs during exercise, the test will be immediately stopped and you will be given proper medical attention. Emergency equipment will be on site for all testing procedures and staff personnel are certified in CPR and First Aid by the American Red Cross. If you have an abnormal response to the treadmill test, you will be told of the findings and will be encouraged to contact your primary care clinician. 
Participant’s Initials

University of Pittsburgh

Institutional Review Board

Approval Date: September 27, 2006

Renewal Date: September 27, 2007

IRB Number: 0609092

Session 1. Fitness Assessment.

Session 2. Exercise Session.

Physical Activity Questionnaire

RPE Scale Instruction

Medical History

Exercise Prescription

Informed Consent

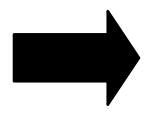

20 Minute Intermittent Exercise

Figure 15. Exercise Session Flow-

All procedures will take place at the Center for Exercise and Health-Fitness Research located in Trees Hall at the University of Pittsburgh. Each testing session will include the following procedures administered by the principal investigator who is an American College of Sports Medicine, Certified Exercise Specialist ${ }^{\circledR}$ from the Department of Health and Physical Activity at the University of Pittsburgh:

Procedures:

1. Before starting the study protocol, you will complete a medical history form and a physical activity readiness questionnaire (PAR-Q). Both forms will take less than five minutes to complete.

2. During both of the exercise sessions, a heart rate monitor will be placed around your chest and secured in place with an elastic strap. A rubber mouthpiece, connected to a headset, will be placed in your mouth during the treadmill exercises to determine the amount of oxygen that you use during exercise. A clip will be attached to your nose to insure that all the air that you breathe comes in and out through your mouth. Some individuals become anxious when fitted with the nose clip and mouthpiece. If this occurs to you, please inform the individual performing the test and the test will be stopped. Your heart rate and the amount of oxygen that your body uses will be measured during the treadmill exercise.

3. Prior to both of the exercise sessions, you will receive standard instructions on OMNI RPE scaling procedures. The investigator will first read you the following definition of RPE: "The perception of physical exertion is defined as the subjective intensity of effort, strain, discomfort, and/or fatigue that you feel during exercise". You will then be read a 
set of instructions from a script on how to use the OMNI RPE scale during each of the exercise sessions.

Participant's Initials

University of Pittsburgh

Institutional Review Board

Approval Date: September 27, 2006

Renewal Date: September 27, 2007

IRB Number: 0609092

\section{Session 1: Fitness Assessment Session}

4. Measurement of your body height and weight using a standard physicians' scale.

5. Body composition will be assessed using a Tanita bioelectrical impedance analyzer (BIA) scale. The BIA is a non-invasive pain-free procedure for assessing body composition in which a low-grade electrical impulse is transmitted through the body. The resistance to current flow through tissues reflects the relative amount of fat present. You will remove you shoes and socks and stand on the scale for approximately 10 seconds to obtain body composition assessment on the Tanita scale. During the body composition measurement there may be a potential for the hair on your arms and legs to stand up.

6. Based on the information you provide on the medical history and physical activity questionnaire. If you do not have any conditions that would limit your ability to exercise, you will complete the first testing session to measure your aerobic fitness $\left(\mathrm{VO}_{2 \mathrm{max}}\right)$. The aerobic fitness test will be administered on a motorized treadmill. The speed and grade will increase every 3 minutes and you will be encouraged to continue until fatigued. However, you may stop the test at any time for any reason.

\section{Session 2: Exercise Session}

7. 2 to 3 days after you have completed the first session, you will return to complete the 20 minute intermittent exercise on a motorized treadmill.

8. Based on the results of your Session 1 fitness assessment, you will be prescribed two target RPE's set alternately at the high and low end of your aerobic fitness level.

9. The 20 minute intermittent exercise session will be a continuous bout of exercise consisting of four, five minute intervals alternating between the two prescribed target RPE's.

10. Based on your perception of physical exertion, you will be responsible for self-regulating the treadmill speed and grade to achieve your prescribed target RPE's during the intermittent exercise session. 
University of Pittsburgh

Institutional Review Board

Approval Date: September 27, 2006

Renewal Date: September 27, 2007

IRB Number: 0609092

What are the possible risks, side effects, and discomforts of this research study?

\section{Risks of the Graded Exercise Test}

Abnormal responses, such as excessive rises in blood pressure, mental confusion, shortness of breath, chest pain, heart attack, and death, to maximal aerobic exercise tests in young healthy adults are rare, occurring in less than 1\% of people (less than 1 out of 100 people tested). However, some common risks, occurring in 1\% to 25\% of people (1 to 25 out of 100 people tested), of maximal exercise testing include; heavy breathing, dizziness, muscle fatigue, headache, and overall fatigue.

\section{Risks of the Study Monitors}

Risk associated with study monitors (e.g. heart rate monitor, mouthpiece, etc.) include redness, irritation, and chafing.

\section{What are possible benefits from taking part in this study?}

You will likely receive no direct benefit from taking part in this research study. However, you will receive information regarding your aerobic fitness level, percent body fat, the importance of promoting cardiovascular health.

If I agree to take part in this research study, will I be told of any new risks that may be found during the course of the study?

You will be promptly notified if, during the conduct of this research study, any new information develops which may cause you to change your mind about continuing to participate.

Will my insurance provider or I be charged for the costs of any procedures performed as part of this research study?

Neither you, nor your insurance provider, will be charged for the costs of any procedures performed for the purpose of this research study.

Will I be paid if I take part in this research study?

You will be paid $\$ 20.00$ upon completion of both visits. There will be no partial compensation for completion of only one of the visits. 


\title{
Participant's Initials
}

\author{
University of Pittsburgh \\ Institutional Review Board
}

Approval Date: September 27, 2006

Renewal Date: September 27, 2007

IRB Number: 0609092

\section{Who will pay if I am injured as a result of taking part in this study?}

University of Pittsburgh researchers and their associates who provide services at UPMC recognize the importance of your voluntary participation in their research studies. These individuals and their staffs will make reasonable efforts to minimize, control, and treat any injuries that may arise as a result of this research. If you believe that you are injured as a result of the research procedures being performed, please contact immediately the Principal Investigator or one of the Co-Investigators listed on the first page of this form.

Emergency medical treatment for injuries solely and directly related to your participation in this research study will be provided to you by the hospitals of the UMPC. It is possible that the UPMC may bill your insurance provider for the costs of this emergency treatment, but none of these costs will be charged directly to you. If your research-related injury requires medical care beyond this emergency treatment, you will be responsible for the cost of this follow-up unless otherwise specifically stated below. There is no plan for monetary compensation. You do not, however, waive any legal rights by signing this form.

\section{Who will know about my participation in this research study?}

Any information about you obtained from this research will be kept as confidential (private) as possible. All records related to your involvement in this research study will be stored in a locked file cabinet. Your identity on these records will be indicated by a case number rather than by your name, and the information linking these case numbers with your identity will be kept separate from the research records. You will not be identified by name in any publication of the research results unless you sign a separate consent form giving your permission (release).

\section{Will this research study involve the use or disclosure of my identifiable medical information?}

This research study will not involve the use or disclosure of any identifiable medical information. 
Participant's Initials

University of Pittsburgh

Institutional Review Board

Approval Date: September 27, 2006

Renewal Date: September 27, 2007

IRB Number: 0609092

\section{Who will have access to identifiable information related to my participation in this research study?}

In addition to the investigators listed on the first page of this authorization (consent) form and their research staff, the following individuals will or may have access to identifiable information related to your participation in this research study:

- Authorized representatives of the University of Pittsburgh Research Conduct and Compliance Office may review your identifiable research information for the purpose of monitoring the appropriate conduct of this research study.

- In unusual cases, the investigators may be required to release identifiable information related to your participation in this research study in response to an order from a court of law. If the investigators learn that you or someone with whom you are involved is in serious danger or potential harm, they will need to inform, as required by Pennsylvania law, the appropriate agencies.

- Authorized people sponsoring this research study, because they need to make sure that the information collected is correct, accurate, and complete, and to determine the results of this research study.

- Authorized representatives of the UPMC hospitals or other affiliated health care providers may have access to identifiable information related to your participation in this research study for the purpose of (1) fulfilling orders, made by the investigators, for hospital and health care services (e.g. laboratory tests, diagnostic procedures) associated with research study participation; (2) addressing correct payment for tests and procedures ordered by the investigators; and/or (3) for internal hospital operations (i.e. quality assurance).

\section{For how long will the investigators be permitted to use and disclose identifiable information related to my participation in this research study?}

The investigators may continue to use and disclose, for the purposes described above, identifiable information related to your participation in this research study for a minimum of five years after final reporting or publication of a project. 
Participant's Initials

University of Pittsburgh
Institutional Review Board

Approval Date: September 27, 2006

Renewal Date: September 27, 2007

IRB Number: 0609092

\section{Is my participation in this research study voluntary?}

Your participation in this research study, to include the use and disclosure of your identifiable information for the purposes described above, is completely voluntary. (Note, however, that if you do no provide your consent for the use and disclosure of your identifiable information for the purposes described above, you will not be allowed, in general, to participate in this research study.) Whether or not you provide your consent for participation in this research study will have no affect on your current or future relationship with the University of Pittsburgh. Whether or not you provide your current for participation in this research study will have no effect on your current or future medical care at a UPMC hospital or affiliated health care provider or your current or future relationship with a health care insurance provider.

\section{May I withdraw, at a future date, my consent for participation in this research study?}

You may withdraw, at any time, your consent for participation in this research study, to include the use and disclosure of your identifiable information for the purposes described above. Any identifiable research information recorded for, or resulting from, your participation in this research study prior to the date that you formally withdrew your consent may continue to be used and disclosed by the investigators for the purposes described above.

To formally withdraw your consent for participation in this research study you should provide a written and dated notice of this decision to the principal investigator of this research study at the address listed on the first page of this form.

Your decision to withdraw your consent for participation in this research study will have no effect on your current of future relationship with the University of Pittsburgh. Your decision to withdraw your consent for participation in this research study will have no effect on your current of future medical care at a UPMC hospital or affiliated health care provider or your current or your future relationship with a health care insurance provider.

\section{If I agree to take part in this research study, can I be removed from the study without my consent?}

It is possible that you may be removed from the research study by the researchers to protect your safety or if you are unable or unwilling to complete the research protocol. 


\section{Participant's Initials}

\section{VOLUNTARY CONSENT}

All of the above has been explained to me and all of my questions have been answered. I understand that any future questions I have about this research study during the course of this study, and that such future questions will be answered by the investigators listed on the first page of this consent document at the telephone numbers given. Any questions I have about my rights as a research subject will be answered by the Human Subject Protection Advocate of the IRB Office, University of Pittsburgh (1-866-212-2668). By signing this form, I agree to participate in this research study.

\section{Participant's Name (Print)}

Participant's Signature

\section{Date}

\section{CERTIFICATION OF INFORMED CONSENT}

I certify that I have explained the nature and purpose of this research study to the above-named individual, and I have discussed the potential benefits, and possible risks associated with participation. Any questions the individual has about this study have been answered, and we will always be available to address future questions as they arise.

Printed Name of Person Obtaining Consent

Signature of Person Obtaining Consent
Role in Research Study

Date 


\section{BIBLIOGRAPHY}

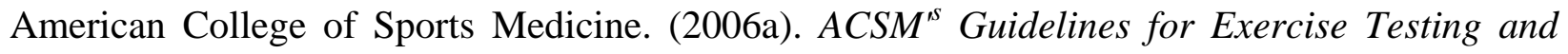
Prescription (7th ed.). Philadelphia, PA: Lippincott Williams \& Wilkins.

American College of Sports Medicine. (2006b). ACSM's Resource Manual for Guidelines for Exercise Testing and Prescription (5th ed.). Philadelphia, PA: Lippincott Williams and Wilkins.

Bayles, C. M., Metz, K. F., Robertson, R., Goss, F., Cosgrove, J., \& McBurney, D. (1990). Perceptual Regulation of Prescribed Exercise. Journal of Cardiopulmonary Rehabilitation 10, 25-31.

Bland, J. M., \& Altman, D. G. (1986). Statistical methods for assessing agreement between two methods of clinical measurement. Lancet, 1(8476), 307-310.

Borg, G. A. (1982). Psychophysical bases of perceived exertion. Medicine and Science in Sports Exercise, 14(5), 377-381.

Borg, G. A. V. (1961). Interindividual scaling and perception of muscular force. Kungliga Fysiologiska Sallskapet i Lunds Forhandlingar, 32(2), 117-125.

Borg, G. A. V. (1962). Physical Performance and perceived exertion. Lund, Gleerup: Investigationes XI.

Borg, G. A. V., \& Dahlstrom, H. (1960). The perception of muscular work. Umea vetenskapliga biblioteks skrifserie 5, 1-26.

Brooks, G., Fahey, T. D., \& Baldwin, K. M. (2005). Exercise Physiology. Human Bioenergetics and its Applications (Fourth ed.). Boston: McGraw Hill. 
Ceci, R., \& Hassmen, P. (1991). Self-monitored exercise at three different RPE intensities in treadmill vs field running. Med Sci Sports Exerc, 23(6), 732-738.

Chow, R. J., \& Wilmore, J. H. (1984). The Regulation of Exercise Intensity by Ratings of Perceived Exertion. Journal of Cardiac Rehabilitation 4, 382-387.

Dishman, R. K. (1994). Prescribing exercise intensity for healthy adults using perceived exertion Medicine and Science in Sports and Exercise, 26(9), 1087-1094.

Dunbar, C., Robertson, R. J., Baun, R., Bladin, M. F., Metz, K., Burdett, R., \& Goss, F. L. (1992). The validity of regulating exercise intensity by ratings of perceived exertion Medicine and Science in Sports and Exercise, 24(1), 94-99.

Dunbar, C. C., Goris, C., Michielli, D. W., \& Kalinski, M. I. (1994). Accuracy and reproducibility of an exercise prescription based on Ratings of Perceived Exertion for treadmill and cycle ergometer exercise. Percept Mot Skills, 78(3 Pt 2), 1335-1344.

Eston, R. G., Davies, B. L., \& Williams, J. G. (1987). Use of perceived effort ratings to control exercise intensity in young healthy adults. Eur J Appl Physiol Occup Physiol, 56(2), 222224.

Eston, R. G., Lamb, K. L., Bain, A., Williams, A. M., \& Williams, J. G. (1994). Validity of a perceived exertion scale for children: a pilot study. Percept Mot Skills, 78(2), 691-697.

Eston, R. G., \& Williams, J. G. (1988). Reliability of ratings of perceived effort regulation of exercise intensity. Br J Sports Med, 22(4), 153-155.

Fonzi, L., Yoon, K., Shouey, L., Welikonich, M., Goss, F. L., \& Robertson, R. J. (2007). Anticipation Bias during a Cycle Ergometer Perceptual Production Protocol. Med Sci Sports Exerc, 39(5 Suppl), S25.

Fulton, J. E., Masse, L. C., Tortolero, S. R., Watson, K. B., Heesch, K. C., Kohl, H. W., 3rd, Blair, S. N., \& Caspersen, C. J. (2001). Field evaluation of energy expenditure from continuous and intermittent walking in women. Med Sci Sports Exerc, 33(1), 163-170. 
Gairola, A., Gallagher, M., Jr., Schafer, M., Resler, K., Goss, F. L., Aaron, D. J., Metz, K. F., \& Robertson, R. J. (2006). Validation of the OMNI Walk/Run RPE Scale for Intermittent Treadmill Exercise. Med Sci Sports Exerc, 38(5 Suppl), S79.

Glass, S. C., Knowlton, R. G., \& Becque, M. D. (1992). Accuracy of RPE from graded exercise to establish exercise training intensity. Med Sci Sports Exerc, 24(11), 1303-1307.

Groslambert, A., Monnier Benoit, P., Grange, C. C., \& Rouillon, J. D. (2005). Self-regulated running using perceived exertion in children. J Sports Med Phys Fitness, 45(1), 20-25.

Hartshorn, J. E., \& Lamb, K. L. (2004). The reproducibility of perceptually regulated exercise responses during short-term cycle ergometry. Int J Sports Med, 25(5), 362-367.

Jakicic, J. M., Winters, C., Lang, W., \& Wing, R. R. (1999). Effects of intermittent exercise and use of home exercise equipment on adherence, weight loss, and fitness in overweight women: a randomized trial. Jama, 282(16), 1554-1560.

Joo, K. C., Brubaker, P. H., MacDougall, A., Saikin, A. M., Ross, J. H., \& Whaley, M. H. (2004). Exercise prescription using resting heart rate plus 20 or perceived exertion in cardiac rehabilitation. J Cardiopulm Rehabil, 24(3), 178-184; quiz 185-176.

Kang, J., Chaloupka, E. C., Mastrangelo, M. A., Donnelly, M. S., Martz, W. P., \& Robertson, R. J. (1998). Regulating exercise intensity using ratings of perceived exertion during arm and leg ergometry. European Journal of Applied Physiology, 78, 241-246.

Kang, J., Hoffman, J. R., Walker, H., Chaloupka, E. C., \& Utter, A. C. (2003). Regulating intensity using perceived exertion during extended exercise periods. European Journal of Applied Physiology 89, 475-482.

Lamb, K. L., Eston, R. G., \& Corns, D. (1999). Reliability of ratings of perceived exertion during progressive treadmill exercise. Br J Sports Med, 33(5), 336-339.

Laursen, P. B., \& Jenkins, D. G. (2002). The scientific basis for high-intensity interval training: optimising training programmes and maximising performance in highly trained endurance athletes. Sports Med, 32(1), 53-73.

Laursen, P. B., Shing, C. M., Peake, J. M., Coombes, J. S., \& Jenkins, D. G. (2002). Interval training program optimization in highly trained endurance cyclists. Med Sci Sports Exerc, 34(11), 1801-1807. 
Marriott, H. E., \& Lamb, K. L. (1996). The use of ratings of perceived exertion for regulating exercise levels in rowing ergometry. Eur J Appl Physiol Occup Physiol, 72(3), 267-271.

McArdle, W. D., Katch, F. I., \& Katch, V. L. (1986). Exercise Physiology: Energy, Nutrition and Human Performance. Philadelphia: Lea and Febiger.

Morgan, W. P. (1994). Psychological components of effort sense. Med Sci Sports Exerc, 26(9), 1071-1077.

NIH. (1996). Physical activity and cardiovascular health. NIH Consensus Development Panel on Physical Activity and Cardiovascular Health. Jama, 276(3), 241-246.

Noble, B. J., \& Robertson, R. J. (1996). Perceived Exertion (1st ed.). Champaign, IL Human Kinetics

Peterson, M. J., Palmer, D. R., \& Laubach, L. L. (2004). Comparison of caloric expenditure in intermittent and continuous walking bouts. J Strength Cond Res, 18(2), 373-376.

Pfeiffer, K. A., Pivarnik, J. M., Womack, C. J., Reeves, M. J., \& Malina, R. M. (2002). Reliability and validity of the Borg and OMNI rating of perceived exertion scales in adolescent girls. Med Sci Sports Exerc, 34(12), 2057-2061.

Potteiger, J. A., \& Evans, B. W. (1995). Using heart rate and ratings of perceived exertion to monitor intensity in runners. J Sports Med Phys Fitness, 35(3), 181-186.

Robertson, R. (2004). Perceived Exertion for Practitioners. Champaign, IL: Human Kinetics.

Robertson, R. J. (2001). Exercise Testing and Prescription Using RPE as a Criterion Variable. International Journal of Sports Psychology, 32, 177-188.

Robertson, R. J., Goss, F. L., Andreacci, J. L., Dube, J. J., Rutkowski, J. J., Frazee, K. M., Aaron, D. J., Metz, K. F., Kowallis, R. A., \& Snee, B. M. (2005). Validation of the Children's OMNI-Resistance Exercise Scale of perceived exertion. Med Sci Sports Exerc, 37(5), 819-826.

Robertson, R. J., Goss, F. L., Andreacci, J. L., Dube, J. J., Rutkowski, J. J., Snee, B. M., Kowallis, R. A., Crawford, K., Aaron, D. J., \& Metz, K. F. (2005). Validation of the children's OMNI RPE scale for stepping exercise. Med Sci Sports Exerc, 37(2), 290-298. 
Robertson, R. J., Goss, F. L., Bell, J. A., Dixon, C. B., Gallagher, K. I., Lagally, K. M., Timmer, J. M., Abt, K. L., Gallagher, J. D., \& Thompkins, T. (2002). Self-regulated cycling using the Children's OMNI Scale of Perceived Exertion. Med Sci Sports Exerc, 34(7), 11681175.

Robertson, R. J., Goss, F. L., Boer, N., Gallagher, J. D., Thompkins, T., Bufalino, K., Balasekaran, G., Meckes, C., Pintar, J., \& Williams, A. (2001). OMNI scale perceived exertion at ventilatory breakpoint in children: response normalized. Med Sci Sports Exerc, 33(11), 1946-1952.

Robertson, R. J., Goss, F. L., Boer, N. F., Peoples, J. A., Foreman, A. J., Dabayebeh, I. M., Millich, N. B., Balasekaran, G., Riechman, S. E., Gallagher, J. D., \& Thompkins, T. (2000). Children's OMNI scale of perceived exertion: mixed gender and race validation. Med Sci Sports Exerc, 32(2), 452-458.

Robertson, R. J., Goss, F. L., Dube, J., Rutkowski, J., Dupain, M., Brennan, C., \& Andreacci, J. (2004). Validation of the adult OMNI scale of perceived exertion for cycle ergometer exercise. Med Sci Sports Exerc, 36(1), 102-108.

Robertson, R. J., Goss, F. L., Rutkowski, J., Lenz, B., Dixon, C., Timmer, J., Frazee, K., Dube, J., \& Andreacci, J. (2003). Concurrent validation of the OMNI perceived exertion scale for resistance exercise. Med Sci Sports Exerc, 35(2), 333-341.

Robertson, R. J., \& Noble, B. J. (1997). Perception of physical exertion: methods, mediators, and applications. Exerc Sport Sci Rev, 25, 407-452.

Smutok, M. A., Skrinar, G. S., \& Pandolf, K. B. (1980). Exercise intensity: subjective regulation by perceived exertion. Arch Phys Med Rehabil, 61(12), 569-574.

Swain, D. P., \& Leutholtz, B. C. (1997). Heart rate reserve is equivalent to \%VO2 reserve, not to \%VO2max. Med Sci Sports Exerc, 29(3), 410-414.

Swank, A.M., Funck, A., Robertson, R.J., Moore, A., Steinel, L., Manire, J.T. (2007). Evaluation of anticipation bias for RPE during progressive exercise testing. Perceptual Motor Skills, 100(3 Pt 1), 841-850.

Thompson, D. L., \& West, K. A. (1998). Ratings of perceived exertion to determine intensity during outdoor running. Can J Appl Physiol, 23(1), 56-65. 
Tran, Z. V. (1997). Estimating sample size in repeated-measures analysis of variance. In: Measurement in Physical Education and Exercise Science (Special Issue). Manwah, NJ: Erlbaum: T.M. Wood (Ed.).

Utter, A. C., Kang, J., Nieman, D. C., Dumke, C. L., \& McAnulty, S. R. (2006). Validation of Omni scale of perceived exertion during prolonged cycling. Med Sci Sports Exerc, 38(4), 780-786.

Utter, A. C., Robertson, R. J., Green, M., Suminski, R. R., Mcanulty, S. R., \& Nieman, D. C. (2004). Validation of the Adult OMNI Scale of Perceived Exertion for Walking/Running Exercise. Medicine and Science in Sports and Exercise, 36(10), 1776-1780.

Utter, A. C., Robertson, R. J., Nieman, D. C., \& Kang, J. (2002). Children's OMNI Scale of Perceived Exertion: walking/running evaluation. Med Sci Sports Exerc, 34(1), 139-144.

Weiser, P.C., Wojciechowicz, V., Funck, A., \& Robertson, R.J. (2007). Perceived effort step-up procedure for self-regulating stationary cycle exercise intensity by patients with cardiovascular disease. Perceptual Motor Skills, 104(1), 236-253.

Whaley, M. H., \& Forsyth, G. (1990). The value of traditional Intensity Feedback for SelfRegulation of Inital Exercise Training. Journal of Cardiopulmonary Rehabilitation, 10, 98-106. 